\title{
IMPLANTAÇÃO DA METODOLOGIA DE DENSITOMETRIA DE RAIOS-X EM MADEIRA
}

\author{
ALINA CÉLIA BANZATTO AMARAL \\ Enga Agrônoma
}

Orientador: Prof. Dr. MÁRIO TOMAZELLO FILHO

Dissertação apresentada à Escola Superior de Agricultura "Luiz de Queiroz", da Universidade de São Paulo, para obtenção do título de Mestre em Ciências, Área de Concentração: Ciências Florestais.

PIRACICABA

Estado de São Paulo - Brasil

Junho - 1994 
Aos meus pais

ALMIRA e

DAVID (em memória)

Aos meus filhos

DANILO, TATIANA, MARIA E FREDERICO

e especialmente ao meu marido FREDERICO, cujo amor, compreensão e incentivo foram fundamentais durante o desenvolvimento deste trabalho.

DEDICO. 


\section{AGRADECIMENTOS}

Esta dissertação é fruto de alguns anos de trabalho, dedicação e paciência envolvendo um grupo de pessoas e alguns órgãos e instituições, sem os quais teria sido impossível a sua realização. Queremos portanto, manifestar nosso profundo agradecimento:

- Ao Prof. Dr. Mário Tomazello Filho, que nos acolheu em seu laboratório, nos orientou e nos proporcionou a chance de desenvolver um trabalho desta natureza, não poupando esforços no sentido de trazer o que de melhor existe na área de densitometria de raios-X.

- Ao Prof. Dr. Hilton Thadeu Z. do Couto, sempre pronto em nos atender, sugerindo, orientando e colaborando na área de estatística.

- Ao Prof. Dr. José Nivaldo Garcia, pelas constantes elucidações de dúvidas.

- Ao Prof. Dr. Lucien Fraipont da Faculdade de Ciências Agronômicas da Universidade de Gembloux - Bélgica e ao Mr. Ernest Schär do Instituto Federal de Pesquisas Florestais da Suiça, pela paciência e dedicação no ensino do manuseio do microdensitômetro.

- Ao funcionário do DCF/IPF Milton C. Ribeiro, do Setor de Computação, de maneira muito especial, pelo desenvolvimento do sistema computacional. 
- À Faculdade de Farmácia e Odontologia da Unicamp, nas pessoas do Prof. Dr. Frab Norberto Boscolo, Prof. Dr. Agenor Montebello Filho e do técnico Rubens Marques Payão que muito nos auxiliaram na técnica de obtenção das radiogafias.

- À PIZA FLORESTAL SIA na pessoa da Eng. FI. Vanilda Rosângela de Souza Shimoyama, responsável pelo fornecimento e coleta das amostras de madeira.

- À Coordenação de Aperfeiçoamento de Pessoal de Nível Superior - CAPES, pela bolsa concedida.

- Às técnicas Maria Regina Buch e Maria Aparecida R.C. Bermudes pela colaboração recebida.

- À Marialice Poggiani, pela revisão das citações bibliográficas.

- Ao meu irmão Diógenes A. Banzatto e ao colega Nils J. Wehr pela colaboração na parte fotográfica.

- À amiga e companheira, bióloga Sandra Monteiro B. Florsheim, pelo constante incentivo e apoio assim como ao seu marido, Geraldo Florsheim, pela orientação em traduções e versões da língua inglêsa.

- Ao Jorge Luiz Diorio, pelo profissionalismo na digitação do texto.

- Aos amigos do Departamento de Ciências Florestais que direta ou indiretamente colaboraram para a realização deste trabalho, e àqueles que porventura tiveram seus nomes omitidos. 


\section{ÍNDICE}

Página

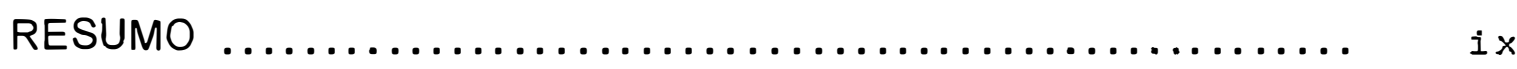

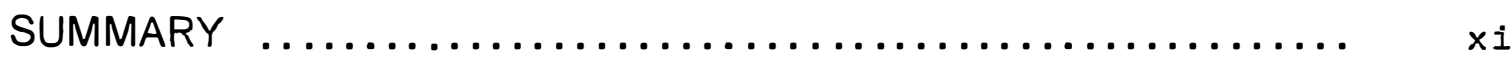

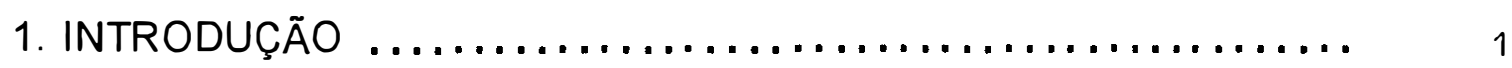

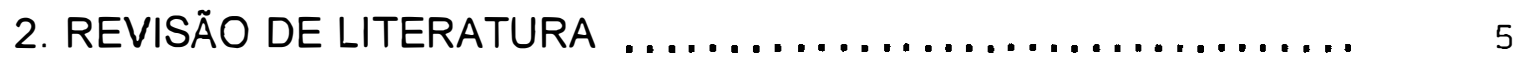

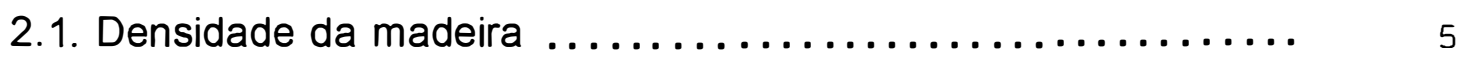

2.1.1. Variação da densidade da madeira $\ldots . \ldots \ldots \ldots \ldots \ldots$, 7

2.1.1.1. Variação da densidade da madeira dentro

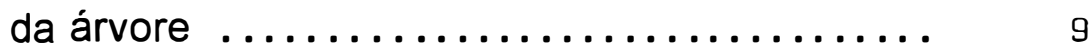

2.1.1.2. Variação da densidade da madeira entre árvores

2.2. Textura da madeira (\% de lenho outonal) ............... 13

2.2.1. Importância da textura da madeira $\ldots \ldots \ldots \ldots \ldots \ldots$.

2.3. Largura do anel de crescimento ..................... 16

2.3.1. Variação da largura do anel de crescimento .......... 16

2.3.1.1. Variação dentro da árvore $\ldots \ldots \ldots \ldots \ldots \ldots \ldots .17$

2.3.1.2. Variação entre árvores $\ldots \ldots \ldots \ldots \ldots \ldots \ldots \ldots . . \ldots \ldots$

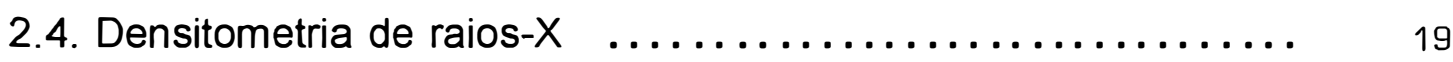

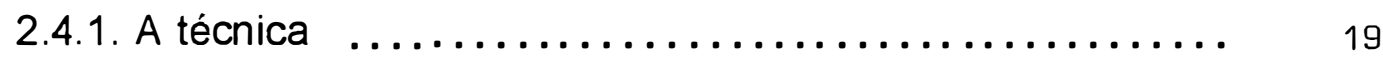

2.4.2. Aplicação da densitometria de raios-X na madeira $\ldots . . \quad 22$

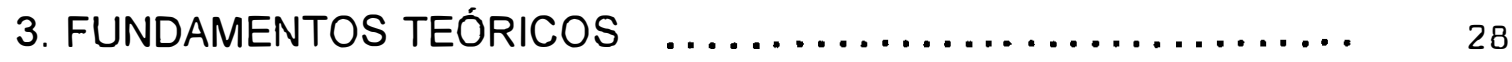

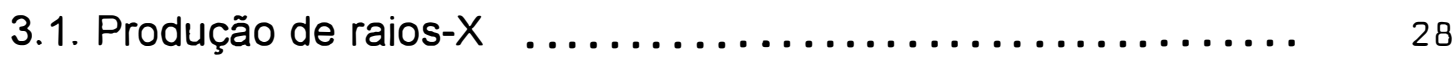

3.2. Sistema receptor de imagem $\ldots \ldots \ldots \ldots \ldots \ldots \ldots \ldots \ldots . . . \ldots \ldots$

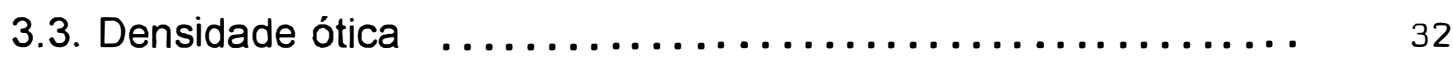

3.4. Aplicação da densitometria de raios-X na madeira ....... 34

3.4.1. Absorção dos raios-X $\ldots \ldots \ldots \ldots \ldots \ldots \ldots \ldots \ldots \ldots . . . \ldots \ldots$

3.4.2. Ação fotográfica dos raios-X $\ldots \ldots \ldots \ldots \ldots \ldots \ldots \ldots . . \ldots \ldots$ 
4. MATERIAL E MÉTODOS $\ldots \ldots \ldots \ldots \ldots \ldots \ldots \ldots \ldots \ldots \ldots \ldots \ldots . \ldots \ldots$

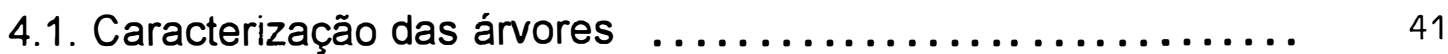

4.2. Obtenção e preparo das amostras de madeira ........... 43

4.2.1. Amostragem não destrutiva $\ldots \ldots \ldots \ldots \ldots \ldots \ldots \ldots . \quad 44$

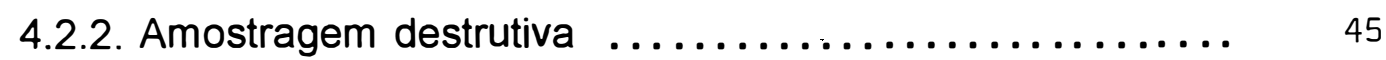

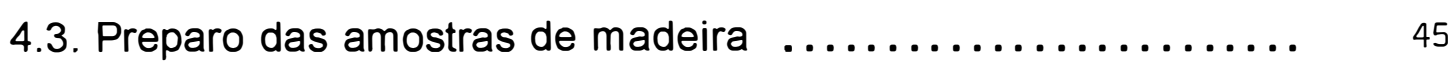

4.4. Extração de resina da madeira $\ldots . \ldots \ldots \ldots \ldots \ldots \ldots \ldots \ldots . . . \ldots \ldots$

4.5. Radiografia das amostras de madeira ................ 47

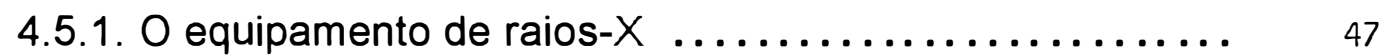

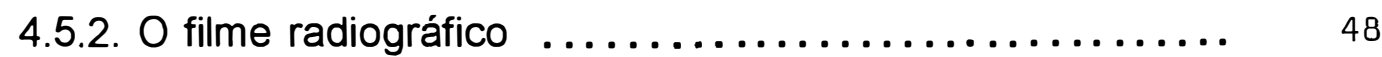

4.5.3. A exposição dos filmes radiográficos ............... 49

4.5.3.1. Orientação das amostras em relação ao feixe de raios-X .......................... 51

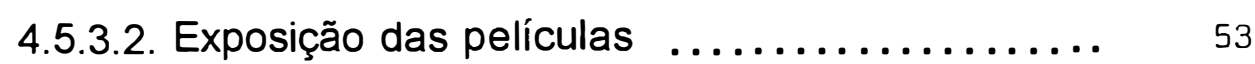

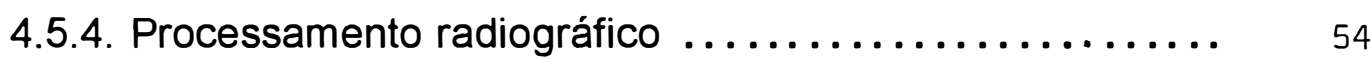

4.5.4.1. Sequência do processamento radiográfico ..... 56

4.6. Análise das radiografias $\ldots . \ldots \ldots \ldots \ldots \ldots \ldots \ldots \ldots . . . \ldots \ldots$

4.6.1. O microdensitômetro Joyce Loebl MK III-C ........... 57

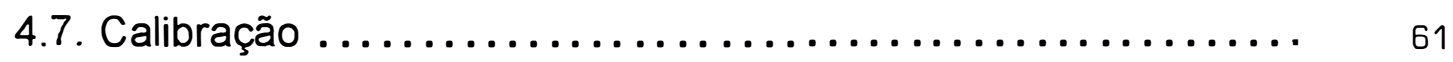

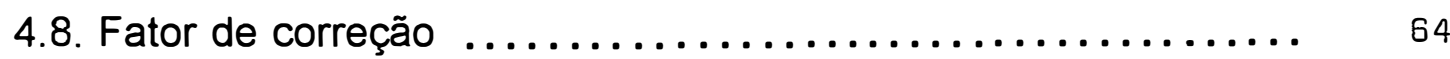

4.9. Definição do lenho outonal ......................... 66

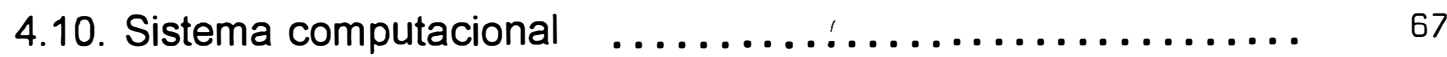

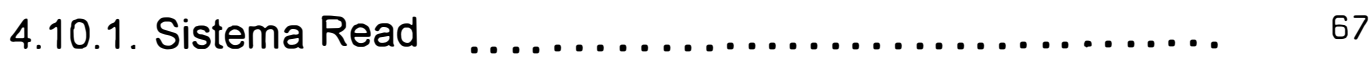

4.10.2. Sistema Analysis $\ldots \ldots \ldots \ldots \ldots \ldots \ldots \ldots \ldots \ldots . \ldots \ldots \ldots$

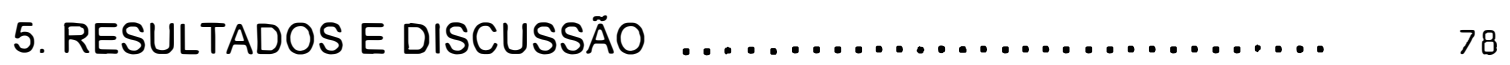

5.1. Radiografia das amostras de madeira .............. 78

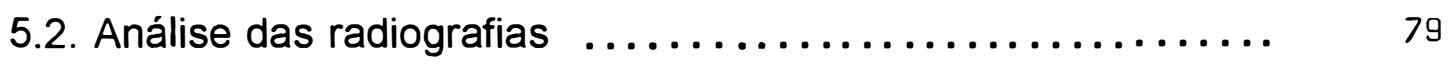

5.3. Perfis densitométricos radiais das amostras de madeira $\quad . . . \quad 81$ 
5.4. Parâmetros analisados nos anéis de crescimento da

5.5. Caracterização dos anéis de crescimento da madeira das árvores

5.5.1. Densidades mínimas e médias dos lenhos primaveris .. 89

5.5.2. Densidades máximas e médias dos lenhos outonais ... 95

5.5.3. Densidades médias dos anéis de crescimento anuais e dos lenhos primaveris e outonais $\ldots \ldots \ldots \ldots \ldots \ldots . \quad 96$

5.5.4. Largura dos anéis de crescimento anuais e dos lenhos

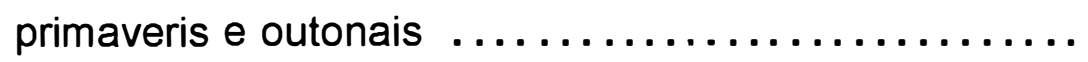

5.5.5. Porcentagem dos lenhos outonais nos anéis de

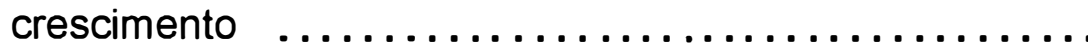

5.5.6. Médias das densidades, larguras e porcentagem de lenhos outonais dos anéis de crescimento .......... 104

5.5.7. Densidades médias das amostras radiais de madeira .. 107

5.5.8. Produtividade em volume e biomassa de madeira das árvores ................................... 109

5.6. Procedimentos para a análise densitométrica de madeiras $\ldots . .117$

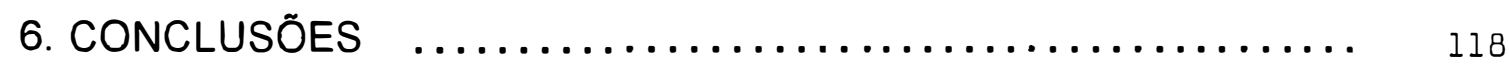

REFERENCIAS BIBLIOGRÁFICAS $\ldots \ldots \ldots \ldots \ldots \ldots \ldots \ldots \ldots \ldots \ldots \ldots \ldots \ldots \ldots \ldots$

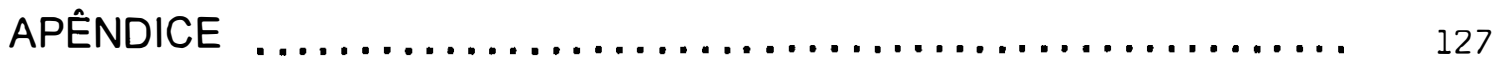




\title{
IMPLANTAÇÃO DA METODOLOGIA DE DENSITOMETRIA DE RAIOS-X EM MADEIRA
}

\author{
Autora: Alina Célia Banzatto Amaral \\ Orientador: Prof. Dr. MÁRIO TOMAZELLO FILHO
}

\section{RESUMO}

O presente trabalho teve como objetivo o desenvolvimento e implantação da metodologia de um novo método de determinação de densidade da madeira em nosso país, a densitometria de raios-X.

Pesquisas básicas foram realizadas para o estabelecimento das várias etapas necessárias à implantação desta técnica, a saber: a) tipo, preparo e acondicionamento das amostras de madeira a serem utilizadas; b) tipo de filme a ser usado; c) tipo de aparelho de raios- $X$ que permitisse a obtenção das radiografias da madeira, assim como as condições de exposição dos filmes; d) tipo de processamento mais adequado; e) o uso do aparelho (microdensitômetro) utilizado para determinar a densidade ótica das amostras; f) a confecção dos padrões para obtenção das curvas de calibração e; g) o desenvolvimento de um sistema computacional para registrar, transformar e analisar os dados. 
Para permitir a visualização dos resultados, é fornecido um exemplo prático de análise densitométrica de amostras retiradas de discos da base de árvores de Pinus taeda, coletadas dentro de diversas classes de diâmetro.

O trabalho permitiu o estabelecimento completo da técnica. Os resultados obtidos são comparáveis àqueles obtidos em outros países. 


\title{
IMPLEMENTATION METHODOLOGY OF X-RAY DENSITOMETRY \\ IN WOOD
}

\author{
Author: Alina Célia Banzatto Amaral \\ Adviser:- Prof. Dr. Mário Tomazello Filho
}

\section{SUMMARY}

The present work had as its aim the development and implementation of the methodology of a new method to determine wood density in this country: X-ray densitometry.

Basic research was done to establish the following stages required to implement this technique: a) kind, preparation and acclimatization of the wood samples to be used; b) kind of film to be used; c) kind of X-ray apparatus that would allow us to obtain the radiographs of the exposure conditions of the films; d) the most adequate kind of processing; e) the utilization of the apparatus (microdensitometer) used to determine the optical density of the samples; f) the establishment of the standards for obtaining the calibration curves; g) the development of a computing system to record, transform and analyse the data. 
In order to allow the visualization of the results a practical example is given of the densitometry analysis of samples taken from base discs of Pinus taeda, L., trees collected from several diameter classes.

This work has allowed the complete development of the technique. The results obtained are comparable to those obtained abroad. 


\section{INTRODUÇÃO}

Os anéis de crescimento em coniferas aparecem em secções transversais do tronco sob a forma de uma sucessão de zonas claras e zonas escuras. As primeiras correspondem à madeira formada no início do período de crescimento (lenho inicial ou primaveril), com células caracterizadas por paredes finas e lúmens de grande diâmetro. A madeira produzida no final do período de crescimento (lenho tardio ou outonal) é, ao contrário, constituída por células com paredes espessas e lúmens reduzidos. A transição entre o lenho inicial e o tardio de um ano é progressiva, com as dimensões das células variando de maneira quase que contínua durante esse período de crescimento. Isso se deve aos fatores que afetam a fisiologia da árvore, como a disponibilidade de seiva orgânica e de hormônios de crescimento. Ao contrário, a passagem do lenho tardio de um ano para o inicial do ano seguinte é abrupta, o que permite a fácil detecção dos anéis sucessivos e a medição de sua largura.

Além da competicão de árvores vizinhas, e dos fatores edáficos (que diminuem a riqueza do solo e sua economia em água), o crescimento anual 
das árvores é afetado pelos fatores do clima (pluviosidade, temperatura, insolação, duração e intensidade de nevadas, etc), de maneira que a largura do anel varia, às vezes, consideravelmente entre as estações de crescimento.

O estudo das variações na largura dos anéis de crescimento deu origem à ciência da dendrocronologia que vem a ser a datação através desses anéis. À partir desta ciência desenvolveu-se a dendroclimatologia; a dendroclimatografia, dendroecologia, dendrohidrologia e dendrogeomorfologia que vem a ser respectivamente a aplicação de análises de anéis das árvores ao estudo e mapeamento de climas passados e presentes, ecologia de comunidades bióticas passadas, históricas vazões e enchentes dos rios e processos geomórficos.

Em diversos países da Europa, assim como no Japão, Estados Unidos e Canadá os estudos dendrocronológicos e seus derivados ganharam um grande impulso com um "novo" método de determinação da densidade dos anéis de crescimento da madeira: a densitometria de raios $X$.

Na densitometria de raios-X aplicada na pesquisa dos anéis das árvores, determina-se a variação da densidade da madeira nos anéis individuais, pela medição da absorção de "raios moles" ou de longo comprimento de onda; a medida que eles atravessam secções finas de madeira (POLGE, 1966). Esta técnica permite medir as variações da densidade em pequenas áreas e, em particular, as variações dentro dos anéis de crescimento, o que é muito difícil de se medir através de métodos gravimétricos convencionais. Além das variações da densidade de uma maneira contínua, pode-se medir a largura dos lenhos outonal 
e primaveril e a largura do anel de crescimento, assim como determinar a porcentagem de lenho outonal.

A importância destes parâmetros foi enfatizada por POLGE (1978) ao analisar o desenvolvimento da técnica de raios-X por um período de quinze anos, demonstrando que os componentes da densidade têm sido utilizados com sucesso nos estudos anatômicos, fisiológicos e tecnológicos. Podem também como variáveis dependentes, determinar os efeitos da herdabilidade, fertilização, taxa de crescimento, desfolha por insetos, irrigação, poluição industrial, desrama artificial, fenologia ou fatores climáticos na estrutura e qualidade da madeira. Como variáveis explanatórias, podem informar sobre a resistência mecânica da madeira, avaliação da quebra pelo vento em troncos de árvores vivas, etc. A densitometria constitui-se em um poderoso instrumento, tanto para a avaliação mais detalhada dos efeitos de um dado tratamento silvicultural na qualidade da madeira como para explicar outros resultados tecnológicos.

A técnica da densitometria de raios- $X$ aplicada à madeira não existe no Brasil e devido à sua importância, sua implantação deverá suscitar o interesse nas diversas áreas do setor florestal.

O trabalho tem portanto, como objetivo principal, a implantação da técnica de determinação da densidade através da densitometria de raios-X.

Para a visualização dos resultados que podem ser obtidos através deste método, são utilizadas árvores de Pinus taeda L., por ser esta espécie uma conífera importante cultivada em nosso país. Além de sua importância, 
essa espécie apresenta anéis muito bem delimitados, o que a coloca como espécie indicada para estudos de densitometria aplicados tanto na área de manejo silvicultural como em dendroclimatologia. 


\section{REVISÃO DA LITERATURA}

\subsection{Densidade da madeira}

Por definição, a densidade de uma substância é a relação entre a sua massa e o seu volume. Entretanto, em se tratando de madeira, um material que possui grande afinidade por água, diversas definições de densidade têm sido estabelecidas, conforme o teor de umidade em que pesos e volumes são determinados. Quando utilizamos para sua determinação peso seco e volume seco, a densidade é chamada de densidade anidra ou "oven dry density"; quando utilizamos peso e volume à um certo teor de umidade teremos a densidade neste teor de umidade (p.ex.: $D_{12}$ ou $D_{15}$, ou geralmente chamada de densidade a umidade ambiente; densidade ao ar ou densidade atual); quando o peso seco e o volume saturado é utilizado, a densidade é chamada de densidade básica ou infradensidade pois é a que dá o menor valor. Desta forma, os valores obtidos são diferentes e devem ser levados em consideração para efeito de comparações afim 
de evitar conclusões errôneas. Além disso, a madeira pode possuir depósitos químicos que afetam a densidade. Neste caso, a densidade deve ser classificada como "com" ou "sem" extrativos, pois os seus valores podem ser muito diferentes (MeGRAW, 1985; PANSHIM \& de ZEEUW, 1970; POLGE, 1966).

Basicamente, a densidade é uma medida da quantidade de material da parede celular numa peça de madeira ou seja, o peso do material lenhoso por unidade de volume, o que a torna um critério essencial para se avaliar a qualidade da madeira nos processos de manufatura ou de suas características em uso. Está estreitamente relacionada com as propriedades físicas da madeira tais como dureza e resistência mecânica e proporciona boa estimativa dos rendimentos em polpa, podendo ser um indicador do comportamento na secagem, resistência ao corte e trabalhabilidade. Durante um longo período, as determinações da densidade da madeira eram feitas apenas em amostras macroscópicas. A partir da década de 60 foram desenvolvidos métodos que utilizam a propriedade da madeira atenuar as radiações, possibilitando a medição das variações da densidade de uma forma contínua empregando-se os raios $\beta$, raios $\gamma$ e raios-X.

Segundo LOUZADA (1990), as primeiras curvas de variação da densidade da madeira foram obtidas pela técnica de radiação dos raios $\beta$ por CAMERON et al. (1959) tendo sido principalmente utilizada por HARRIS na Nova Zelândia. No entanto, esta técnica, devido ao seu fraco poder de resolução (largura da janela de leitura de $0,5 \mathrm{~mm}$ ) e a sua reduzida velocidade de leitura (entre $20 \mathrm{~mm}$ a $60 \mathrm{~mm}$ por hora) está praticamente abandonada. 
A técnica de raios $\gamma$ introduzida por LOOS em 1961 apresenta as mesmas desvantagens dos raios $\beta$ (largura da janela de leitura de $1 \mathrm{~mm}$ e uma velocidade de leitura de $60 \mathrm{~mm}$ por hora). Além disso, segundo POLGE (1966), elas exercem sobre a matéria lenhosa uma ação durável, modificando, de uma maneira variável segundo as essências e as doses utilizadas, características importantes como a resistência à compressão ou flexão estática, o trabalho ao choque e mesmo a afinidade por água, restringindo a utilização posterior das mesmas amostras para estudos das qualidades físicas ou mecânicas.

Atualmente, a técnica densitométrica mais utilizada e rigorosa recorre ao emprego indireto dos raios-X que permite a análise rápida das amostras (cerca de 3 minutos para uma amostra de $15 \mathrm{~cm}$ de comprimento) e uma excelente resolução (largura da janela de leitura de apenas alguns microns se necessário).

\subsubsection{Variação da densidade da madeira}

A variação da densidade da madeira dentro de uma árvore é de origem fisiológica. O tamanho final da célula e a taxa de divisão celular são altamente influenciados pelas auxinas, reguladores de crescimento que são exportados pelas gemas terminais e pelas vigorosas porções da copa formadas em um último estágio de crescimento. A espessura da parede celular está relacionada tanto à taxa de deposição de parede como ao tempo de duração de sua ocorrência. Supõe-se que a duração do período de espessamento seja o mais importante dos 
dois e seja também controlado pelas auxinas. O início da formação sazonal de lenho tardio (células menores com paredes mais espessas) parece coincidir com a parada do crescimento em altura pela gema terminal e com a recente maturidade das acículas. Estes fenômenos influenciam presumivelmente tanto o balanço das auxinas como o suprimento disponivel de fotossintatos. A densidade de uma célula individual é, portanto, amplamente relacionada à sua distância da copa viva e ao tempo de sua formação dentro da estação (MeGRAW, 1985; LARSON, 1969).

Consequentemente, a maioria das árvores possui um padrão de densidade da madeira do centro para fora, da base para o topo, dentro de um anel anual e as vezes mesmo em diferentes lados da árvore em relação ao sol, temperatura, inclinação do tronco, etc. (DADSWELL, 1960; POLGE \& ILLY, 1967; SLUDER, 1972).

ZOBEL \& VAN BUIJTENEN (1989) em revisão sobre o assunto, afirmam que os padrões de variação dentro da árvore têm sido intensivamente estudados para a maioria das espécies mas que entretanto, não existem normas porque cada espécie em cada ambiente pode desenvọlver o seu próprio padrão. Salientam ainda que os silvicultores devem reconhecer as variações existentes e aprender a conviver com elas. Se estas variações não forem reconhecidas e quantificadas, enormes erros poderão ser cometidos nos estudos da madeira.

A literatura sobre o assunto é vasta e muitas vezes conflitante. Em nosso trabalho, tentaremos nos restringir apenas às citações sobre Pinus taeda por ser esta espécie a escolhida para nosso estudo. 


\subsubsection{Variação da densidade da madeira dentro da árvore}

"Mais variabilidade nas características da madeira existe dentro de uma única árvore, do que entre árvores crescendo no mesmo sitio ou entre árvores crescendo em diferentes sitios. Estes padrões devem ser compreendidos; eles estão sempre presentes e é difícil eliminá-los", assim Larson (1967) citado por ZOBEL \& VAN BUIJTENEN (1989) definiu a variação dentro da árvore.

A maior variabilidade da densidade ocorre dentro de um anel anual de crescimento devido ao fato do lenho primaveril e lenho outonal das coníferas serem muito diferentes. Por exemplo, Ifju (1969) citado por ZOBEL \& VAN BUIJTENEN (1989) mostrou que a densidade do lenho primaveril dos pinos do sul dos EUA varia de 0,30 a 0,46 , enquanto a densidade do lenho outonal varia de 0,65 a 0,92. HARRIS (1981) cita o Monterey Pine (Pinus radiata D. Don.) como uma conífera de textura uniforme que possui uma gama de densidade dentro de um anel anual por volta de 1,8 para 1; o Pinus taeda como tendo uma gama de 2,3 para 1 e algumas espécies tais como o Douglas-fir [Peudotsuga menziezii (Mirb.) Franco] como sendo de textura grosseira devido ao fato desta relação ser de 5 para 1.

A quantidade, tipo e brusquidão da formação da célula de lenho outonal tem um grande efeito na qualidade da madeira produzida e nos produtos dela derivados, podendo causar grandes dificuldades na sua utilização.

Para a maioria das indústrias de transformação da madeira, é muito importante o conhecimento do tipo de transição entre o lenho primaveril e 
outonal, bem como o grau de heterogeneidade da densidade dentro dos anéis de crescimento. Para algumas indústrias são preferidas madeiras com densidades mais baixas, outras com densidades mais elevadas, mas em todos os casos, é preferida madeira com maior uniformidade de densidade no anel de crescimento (LOUZADA, 1990). Este autor salienta ainda que uma grande variação entre a densidade do lenho primaveril e outonal não está necessariamente relacionada com uma transição abrupta como inicialmente se pensava.

A variação radial da densidade (da medula para a casca) é frequentemente referida como característica da madeira juvenil (formada diretamente sob a influência da copa, possuindo anéis largos e de baixa densidade) e adulta ou madura (com anéis mais estreitos e de alta densidade). Os padrões podem variar para diferentes grupos de árvores, sendo de fundamental importância em algumas espécies e de pouca importância em outras.

Nos "hard pines" entre os quais se inclui o Pinus taeda, a tendência é possuir um padrão uniforme de baixa densidade na medula, um rápido aumento da densidade no período juvenil, seguido por séries de anéis anuais que possuem uma densidade essencialmente constante, embora flutuante de ano para ano. Este padrão de variação para o Pinus taeda foi mostrado por diversos pesquisadores. MeGRAW (1985) relatou que a densidade do $P$. taeda aumenta do centro para fora em todas as alturas, mas é maior na base da árvore do que nas partes mais altas. Normalmente a mudança da densidade da medula para a casca é maior no lenho outonal e menor no lenho primaveril (PETERSON, 1968). 
A variação axial da densidade da madeira em uma determinada árvore está ligada também às diferenças de madeira juvenil e adulta desta árvore. Para aquelas espécies nas quais a madeira adulta difere muito da madeira juvenil teremos uma mudança automática da densidade com a altura, uma vez que a proporção da madeira juvenil no tronco aumenta extensivamente da base para o topo. De uma maneira geral, os "hard pines" mostram um considerável decréscimo da densidade com o aumento da altura (JAYNE, 1958; BROWN, 1971; PRONIN, 1971)

Para compreender melhor as mudanças das propriedades da madeira com a altura na árvore, é necessário estudar as tendências na madeira juvenil e madura separadamente. Estudos desta natureza são escassos; entretanto, para Pinus taeda, MeGRAW (1985) realizou uma pesquisa deste tipo, encontrando um forte decréscimo na densidade da madeira juvenil da base da árvore até $3 \mathrm{~m}$; acima de $5 \mathrm{~m}$ a densidade foi constante, independente da altura.

Uma variação que deve ser levada em conta ainda, é a variação da densidade com a idade total da árvore. Ela também está ligada à porcentagem de madeira juvenil. Árvores mais velhas possuem maior densidade devido à maior porcentagem de madeira adulta e à deposição de materiais resinosos no cerne. Entretanto, um fenômeno incomum relatado por ZOBEL et al. (1972) e TALBERT \& JETT (1981) é que a madeira juvenil de árvores mais velhas de Pinus taeda possui consideravelmente maior densidade que a madeira juvenil de árvores mais jovens, mesmo após a extração de resina. Inexistem estudos desta 
natureza para outras espécies, mas para Pinus taeda isto ficou muito claro, e o aumento foi muito grande. As razões são desconhecidas. Tem sido sugerido que isto resulta de estresse interno das árvores, as vezes referido como uma teoria de compactação.

\subsubsection{Variação da densidade da madeira entre árvores}

A densidade da madeira de uma árvore é determinada pela interação das características de crescimento intrínsecas ao próprio indivíduo, das condições ambientais e da situação geográfica, que, em conjunto com práticas silviculturais, podem conferir às árvores diferentes modelos de crescimento e formação do lenho (LOUZADA, 1990).

Geralmente as diferenças árvore à árvore na densidade da madeira dentro de uma espécie ou entre procedências são grandes. Entretanto, o padrão de variação de árvorelárvore dentro de uma mesma espécie é constante. MeGRAW (1985) mostrou que em qualquer grupo de árvores de $P$. taeda uma variação na densidade de 0,15 a 0,25 unidades pode ser esperada para qualquer critério comparável de amostragem.

ZOBEL \& BUIJTENEN (1989) resumem a variábilidade entre árvores através de vários tópicos dentre os quais podemos destacar:

a) A quantidade de variação árvore/árvore difere consideravelmente entre espécies. Embora nenhuma espécie possua madeira uniforme, algumas são muito mais uniformes que outras. 
b) A magnitude da variação individual torna difícil estimar acuradamente os efeitos do sitio, ambiental ou silvicultural, na densidade da madeira.

c) Diferenças entre espécies relacionadas tais como os pinos do sul são pequenas quando comparadas com diferenças individuais.

d) Lenho primaveril e lenho outonal diferem grandemente e cada um pode variar de árvore para árvore. O tipo e quantidade de lenho outonal é mais importante em influenciar a qualidade do produto, mas diferenças no lenho primaveril podem também ter grande influência.

e) A variabilidade entre árvores na madeira juvenil é normalmente menor que na madeira adulta.

\subsection{Textura da madeira ( $\%$ de lenho outonal)}

A textura de uma madeira é a relação da largura da zona de madeira outonal à largura total da camada de crescimento, sendo a madeira outonal definida (para as essências que vegetam na zona temperada do hemisfério norte) como a madeira formada no final da estação de vegetação e constituída por tecidos densos, compactos e de coloração escura (POLGE, 1966).

Do ponto de vista anatômico, mais 2 definições foram estabelecidas. A primeira, e mais correntemente utilizada é a de Mork (1926) citado 
por POLGE (1966), segundo a qual a madeira outonal é constituída por "o conjunto de traqueidos para os quais a espessura da membrana comum entre duas cavidades celulares, multiplicada por 2, é superior ou igual à largura do lumen, todas as medidas sendo feitas no sentido radial".

A segunda é a de Klem (1945) citado por POLGE (1966) que fixa o limite entre a madeira primaveril e madeira outonal no interior do anel, "ao lugar onde a dimensão radial das cavidades celulares é exatamente inferior à dimensão tangencial".

Uma terceira definição foi feita por Knig \& Koltzenburg (1964) citado por POLGE (1966) que modificaram ligeiramente a definição de MORK, de maneira a tornar mais precisa a delimitação procurada e a reduzir os erros de medida; eles consideram como células de madeira outonal aquelas para as quais a distância compreendida entre o limite interno (lado da medula) da membrana comum com a célula seguinte é igual à 2 vezes o diâmetro da cavidade celular.

De acordo com POLGE (1966), mesmo utilizando métodos anatômicos, a delimitação procurada está longe de ser rigorosa, uma vez que ela varia de uma fila de células à outra, e também porque podemos encontrar células que apresentam características de madeira primaveril intercaladas entre outras que pertencem notoriamente à madeira outonal. 


\subsubsection{Importância da textura da madeira}

A porcentagem de madeira outonal tem uma importância direta sobre o valor tecnológico da madeira da maioria das essências florestais. Ela está correlacionada com as propriedades mecânicas da madeira e com as características do papel obtido. Entretanto, é necessário precisar mais a noção de textura da madeira a ter em conta, não somente as larguras respectivas da madeira outonal e da madeira primaveril, mas também as variações da densidade de uma e de outra. Por exemplo, CLARKE (1933) encontrou para o freixo (Fraxinus excelsior L.) uma resistência em compressão axial mais elevada para as árvores com estreita zona de madeira outonal, formadas com fibras com paredes espessas, do que para árvores com zona outonal mais larga, porém formada de fibras com paredes finas.

A influência da textura sobre as qualidades do papel é complexa porque madeira primaveril e outonal fornecem pastas de qualidades papeleiras diferentes e em grande parte complementares, de sorte que a superioridade de uma em relação à outra, não se pode apreciar a não ser que em função da utilização que é feita.

WATSON \& DADSWELL (1962) fabricaram folhas de papel à partir de pastas de diversas espécies dos gêneros Pinus e Eucalyptus compreendendo proporções de madeira outonal que variaram de 0 a $100 \%$. Os autores mostraram a influência da textura sobre o rendimento, qualidade e 
características mecânicas do papel. Estes autores mostraram que existe uma certa proporcionalidade direta ou inversa, entre a porcentagem de madeira outonal e as diversas características mecânicas do papel, que se encontram melhoradas ou, ao contrário, degradadas quando a textura aumenta. É possivel determinar um valor ótimo, mas esta porcentagem ideal de madeira outonal varia de uma espécie à outra. Para o Pinus taeda este ótimo é atingido para proporções de madeira outonal variando entre 20 e $50 \%$ em peso, proporções que são às vezes ultrapassadas na natureza.

\subsection{Largura do anel de crescimento}

A largura de um anel de crescimento é obtida através da medição do início da zona clara (lenho primaveril) ao final da zona escura (lenho outonal) e fornece a quantidade de crescimento num determinado ano. Os anéis largos indicam um crescimento acelerado, enquanto que anéis estreitos indicam um crescimento mais lento.

\subsubsection{Variação da largura do anel de crescimento}

Assim como a densidade, os anéis tendem a apresentar modelos de variação tanto dentro da árvore como entre árvores. 


\subsubsection{Variação dentro da árvore}

A largura do anel de crescimento, estando diretamente ligada às condições de crescimento da árvore, pode variar dentro de uma árvore tanto na direção radial, como axial, e às vezes, entre direções.

Próximo à medula, os anéis são largos, diminuindo rapidamente nos primeiros anos e, frequentemente, estabilizando-se após a fase juvenil. Oscilações na largura do anel do lenho adulto podem ser devidas a efeitos ambientais ou à tratamentos silviculturais, principalmente desbastes.

Geralmente a largura do anel é maior junto à base da copa e decresce tanto na direção da base como do vértice do tronco (PANSHIN \& de ZEEUW, 1970).

Variações da largura do anel entre direções no mesmo nível, aparecem quandos os efeitos ambientais não são os mesmos em toda periferia do anel em formação. Por exemplo árvores que recebem muito mais sol de um lado do que de outro, árvores sujeitas à ventos constantes em uma só direção, provocando a ocorrência de madeira de compressão, etc.

\subsubsection{Variação entre árvores}

A variação entre árvores pode ser devida à constituição genética dos indivíduos, e efeitos do local ou da situação geográfica ou ainda à influência de práticas silviculturais. 
Segundo Mandaltsi (1977) citado por LOUZADA (1990), "a diversidade genética modifica o crescimento da árvore de um modo sutil e frequentemente imprevisivel". Assim, as diferenças genéticas podem influenciar o tipo e a forma da copa afetando o tipo de lenho formado.

Por exemplo, as árvores podem diferir na duração da atividade cambial. Uma árvore pode terminar rapidamente a sua atividade cambial após o crescimento terminal com pouca produção de lenho outonal enquanto outra pode continuar a produzir lenho outonal até muito mais tarde.

O ambiente desempenha um papel fundamental no crescimento das árvores, porém é necessário contar com a capacidade intrínseca do indivíduo para responder a seus efeitos. Efeitos ambientais são geralmente expressos pelos vários fatores climáticos, tais como pluviosidade, temperatura, insolação, etc.

O local pode influir na largura do anel. Geralmente locais melhores produzem anéis bem mais largos que os piores locais.

A largura do anel é bastante afetada por práticas silviculturais tais como desbaste, desrama e fertilização.

A desrama afeta os anéis de crescimento de maneira inversa a dos desbastes (LARSON, 1963). Enquanto que os desbastes provocam um aumento do volume do lenho nas partes mais baixas da árvore, a desrama provoca uma diminuição dos anéis nas partes onde foram eliminados os ramos vivos e abaixo dela, sendo que a parte acima não é afetada.

A aplicação de fertilizantes aumenta significativamente a taxa de crescimento da árvore (OHTA et al., 1983; POLGE, 1962). Segundo LOUZADA 
(1990) este aumento pode variar entre os 10 e $55 \%$, conforme o fertilizante, a espécie e o povoamento em causa.

A largura dos anéis de crescimento pode ainda ser reduzida por fatores tais como: ataque de insetos, fogo, etc.

\subsection{Densitometria de Raios-X}

\subsubsection{A técnica}

A técnica de densitometria de raios- $X$ consiste na obtenção de radiografias de madeira, colocando-se uma fina secção transversal de madeira sobre um filme radiográfico. O filme é então exposto à fonte de raios- $X$ e com a passagem da radiação através da amostra de madeira, forma-se uma imagem da estrutura transversal dos anéis de crescimento. A maior dificuldade na densitometria de raios- $X$ é a obtenção de uma imagem da madeira bem definida na radiografia. Existem duas limitações nas imagens radiográficas que devem ser corrigidas. O primeiro obstáculo é o fenômeno da paralaxe, ou seja, a forma de propagação dos raios-X à partir da fonte. Os raios emitidos pela fonte devem estar aproximadamente paralelos quando passam através da amostra para evitar sombras nas radiografias. A técnica estacionária (POLGE, 1965; 1966; PARKER \& MELESKIE, 1970) evita o problema da paralaxe separando por suficiente distância a fonte de raios- $X$ da amostra e do filme, de modo que os raios que sensibilizam o filme estarão aproximadamente paralelos. 
Outra proposta para evitar o problema da paralaxe é a técnica da fenda móvel ou a técnica "em movimento" descrita por ECHOLS $(1970,1972)$ na qual os raios que sensibilizam o filme são colimados.

A segunda variável que pode impedir a formação de imagens radiográficas bem delineadas é relacionada com a má orientação dos limites dos anéis de crescimento na direcão longitudinal. Se estes limites não forem paralelos aos raios, serão formadas imagens borradas na radiografia. Este problema pode ser minimizado trabalhando-se com amostras de madeira mais finas. A definição da imagem radiográfica será melhor nas amostras mais finas que nas mais espessas, com o mesmo grau de desalinhamento.

Para que a densitometria de raios- $X$ seja possivel, há necessidade de remoção da resina das amostras de madeira e seu acondicionamento a um teor de umidade padrão. A resina presente na madeira afeta sua densidade, e pode mesmo obscurecer os limites dos anéis de crescimento nas radiografias (THOMAS, 1972). Apesar de alguns investigadores extraírem a resina de todas as amostras de madeira (LENZ et al., 1976), verifica-se que na maioria das pesquisas a extração é feita apenas quando as amostras apresentam altos teores de resina.

O teor de umidade das amostras de madeira definitivamente afeta a precisão das medições de densidade das mesmas na radiografia (THOMAS, 1972; THOMAS \& WOOTEN, 1973). Dessa forma, a maioria dos laboratórios acondicionam as amostras de madeira num determinado teor de umidade antes de 
radiografá-las (ECHOLS, 1970, 1972, 1973; McGRAW \& NEARN, 1972; SCHWEINGRUBER et al., 1978).

A densitometria de raios- $X$ na madeira foi inciada por POLGE $(1962,1965,1966)$ que radiografou baguetas de madeira de $5 \mathrm{~mm}$ de espessura com um aparelho estacionário. As baguetas de madeira foram colocadas sobre um filme de raios-X distante $2,5 \mathrm{~m}$ da fonte de radiação, com o filme centrado sob 0 ponto focal da fonte. POLGE (1965) considerou que o efeito da paralaxe foi adequadamente reduzido pela distância de $2,5 \mathrm{~m}$ da fonte ao filme para os maiores filmes usados $(18 \mathrm{~cm} \times 24 \mathrm{~cm})$. As baguetas eram inclinadas quando os limites dos anéis de crescimento eram mal orientados, até um ângulo que os tornassem aproximadamente paralelos aos raios. Um microdensitômetro de varredura transformava as imagens radiográficas das baguetas em gráficos de variação da densidade da madeira.

O uso de baguetas na obtenção das radiografias possui a vantagem de facilitar a extração, não causar grandes danos às árvores e não precisar de trabalhabilidade adicional das amostras. Entretanto, segundo SARDINHA (1976) estas amostras possuem uma série de desvantagens: i) as radiografias das amostras devem ser varridas exatamente ao longo de sua linha central porque é somente nela que os raios- $X$ atravessam toda a porção de $5 \mathrm{~mm}$ das amostras. Um desvio de apenas $0,5 \mathrm{~mm}$ desta linha central, significará um erro no valor da densidade de $2,12 \%$ e com um desvio de $1 \mathrm{~mm}$ este erro cresce para $9,2 \%$; ii) o tempo necessário para posicionar a amostra é de 2 vezes maior que 
aquele para amostras "fatiadas", principalmente para aquelas que têm tendência ao escurecimento devido às quantidades de tanino.; iii) considerável variabilidade ocorre na espessura da amostra mesmo quando são usadas sondas bem afiadas.

Por este motivo, a tendência dos vários laboratórios é a utilização de "fatias" de madeira, obtidas tanto pela trabalhabilidade das baguetas (amostragem não destrutiva) como pela trabalhabilidade de "fatias" de discos (amostragem destrutiva).

Segundo LENZ \& SCHWEINGRUBER (1976), o sistema estacionário de densitometria de raios- $X$ do Instituto de Pesquisas Florestais da Suiça é um dos mais avançados pela possibilidade de obtenção de radiografias à partir de "fatias" de madeira com espessura de apenas 1,25 mm. O microdensitômetro do instituto digita automaticamente os perfis dos anéis de crescimento e registra a densidade mínima do lenho primaveril, densidade máxima do lenho outonal, largura do anel, largura do lenho primaveril e largura do lenho outonal em cada anel de crescimento.

\subsubsection{Aplicação da densitometria de raios- $X$ na madeira}

Uma extensa revisão sobre a densitometria de raios-X é fornecida por PARKER \& KENNEDY (1973). Segundo estes autores a densitometria de raios-X na madeira foi iniciada por POLGE e colaboradores do Centro Nacional de Pesquisas Florestais em Champenoux, França em 1963. A partir desta data são 
citados inúmeros trabalhos realizados neste Centro. Pesquisas usando as técnicas de raios-X foram também conduzidas na Austrália na Universidade Nacional da Austrália - Camberra por RUDMAN et al. (1969), e no Laboratorio de Produtos Florestais em Melbourne - Austrália por NICHOLLS \& BROWN (1971) e POLGE \& NICHOLLS (1972); na Nova Zelândia no Instituto de Pesquisas Florestais, Rotorua (ELLIS, 1971); na Inglaterra, na Universidade de Oxford (FLETCHER \& HUGHES, 1970); no Canadá na Inspetoria Geológica do Canadá em Otawa, na Universidade da Columbia Britânica e no Laboratorio de Produtos Florestais do Oeste em Vancouver (PARKER et al., 1969); nos Estados Unidos, na Estação Experimental de Florestas e Reservas do Sudoeste do Pacífico, Berkeley, California (ECHOLS à partir de 1970) e na Companhia Weyerhaeuser, Seattle, Washington por McGRAW \& NEARN (1972). Estes últimos pesquisadores mencionados introduziram em seu sistema a inovação de medir os raios-X diretamente, eliminando a utilização de filme. $\mathrm{O}$ autor cita ainda como os mais bem equipados os laboratórios da Universidade de Brocks, Ontario e o Laboratório de Pesquisas em Anéis de Árvores da Universidade do Arizona, em Tucson, Arizona.

No início, uma grande parte das informações publicadas a respeito da densitometria de raios-X se referia principalmente à técnica, onde os autores descreviam os tipos de aparelhos utilizados, as inovações feitas pelos diversos laboratórios que a utilizavam e a forma de obtenção dos dados. Atualmente, inúmeros trabalhos têm sido produzidos para mostrar sua aplicação. nas diversas áreas. 
Em 1966, POLGE (1966) quando do desenvol-vimento da metodologia, apresentou diversas utilizações do método tais como: i) avaliação da qualidade da madeira; ii) pesquisa de madeiras anormais (madeira de reação); iii) estudo da retratabilidade, do colapso e sobretudo do recondicionamento; iii) comparações entre características dos perfis densitométricos para diferentes procedências de uma mesma espécie. $O$ autor mostrou ainda que o método por exploração densitométrica de radiografias permite localizar no interior da madeira, certas substâncias extrativeis como a resina. É igualmente possível estudar, a distribuição de água numa árvore viva, mostrando que o teor de água varia consideravelmente ao longo de um mesmo anel de crescimento anual, colocando em evidência zonas secas no início da madeira primaveril e no final da madeira outonal, assim como bandas muito estreitas com pouco teor de água no interior de porções de anéis com umidade elevada.

POLGE (1966) pode estabelecer, por um lado, que a forma dos perfis densitométricos é característica do ano de produção dos anéis, e por outro lado que certos critérios novos (densidade máxima anual, densidade mínima anual, contraste de densidade entre os limites dos anéis), que não se podia obter até aqui por outros métodos, permitem distinguir mais facilmente entre si, as espécies, os anos e as posições (orientação da madeira no interior da árvore), que os critérios antigos tais como largura do anel e principalmente porcentagem de lenho outonal. O autor chamou a atenção para o fato de que estas características novas parecem mais do que as outras, estar sob a dependência direta dos fatores ambientais e em particular dos fatores climáticos, com os quais correlações muito significativas foram 
colocadas em evidência. As curvas de variação da densidade podem assim servir de base à uma xilocronologia, ou seja, a um método de datação através da madeira.

A partir dos trabalhos de Polge, inúmeros trabalhos foram realizados na área da densitometria de raios-X relacionando as variáveis intraanuais de densidade com fatores ambientais nos campos de climatologia, hidrologia, ecologia e geomorfologia. Relações altamente significativas foram encontradas entre dados da densidade e largura do anel com temperatura, precipitação e vazão dos rios. A densidade máxima tem sido particularmente bem correlacionada com estes parâmetros ambientais.

A densitometria de raios- $X$ também melhorou o potencial para datação de anéis das árvores, particularmente para aquelas com pouca variação na largura do anel como as encontradas na costa oeste dos Estados Unidos, com muito mais de 1.000 anos de idade e no Canadá Ártico com idade em torno de 500 anos.

Por exemplo, no Canadá Artico, PARKER (1976) relatou que alguns parâmetros densitométricos dos anéis de crescimento da madeira de Picea glauca (Moench) Voss foram sensíveis ao clima. As densidades máxima e a média do lenho outonal foram em grande parte superiores à largura do anel e outras características intra-anuais para propósitos de "cross-datação". As densidades mínima e média do lenho primaveril foram fortemente afetadas como um todo. 
O efeito de práticas silviculturais tais como fertilização, desbaste, irrigação e poda verde, pode ser avaliado através do uso de téćnicas radiográficas para mostrar a redistribuição da densidade dentro do anel de crescimento, mesmo quando a densidade global não é afetada significativamente. Muitos trabalhos têm sido conduzidos neste campo e conclusões importantes têm sido relatadas. MOSCHLER et alii (1989) estudando árvores de Pinus taeda em plantações do Tennessee, USA, sujeitas a três tipos de desbastes: i) pesado; ii) moderado; e iii) leve, concluíram que as árvores remanescentes após desbaste pesado, moderado e leve, produziram madeira cuja densidade média não diferiu da testemunha. A densidade da madeira primaveril diminuiu após os desbastes pesado e moderado, enquanto que a densidade da madeira outonal aumentou. Houve portanto, uma mudança dentro dos anéis anuais, da distribuição das densidades do lenho outonal e primaveril, o que pode afetar negativamente a qualidade da polpa da madeira, uma vez que uma madeira mais uniforme é preferida, porque ela melhora a qualidade do papel.

JOZSA et alii (s/d) descreveram os resultados obtidos em uma análise densitométrica de raios-X de árvores de Douglas-fir (Pseudotsuga menziezii) com 50 anos de idade em Vancouver. Uma atenção especial foi dada para a extensão e distribuição da madeira juvenil e o efeito da idade cambial e posição no tronco, sobre a densidade da madeira. O trabalho permitiu testar várias estratégias de manejo florestal que influenciam no volume da madeira juvenil e na uniformidade da madeira tanto para polpa como para serraria. 
Numerosas aplicações da densitometria de raios- $X$ podem ser encontradas no trabalho de revisão efetuado por PARKER \& KENNEDY (1973) que relacionam uma série de estudos realizados por diversos pesquisđ̃ores através desta técnica para avaliar a estrutura e propriedades da madeira, o efeito de práticas silviculturais e aspectos biológicos do crescimento da árvore. 


\section{FUNDAMENTOS TEÓRICOS}

\subsection{Produção de Raios-X}

Os raios-X são produzidos por tubos de raios-X que são constituídos de uma haste de cobre (ânodo) com uma pequena chapa em sua extremidade, geralmente de tungstênio (alvo) e de um filamento de tungstênio (cátodo) localizados dentro de um recipiente de vidro, com vácuo no seu interior. O tungstênio $(Z=74)$ é o material mais usado devido ao seu alto ponto de fusão $\left(3.370^{\circ} \mathrm{C}\right)$ e rápido poder de dissipação térmica, uma vez que grande quantidade de calor é produzida no processo. Possui também, alto número atômico, o que permite uma maior eficiência na produção de raios-X.

A Figura 1 apresenta de forma bastante simplificada, 0 esquema do tubo de raios- $X$. A fonte de tensão (1) aplicada no cátodo (2) aqueceo, havendo liberação de elétrons, de modo que se forma uma nuvem eletrônica ao redor do filamento de tungstênio (3). A fonte de alta tensão (4) aplicada entre o 
ânodo (5) e o cátodo (2) é responsável pela aceleração dos elétrons (6) através do tubo, os quais, após atingirem altas velocidades, colidem com o alvo de tungstênio (7). Ao serem desacelerados, já dentro do alvo, os elétrons perdem parte de sua energia que é irradiada na forma de raios-X (BROCHI, 1990).

\section{LEGENDA:}

1-Fonte de tensão

2-cátodo

3-filamento de tungstênio

4-fonte de alta tensão-KV

5-anodo

6-aceleração dos elétrons

7-alvo

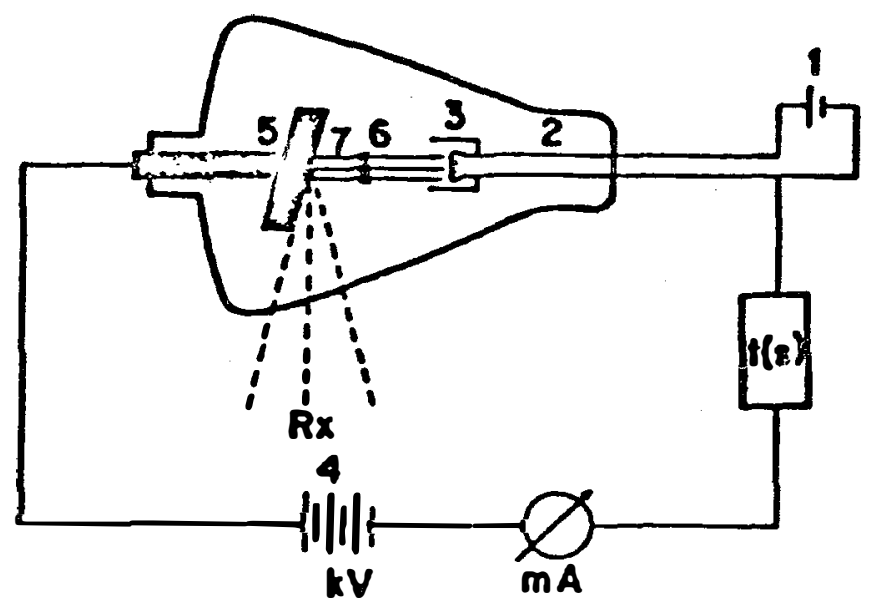

Figura 1. Esquema simplificado de um tubo de raios-X.

Os raios-X são, portanto, radiação eletro-magnética cujo comprimento de onda pode variar de $10^{-5}$ a $10^{3} \mathrm{~A}^{\circ}$, segundo a tensão aceleradora 
nos limites do tubo, e cuja intensidade varia em função da intensidade da corrente que passa no filamento do cátodo.

Dependendo do comprimento de onda os raios-X podem ser classificados em raios moles ou raios duros. Os raios moles são obtidos quando se empregam kilovoltagens baixas, eles possuem um comprimento de onda maior e são absorvidos facilmente. Os raios duros, ao contrário, são obtidos quando se empregam kilovoltagens altas e se caracterizam por apresentar um comprimento de onda mais curto, mais energia e serem muito mais penetrantes.

\subsection{Sistema receptor de imagem}

Para a visualização da imagem radiográfica, é necessário um sistema que absorva os fotons-X transmitidos pelo material em estudo e os converta em imagem visivel. Isto pode ser conseguido basicamente de duas formas: produzindo uma imagem num filme ou numa tela fluorescente de um intensificador de imagens (BROCHI, 1990).

A radiografia (registro final), se faz em uma película especial por um processo fotográfico. As películas radiográficas são compostas de emulsão (gelatina que contém compostos de prata) e uma base transparente tingida de azul. A base de segurança é um produto plástico transparente cujas propriedades se adaptam aos requisitos de combustão lenta e outras medidas de segurança 
impostas pela Associação Americana de Pesos e Medidas. Tem uma espessura aproximada de 0,2032 $\mathrm{mm}$ e é suficientemente rígida e plana para que se possa manipular comodamente. Ao microscópio se vê que a emulsão visivel é formada por inúmeros grãos ou cristais de halogenados de prata na gelatina. A emulsão é colocada em ambas as superfícies da base para proporcionar à película sensibilidade máxima e contraste adequado, assim como para que possa revelarse, fixar-se e secar-se ao menor tempo possivel. A espessura da emulsão é de aproximadamente $0,0254 \mathrm{~mm}$. A emulsão é muito sensivel e quando exposta aos raios-X ou à luz ocorre uma modificação física. Esta modificação chamada imagem latente é tão pequena que não pode ser observada por meios físicos ordinários. Entretanto, quando a película exposta é tratada com uma solução chamada revelador, tem lugar uma reação química que transforma os grãos expostos de sais de prata em diminutas partículas de prata metálica negra, sem afetar essencialmente os grãos não expostos. É esta prata suspendida em gelatina que constitui a imagem visível na radiografia (KODAK, 1961). A seguir damos um esquema de um filme radiográfico (Figura 2) que é constituído de diversas camadas.

Essas camadas compreendem um suporte de triacetato de celulose (d), uma camada delgada, denominada substrato (C) para possibilitar a aderência da camada de emulsão (b) ao suporte de triacetato e uma camada de gelatina endurecida (a) que protege a emulsão. 


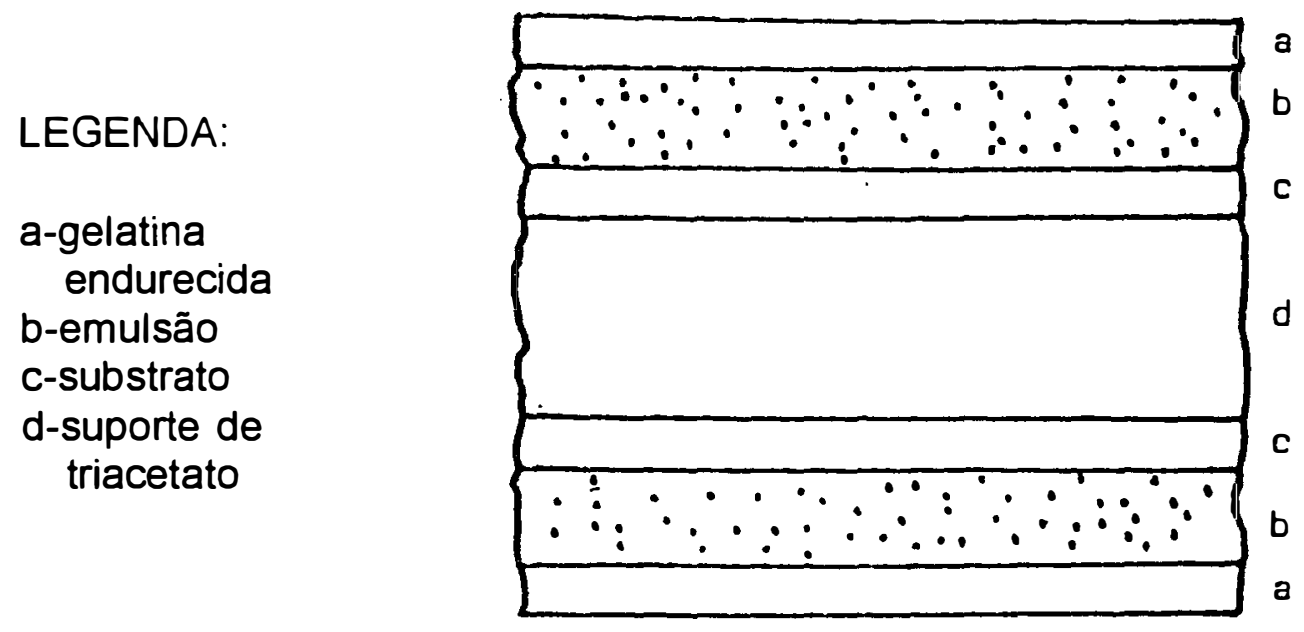

Figura 2. Corte esquemático de um filme radiográfico mostrando as diferentes camadas.

\subsection{Densidade ótica}

A imagem radiográfica é formada por inúmeras massas de diminutas partículas de prata metálica distribuídas pelas duas capas de emulsão da película. Esta imagem se observa à luz transmitida por um negatoscópio. A transparência relativa das diferentes áreas da radiografia depende da distribuição das partículas de prata negra. Existe uma relação aproximada entre a quantidade 
de prata em uma zona da radiografia e o grau com que a prata interrompe a transmissão do feixe de luz que passa através desta área. É esta variação na quantidade de luz transmitida que faz com que a imagem seja visível. Quanto mais espessos são os depósitos de prata negra, maior é a quantidade de luz absorvida e mais escura aparece a área. Esta obscuridade se chama densidade e é maior ou menor segundo mais ou menos luz seja transmitida pela radiografia.

A ciência que controla a exposição e a revelação e que mede a densidade resultante se chama sensitometria. Para medirmos a densidade emprega-se um aparelho chamado densitômetro.

Do ponto de vista científico a densidade ótica (DO) de um filme se define como uma medida de enegrecimento do mesmo colocando-o diante de uma fonte de luz uniforme com intensidade 10 . Medindo-se a intensidade de luz transmitida (I) pelo filme, têm-se:

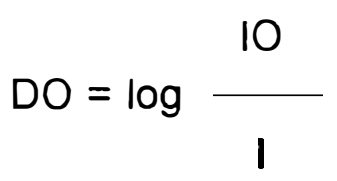

Quando a prata permite passar $1 / 10$ de luz a proporção é de 10:1. O logarítmo de 10 (na base 10) é 1. Portanto se deduz que esta área tem uma densidade ótica $=1$. Se o que passa é somente $1 / 100$ de luz, esta zona tem densidade ótica $=2$. Os valores de densidade ótica mais aceitos estão entre 0,5 (mais claro) e 2,0 (mais escuro). 


\subsection{Aplicação da densitometria de raios- $X$ na madeira}

O método de análise densitométrica de madeira utilizando os raios-X se baseia principalmente em 2 propriedades dos raios-X:

- Sua absorção pela matéria que eles atravessam.

- Sua ação fotográfica.

\subsubsection{Absorção dos raios- $X$}

$A$ radiação $X$ é uma radiação eletromagnética emitida em quanta, isto é, a interação dos raios-X com a matéria é caracterizada pelo fato de que cada foton de raios- $X$ é removido individualmente do raio incidente num único evento, Davisson (1965) citado por SARDINHA (1974). Assim, o número de fotons removidos, dl é proporcional à espessura atravessada $\mathrm{dX}$ e ao número de fotons incidentes, lo, isto é:

$$
d l=\mu 10 d X
$$

onde $\mu$ é chamado de coeficiente de atenuação. Se a radiação é homogênea $\mu$ é constante e a integração de (2) se torna:

$$
I=10 \cdot e^{\mu x}
$$

onde I é igual ao número de fotons transmitidos e lo é o número de fotons incidentes. 
Do ponto de vista da absorção, a densidade do material e sua espessura desempenham um papel análogo; podemos portanto reunir estas duas variáveis considerando-se seu produto que chamamos impropriamente de peso superficial. Se a espessura do material atravessado é dada por t e a densidade por d, a equação 3 se torna:

$$
I=10 \cdot e^{-\mu t d}
$$

De acordo com a equação (4) deduz-se que conhecendo-se I, lo e $t$, a densidade da madeira pode ser determinada. A transformação logarítmica da equação (4) nos dá:

$$
\log I=\log 10-\text { utd }
$$

o que sugere que para algumas condições operacionais podemos ter uma relação quase linear entre a densidade ótica e o logarítmo da dose recebida.

A madeira sendo constituída essencialmente por celulose, hemicelulose e lignina ou seja $\mathrm{C}, \mathrm{H}$ e $\mathrm{O}$, em proporções variáveis, possui um coeficiente de absorção de massa muito fraco (levando-se em consideração também as grandes quantidades de poros que a constituem) e também constante através da espessura da madeira. Desta forma, qualquer variação notada na radiação transmitida por toda uma espessura constante é atribuída a diferenças na densidade. 
As variações da densidade na madeira se traduzem pelas variações na absorção do raio incidente (e portanto na intensidade do raio transmitido), o que provoca um enegrecimento variável nos filmes radiográficos.

Como visto em 3.3 , os graus de enegrecimento poderão ser registrados por um aparelho que será descrito mais adiante que é o micro densitômetro.

\subsubsection{Ação fotográfica dos raios-X}

A determinação da intensidade das diferenças registradas fotograficamente na absorção dos raios- $X$ em relação às diferenças na densidade das amostras é baseada na fórmula (1) vista em 3.3., ou seja:

$$
D O=\log \frac{10}{1}
$$

onde DO é a densidade fotográfica (ótica) no filme de raios- $X$, lo e I sendo os valores da radiação total respectivamente emitida pelo tubo e inabsorvida pela amostra de densidade d e espessura t.

O resultado gráfico da relação entre exposição e a densidade é conhecido como curva característica 
A curva característica de uma emulsão radiográfica do tipo usado para densitometria de raios-Xé uma curva obtida dispondo-se as densidades óticas em ordenadas e o logaritmo da exposição (o produto da intensidade pelo tempo) em abcissa, segundo a Figura 3.

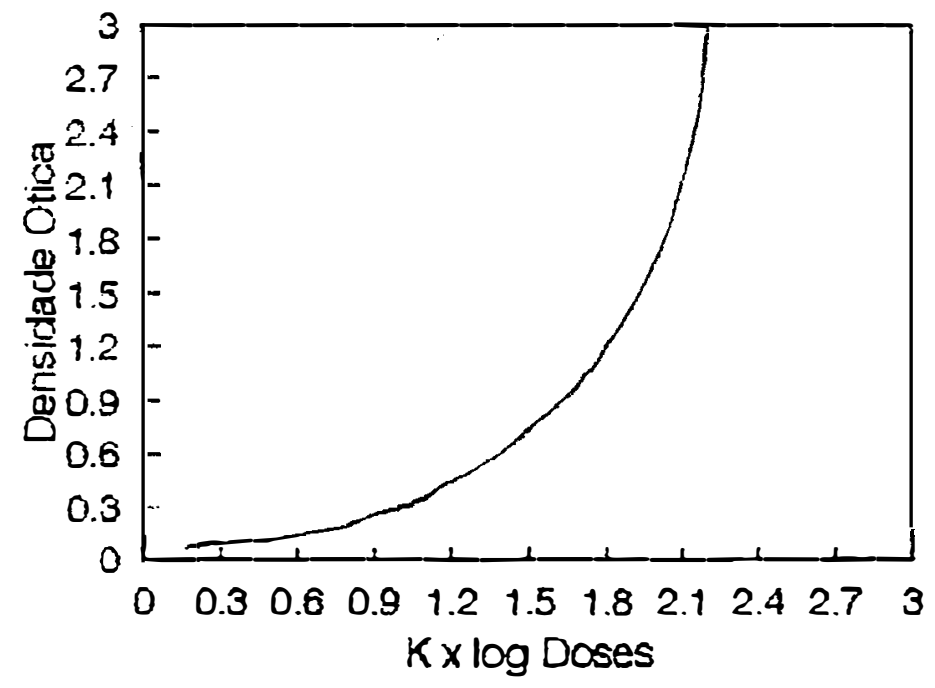

Figura 3. Curva característica de uma emulsão radiográfica para densitometria de raios- $X$.

Constata-se que a curva característica da emulsão empregada em densitometria de raios-X não é uma reta, mas pode ser considerada como tal nas regiōes de fortes densidades óticas.

Da equação (1) e (4) conclui-se que:

$$
D \approx \text { utd }
$$


Como u e t permanecem constantes, a densidade é em grande parte e dentro de certas condições de trabalho, diretamente proporcional à densidade da madeira, isto é, a exploração densitométrica de cada radiografia pode dar uma resposta linear da densidade.

A forma mais conveniente de se representar a resposta de um filme à radiação $X$ é através de sua curva característica. Através destas curvas é possivel determinar o melhor tipo de filme para um determinado uso. A forma destas curvas praticamente independe do objeto ou de suas propriedades de espalhamento, da quilovoltagem ou da miliamperagem utilizadas no aparelho de raios-X. Ela depende praticamente apenas do tipo dos filmes e das condições de revelação.

Os requisitos para se obter uma boa imagem podem ser medidos através da curva característica e dentre eles o contraste é um dos requisitos importantes na densitometria de raios-X.

O contraste de um filme é definido pela inclinação da curva característica em um dado ponto ou seja, é uma medida de variação da densidade obtida para uma dada variação na exposição. A precisão de um registro de densidade ótica aumenta com o comprimento de ondas dos raios- $X$. Consequentemente para detectar pequenas mudanças na densidade da madeira devemos usar ondas longas, ou seja, raios moles. Entretanto, existem algumas limitações práticas na maximização do contraste, a mais importante da qual é o aumento requerido pelo tempo de exposição. Na prática, para termos uma aceitável 
resolução da imagem para um determinado tipo de filme de raios- $X$, necessitamos encontrar o melhor, ou pelo menos o mais aceitável compromisso entre o tempo de exposição, intensidade e voltagem. 


\section{MATERIAL E MÉTODOS}

Por se tratar de um trabalho pioneiro, muito tempo e esforço foram gastos em pesquisas básicas, para a implantação da metodologia. Nesta fase do trabalho foram pesquisados: a) o tipo de amostra de madeira a ser utilizado; b) o tipo de aparelho de raios-X que permitisse a obtenção das radiografias da madeira; c) o tipo de filme a ser usado; d) o tipo de processamento mais adequado (manual ou de máquina); e) o manuseio do aparelho (microdensitômetro) utilizado para determinar a densidade ótica das amostras; f) a confecção dos padrões para obtenção das curvas de calibração; g) o desenvolvimento de um sistema computacional para recolher, transformar e analisar os dados.

Após estas pesquisas básicas iniciamos a aplicação da metodologia no estudo dos anéis de crescimento da madeira de Pinus taeda.

\subsection{Caracterização das ánores}

As árvores de Pinus taeda, num total de 10 indivíduos com idade de 20 anos foram provenientes de um talhão localizado no município de 
Sengés - Paraná - Projeto Mocambo-3 da PISA FLORESTAL SIA. O local de coleta situa-se à $24^{\circ} 13^{\prime}$ de Latitude Sul e à $49^{\circ} 23^{\prime}$ de longitude oeste numa altitude de 880 metros do nível do mar. De acordo com a classificação de Köppen, o clima da região é do tipo Cfb caracterizado como subtropical úmido, mesotérmico com verões frescos e geadas severas ocorrendo frequentemente. As chuvas são bem distribuídas durante o ano havendo, no entanto, um declínio no inverno sem chegar a ser suficiente para determinar em média a existência de um mês mais seco. 0 máximo pluviométrico ocorre no trimestre de verão (dezembro, janeiro e fevereiro), enquanto que os 3 meses menos chuvosos coincidem com o período de inverno, sendo agosto o mês mais seco do ano. A temperatura média do mês mais quente é menor que $22^{\circ} \mathrm{C}$ e a temperatura média do mês mais frio é menor que $18^{\circ} \mathrm{C}$.

O solo é raso, ácido, com $\mathrm{pH}=3,5$ e arenoso, sendo classificado como areia quartzosa álica. O terreno é de topografia plano-barra suave.

O talhão de onde foram retiradas as árvores possuia 2.500 árvores/ha e sofreu dois desbastes, o primeiro em 1982/83 deixando 1.200 árvores/ha e o segundo em 1987, após o que ficou com 550 árvores/ha. O espaçamento inicial foi de $2 \times 2 \mathrm{~m}$.

A origem das sementes é desconhecida.

A amostragem realizada numa parcela de $20,0 \times 31,5$ m indicou um DAP médio de $27,1 \mathrm{~cm}$ e uma altura total média de 19,3 $\mathrm{m}$. 
Com base nestes valores foi obtida a Tabela 1, de distribuição dos indivíduos em classes de diâmetro.

Tabela 1. Distribuição das árvores de Pinus taeda, aos 20 anos de idade através de amostragem realizada em parcela de $20,0 \times 31,5 \mathrm{~m}$.

\begin{tabular}{lc}
$\begin{array}{l}\text { Classe de } \\
\text { diâmetro } \\
N^{0}\end{array}$ & $\begin{array}{c}\text { Variação } \\
\text { do DAP } \\
(\mathrm{cm})\end{array}$ \\
\hline 1 & $33,4-36,6$ \\
2 & $30,5-33,4$ \\
\hline 3 & $27,4-30,5$ \\
5 & $24,4-27,4$ \\
\hline
\end{tabular}

Foram coletadas 2 árvores por classe de diâmetro, cujas dimensões se encontram na Tabela 2. 
Tabela 2. Dimensões das árvores de Pinus taeda aos 20 anos de idade, em 5 diferentes classes de diâmetro.

\begin{tabular}{|c|c|c|c|c|}
\hline $\begin{array}{l}\text { Classe de } \\
\text { diâmetro }\end{array}$ & $\begin{array}{c}\text { Árvore } \\
\text { NNo }^{\circ}\end{array}$ & $\begin{array}{l}\text { DAP } \\
(\mathrm{cm})\end{array}$ & $\begin{array}{c}\text { Altura } \\
\text { comercial } \\
\text { (cm) }\end{array}$ & $\begin{array}{l}\text { Altura } \\
\text { total } \\
(\mathrm{cm})\end{array}$ \\
\hline \multirow[t]{2}{*}{1} & 1 & 35,6 & 17,3 & 21,3 \\
\hline & 2 & 35,0 & 16,3 & 20,0 \\
\hline \multirow[t]{2}{*}{2} & 1 & 32,1 & 15,5 & 19,6 \\
\hline & 2 & 31,5 & 14,9 & 19,0 \\
\hline \multirow[t]{2}{*}{3} & 1 & 29,0 & 13,6 & 17,4 \\
\hline & 2 & 28,6 & 15,5 & 19,3 \\
\hline \multirow[t]{2}{*}{4} & 1 & 25,5 & 13,6 & 18,3 \\
\hline & 2 & 26,1 & 15,5 & 19,4 \\
\hline \multirow[t]{2}{*}{5} & 1 & 22,9 & 11,5 & 15,7 \\
\hline & 2 & 22,6 & 13,4 & 17,3 \\
\hline
\end{tabular}

\subsection{Obtenção e preparo das amostras de madeira}

A obtenção das amostras pode ser conseguida através de 2 métodos a saber. 


\subsubsection{Amostragem não destnutiva}

A obtenção das amostras pelo método não destrutivo é feita utilizando-se de um trado (Sonda Pressler) que é introduzido no tronco da árvore em pé, retirando uma "bagueta" (de 5 ou $10 \mathrm{~mm}$ de diâmetro). Estas amostras podem ser utilizadas desta forma, ou podem ser reduzidas à amostras retilíneas como se fossem uma "fita" de madeira, após passarem por uma dupla serra circular (Figura 4).
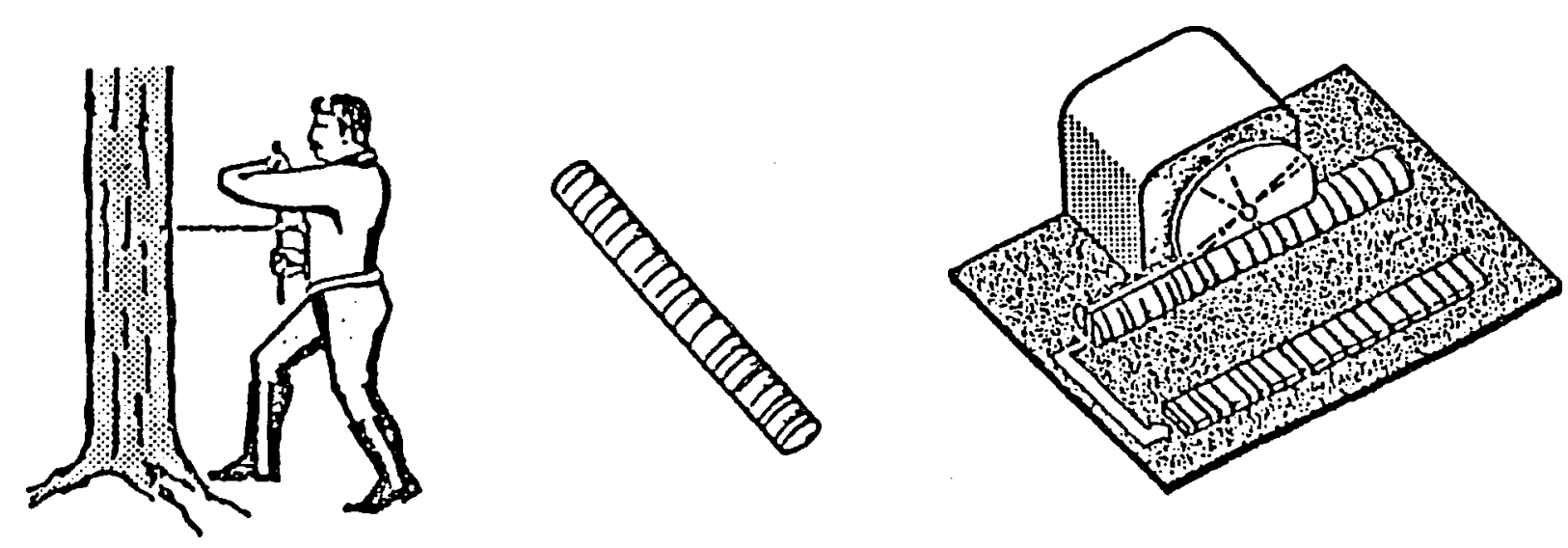

Figura 4. Amostragem não destrutiva: a) Extração da "bagueta", b) "bagueta", c) dupla serra circular reduzindo a "bagueta" em "fita". 


\subsubsection{Amostragem destrutiva}

A amostragem destrutiva, como o próprio nome diz, implica na derrubada da árvore, e retirada de secções transversais do tronco, nas alturas desejadas. Quando se deseja determinar a idade da árvore, deve-se analisar o disco obtido na região mais próxima do solo, com a amostra apresentando todos os anéis de crescimento. No presente trabalho foram utilizadas amostras destrutivas com a coleta dos discos na região da base do tronco das árvores. Os discos retirados mediam $\pm 3 \mathrm{~cm}$ de espessura.

\subsection{Preparo das amostras de madeira}

Os discos de madeira das 10 árvores, foram mantidos para secagem em condições de laboratório no Departamento de Ciências Florestais da ESALQ/USP. Em seguida, tiveram suas superfícies lixadas para a melhor visualização dos anéis de crescimento e defeitos da madeira (madeira de compressão, anéis perdidos, nós, etc). Foram selecionados os melhores diâmetros para cada disco com base na morfologia dos anéis de crescimento e ausência dos defeitos enumerados. As amostras de madeira com dimensões aproximadas de 3,0 $x 1,0 \mathrm{~cm}$ (altura $x$ espessura) foram obtidas em serraria,conforme a Figura 5. 

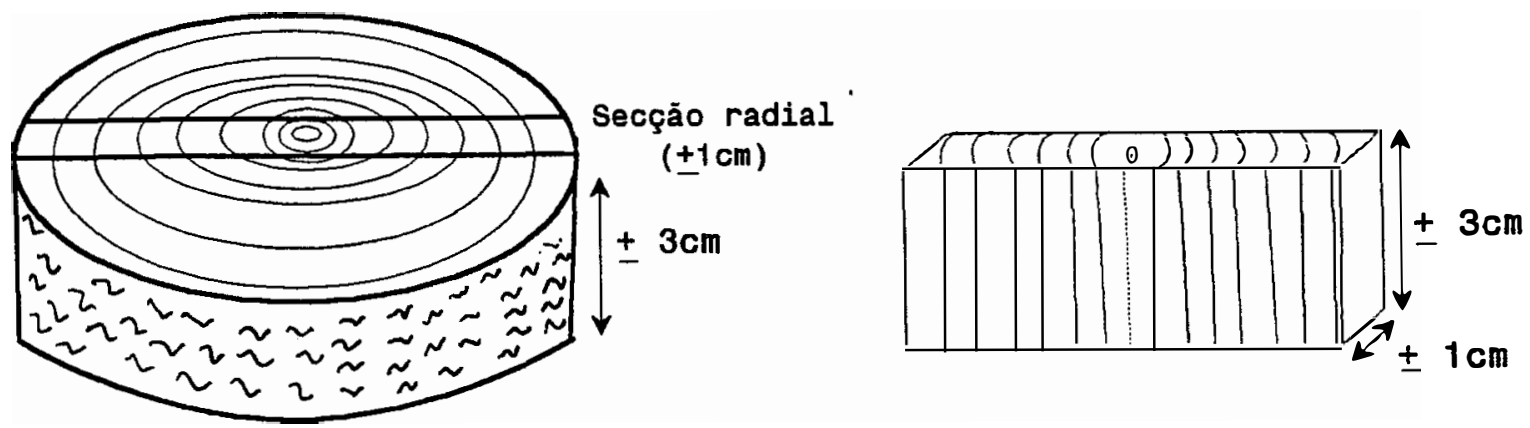

Figura 5. Demarcação e corte das amostras nos discos de madeira de árvores de Pinus taeda, com 20 anos de idade.

Essas amostras de madeira, previamente identificadas, foram novamente mantidas em condições de laboratório até atingirem a umidade de equilíbrio com o ambiente. Em seguida, foram fixadas em um equipamento de dupla serra circular e obtidas amostras radiais com espessura uniforme de 3,2 mm. Essas amostras foram separadas na região da medula, constituindo-se em 2 amostras de madeira por árvore, identificadas com tinta nanquim, que não interfere nas radiografias. 


\subsection{Extração de resina da madeira}

As resinas são produzidas continuamente pelas células secretoras dos ductos resiníferos e não pertencem propriamente a estrutura anatômica da madeira do anel da árvore. Nos trabalhos densitométricos elas devem ser removidas porque variam e afetam na taxa de absorção de raios- $X$, absorvendo relativamente pouco quando comparada com a celulose.

Por esta razão as amostras de madeira foram levadas ao aparelho SOXHLET, para a extração da resina em solução de (i) álcool-tolueno (1:2 em volume) durante 8 horas; (ii) álcool durante 8 horas e (iii) água destilada quente até a obtenção de água límpida durante aproximadamente 48 horas. As amostras de madeira de Pinus taeda, livres de extrativos, foram novamente mantidas em condições de laboratório e secas até a umidade de equilíbrio, com o ambiente e preparadas para serem radiografadas.

\subsection{Radiografia das amostras de madeira}

\subsubsection{O Equipamento de Raios-X}

Foi utilizado um equipamento de raios-X da marca HEWLETT PACKARD, modelo FAXITRON $43805 \mathrm{~N}$, com as seguintes características: equipamento totalmente blindado com paredes de chumbo, constituído por dois 
corpos que possuem prateleiras internas, possibilitando a variação da distância do objeto à fonte de raios-X. $O$ tubo termiônico de raios-X é autoretificador e regulado para 3mA (miliamperagem). A voltagem é variável de 0 a $130 \mathrm{KVp}$ (kilovoltagem). A janela de berilium (material pouco absorvente que permite a passagem do feixe de radiação mais intenso e rico em radiações de baixa freqüência) de 0,63 mm permite um completo espectro dos raios- $X$ mole. O material do anodo é o tungstênio, que tem a finalidade de aumentar o rendimento do tubo. A maior distância possivel da fonte de raios-X ao objeto é de $121,92 \mathrm{~cm}$, permitindo a completa cobertura de um filme de $36 \times 43 \mathrm{~cm}$, com excelente resolução. O tempo de exposição varia de 0 a 5 minutos, com graduações de 0,1 minuto.

\subsubsection{O filme radiográfico}

Formato: $O$ formato $24 \times 18 \mathrm{~cm}$, constituiu-se em boa opção, considerando-se: (i) o limite superior deve ter uma dimensão que possibilite os trabalhos de processamento e que diminua a quantidade de produtos químicos utilizados nas cubas de processamento. Deve também proporcionar uma homogeneidade da dose em toda a superfície da película; (ii) o limite inferior deve possibilitar a disposição de um maior número possível de amostras.

Tipo de filme: o filme da marca KODAK, Diagnostic Film XOmat XK1, com $24 \times 18 \mathrm{~cm}$, apresentou dentre os filmes testados, em radiografia de madeiras, excelente resolução. Esses filmes são produzidos pela Kodak 
brasileira e estão disponíveis no mercado em caixas com 100 películas, sem a individualização em envelopes.

\subsubsection{A exposição dos filmes radiográficos}

As variáveis que controlam a exposição dos filmes radiográficos são: (i) tensão aceleradora no tubo (em KVp); (ii) corrente de aquecimento do cátodo (em mA) e (iii) tempo de exposição (em minutos).

A distância do objeto à fonte de raios-X é também muito importante para se evitar erros de paralaxe na definição dos anéis de crescimento e obter um campo de radiação homogêneo em toda película.

Pelas características do equipamento HP Faxitron e após testes iniciais concluiu-se que as condições de regulagem do equipamento para obtenção de radiografias com bom contraste foram:

- tensão aceleradora no tubo: $16 \mathrm{KVp}$

- corrente de aquecimento do cátodo: $3 \mathrm{~mA}$

- tempo de exposição: 5 minutos

- distância do objeto à fonte de raios-X: 121,92 cm (distância máxima do aparelho), para amostras de Pinus taeda com 3,2 mm de espessura.

As condições de exposição do filme são modificadas em função da espessura da amostra de madeira. 
Constata-se que quanto mais fina é a amostra, menor deverá ser a tensão utilizada e mais longo o tempo de exposição. As Tabelas 3 e 4, apresentadas por DUPONT (1978) mostram a importância destas diferenças.

Tabela 3. Características de exposição para 2 espessuras diferentes (Nancy), segundo DUPONT (1978).

\begin{tabular}{lccc} 
Espessura & $\begin{array}{c}\text { Tensão } \\
\text { aceleradora }\end{array}$ & Intensidade & $\begin{array}{c}\text { Tempo de } \\
\text { exposição }\end{array}$ \\
\hline$(\mathrm{mm})$ & $(\mathrm{KVp})$ & 18 & \\
1,6 & 9,0 & $20 \mathrm{hA})$ & $1{ }^{\prime 2}$ \\
10,0 & 20,5 & & \\
\hline
\end{tabular}

Tabela 4. Características de exposição para diferentes espessuras (Suiça), segundo DUPONT (1978).

\begin{tabular}{lccc}
\hline Espessura & $\begin{array}{c}\text { Tensão } \\
\text { aceleradora } \\
(\mathrm{KVp})\end{array}$ & Intensidade & $\begin{array}{c}\text { Tempo de } \\
\text { exposição } \\
(\mathrm{mm})\end{array}$ \\
\hline 3,00 & 17 & 20 & 6 \\
2,00 & 14 & 20 & 25 \\
1,25 & 11 & 20 & 180 \\
\hline
\end{tabular}




\subsubsection{Orientação das amostras de madeira em relação ao feixe de raios-X}

A orientação dos elementos anatômicos da madeira em relação à passagem do feixe de raios- $X$ constitui-se, também, em uma importante variável a ser definida para a obtenção e qualidade das radiografias. Os feixes de raios-X podem atravessar a amostra de madeira no sentido paralelo ou perpendicular aos elementos axiais (fibras, vasos, canais de resina, etc) (Figura 6).

\section{Feixes de raios- $X$}
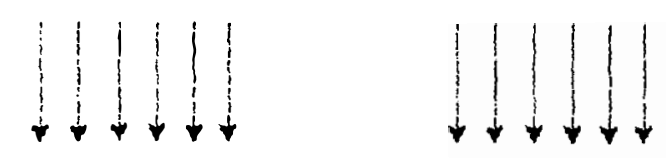

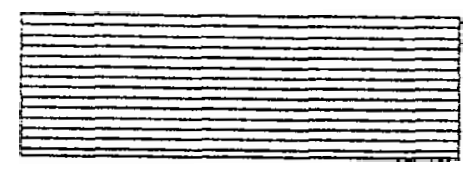

Orientaçāo das fibras no sentido perpendicular ao tedxe de raios- $X$

\section{Amostras de madeira}

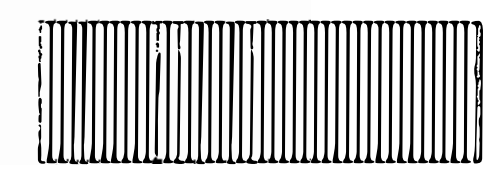

Orientaçao das fibras nosentido paralelo ao teixe de raios- $X$

Figura 6. Representação esquemática da orientação das fibras em amostra de madeira em relação à passagem do feixe de raios- $X$. 
Como numa árvore os anéis são circulares, um raio perpendicular à direcão da madeira e tangencial, atravessará zonas correspondentes à épocas diferentes de um mesmo anel, e isto ocorrerá quanto mais larga for a amostra e menor o raio de curvatura, ou seja, para os anéis próximos da medula.

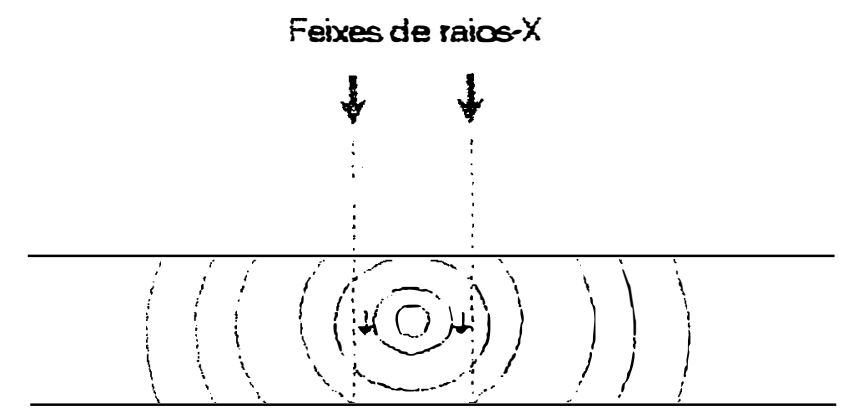

Figura 7. Inconvenientes dos raios perpendiculares para os anéis próximos à medula.

Para se obter as variações de densidade no decurso de um ano é, portanto, preferivel que os raios sejam paralelos às fibras.

Entretanto, para certas madeiras de folhosas, como o carvalho, onde a escolha arbitrária de um raio de exploração não é conveniente em vista de sua heterogeneidade, a radiação perpendicular à direção da madeira tem a vantagem de atravessar os diferentes elementos num mesmo momento do crescimento (vasos, fibras, parênquima) e se avaliar melhor as variações globais da densidade em função do período do ano, DUPONT (1978). 
Em resumo, se a madeira é homogenea ou o raio de curvatura muito pequeno (madeira juvenil), a radiação paralela às fibras é necessária. Ao contrário, para madeiras muito heterogêneas (folhosas e resinosas com grandes canais resiníferos) é necessário a utilização de raios perpendiculares à madeira. Por este motivo nossas amostras de madeira foram irradiadas no sentido paralelo ao plano da madeira.

\subsubsection{Exposição das películas}

A exposição das películas deve ser feita em um ambiente completamente escuro para não haver perigo de velar o filme, que é muito sensível à luz. O aparelho de raios-X encontra-se, portanto, em uma sala completamente vedada à entrada de luz.

As amostras a serem radiografadas foram colocadas sobre um suporte de madeira (mesa) recoberta com duas camadas de acetato de celulose. Uma camada do acetato é fixada no suporte de madeira e a outra é apenas parcialmente fixada, permitindo a entrada do filme, que é colocado nu entre as duas camadas de acetato.

A mesa preparada com as amostras foi colocada dentro do aparelho de raios-X. Com a sala totalmente escura, introduziu-se a película entre as camadas de acetato e acionou-se o aparelho. Após completada a exposição, os filmes foram colocados em caixas, tomando-se o cuidado de impedir qualquer entrada de luz e a seguir foram processados. 


\subsubsection{Processamento radiográfico}

É uma etapa muito importante e muito delicada do processo de análise, uma vez que, para uma mesma dose de radiação recebida, quaisquer superfícies distintas de um mesmo filme devem apresentar a mesma densidade ótica. Para isto é necessário que todos os cristais halogenados de prata da imagem latente, ou seja, portadores de traços de prata, tenham no mesmo momento, a mesma chance de serem reduzidos em prata metálica dentro do revelador. Uma agitação contínua, eficaz e irregular do banho do revelador é necessária. Deve-se evitar que o produto usado repasse ciclicamente pelos mesmos lugares. Em nosso trabalho usou-se banheira plástica com vidro no fundo (para evitar arranhões nas películas) e fez-se a agitação manualmente. O revelador utilizado foi o GBX-Kodak (revelador e reforçador).

Quanto a duração da revelação, sabe-se que:

1) O contraste aumenta com a duração da revelação.

2) Os cristais halogenados de prata não irradiados sofrem igualmente, apesar que bem mais lentamente, uma redução. Disto resulta um tenue escurecimento geral que se chama velamento.

3) A granulação da imagem aumenta à medida que se prolonga a revelação.

A duração da revelação ótima para um filme radiográfico é, portanto, determinada pela relação contraste/densidade mais favorável.

- Temperatura do Revelador

A rapidez da revelação aumenta com a temperatura do revelador. Com temperaturas elevadas é necessário diminuir a duração, a fim de 
evitar um aumento do velamento e uma granulação muito forte. Ao contrário, se a temperatura de revelação é inferior a $18^{\circ} \mathrm{C}$, a hidroquinona, elemento gerador do contraste, perde sua atividade. Por estas razões, é preferível trabalhar entre $18 \mathrm{e}$ $22^{\circ} \mathrm{C}$. A Tabela 5 fornece os tempos de processamento para o filme utilizado.

Tabela 5. Tabela de tempos de processamento radiográfico parafilmes Kodak $\mathrm{X}-\mathrm{K} 1$.

\begin{tabular}{lll} 
Seqüência & Temperatura & Soluções Kodak \\
& & \\
& 20 a $21^{\circ} \mathrm{C}$ & $\pm 3,5 \mathrm{~min}$. \\
21 a $23^{\circ} \mathrm{C}$ & $\begin{array}{l} \pm, 0 \mathrm{~min} . \\
\pm 2,5 \mathrm{~min} . \\
23 \text { a } 24^{\circ} \mathrm{C}\end{array}$ \\
& 24 a $25^{\circ} \mathrm{C}$ & $\begin{array}{l} \pm 1,0 \mathrm{~min} . \\
\text { Revelador }\end{array}$ \\
& 25 a $26^{\circ} \mathrm{C}$ & $\pm 1,0 \mathrm{~min}$. \\
& 26 a $27^{\circ} \mathrm{C}$ & \\
& & 20 segundos \\
Enxague & $\pm 20^{\circ} \mathrm{C}$ & \\
(água limpa) & & 3 a 4 min. \\
\hline Fixador & $\pm 20^{\circ} \mathrm{C}$ & 2 a 3 min. \\
& $\pm 25^{\circ} \mathrm{C}$ &
\end{tabular}




\subsubsection{Seqüência do processamento radiográfico}

O processamento foi feito em uma câmara totalmente escura onde foram preparados os diversos banhos necessários. Inicialmente foram preparadas as diversas cubas com os reagentes ou água, segundo a seqüência.

a) Revelador: $O$ revelador foi preparado segundo as indicações do fabricante. A temperatura do mesmo foi medida e com base nesta temperatura calculou-se o tempo de revelação. O filme foi introduzido nesta cuba e agitado constantemente.

b) Banho intemuptor: Após a permanência no revelador, é indispensável impedir instantaneamente sua ação sobre toda superfície do filme. Por isso, o filme foi mergulhado rapidamente em um banho interruptor contendo $2 \%$ de ácido acético para sustar a ação do revelador.

c) Lavagem: Após o banho de parada o filme foi mergulhado em água limpa, para lavagem, com a finalidade de remoção de todo produto químico.

d) Fixador: Após lavagem rápida o filme foi colocado no fixador durante 5 minutos, onde ele foi agitado durante pelo menos os primeiros 30 segundos. O fixador utilizado foi o GBX-Kodak - fixador e reforçador.

e) Lavagem: O filme foi novamente lavado em água corrente durante, no mínimo, 5 minutos, ou em água parada durante 25 minutos. 
f) Enxague final: Finalmente o filme foi mergulhado num último banho contendo uma solução de Photo-FLO 200 - Kodak, para melhorar a qualidade das radiografias.

g) Secagem: Os filmes foram então pendurados para secagem, em ambiente livre de poeira ou qualquer outra impureza em suspensão.

\subsection{Análise das radiografias}

Após a obtenção das radiografias, elas devem ser varridas num microdensitômetro. O microdensitômetro existente no laboratório é da marca Joyce LoebI MK III-C, cujas características e funcionamento são descritos a seguir.

\subsubsection{O Microdensitômetro Joyce Loebl MK III-C}

É um aparelho que, sob forma de diagrama, registra as variações de densidade ótica ao longo de um caminho sobre uma radiografia. Tratase de um verdadeiro sistema de feixe duplo no qual ambos os feixes provenientes de uma fonte luminosa única são dirigidos alternativamente para um único fotomultiplicador após ter atravessado, um a radiografia e o outro uma cunha ótica. Esta consiste de uma peça em vidro retangular e alongado, cuja densidade ótica 
varia linearmente de uma extremidade a outra. Ela é movida por um servomotor conduzido pelo fotomultiplicador em caso de desigualdade de intensidade dos dois feixes luminosos.

Um sistema de registro é acoplado aos movimentos da cunha. À medida que a radiografia se desloca na presença do raio luminoso ela arrasta a mesa de registro numa relação de velocidade escolhida pelo usuário $(1 / 1,2 / 1,5 / 1$, 10/1, 20/1 ou 50/1), graças a uma ligação mecânica regulável. Este movimento, segundo o eixo dos $X$ e o movimento da cunha segundo o eixo dos $Y$ dão um diagrama que representa as variações de densidade ótica ao longo de um caminho escolhido na radiografia.

A zona analisada, sob a qual a luz é concentrada por um condensador, pode ser reduzida a dimensões ínfimas, da ordem de micron, pelo jogo de uma abertura final (fenda de exploração), que fixa a largura e a altura após aumento obtido pela passagem através de uma objetiva.

A radiografia é colocada sobre uma mesa porta-amostra podendo se deslocar num plano segundo suas direções perpendiculares e segundo um movimento de rotação. A amplitude destes movimentos é controlada por nônios de $0,1 \mathrm{~mm}$. Isto permite posicionar a amostra de maneira que o raio luminoso a explore exatamente segundo seu eixo. Um esquema do funcionamento do microdensitômetro é fornecido na Figura 8.

Duas regulagens (diafragma e fenda) permitem reduzir o feixe de luz que deve atravessar a superfície a ser analisada. 


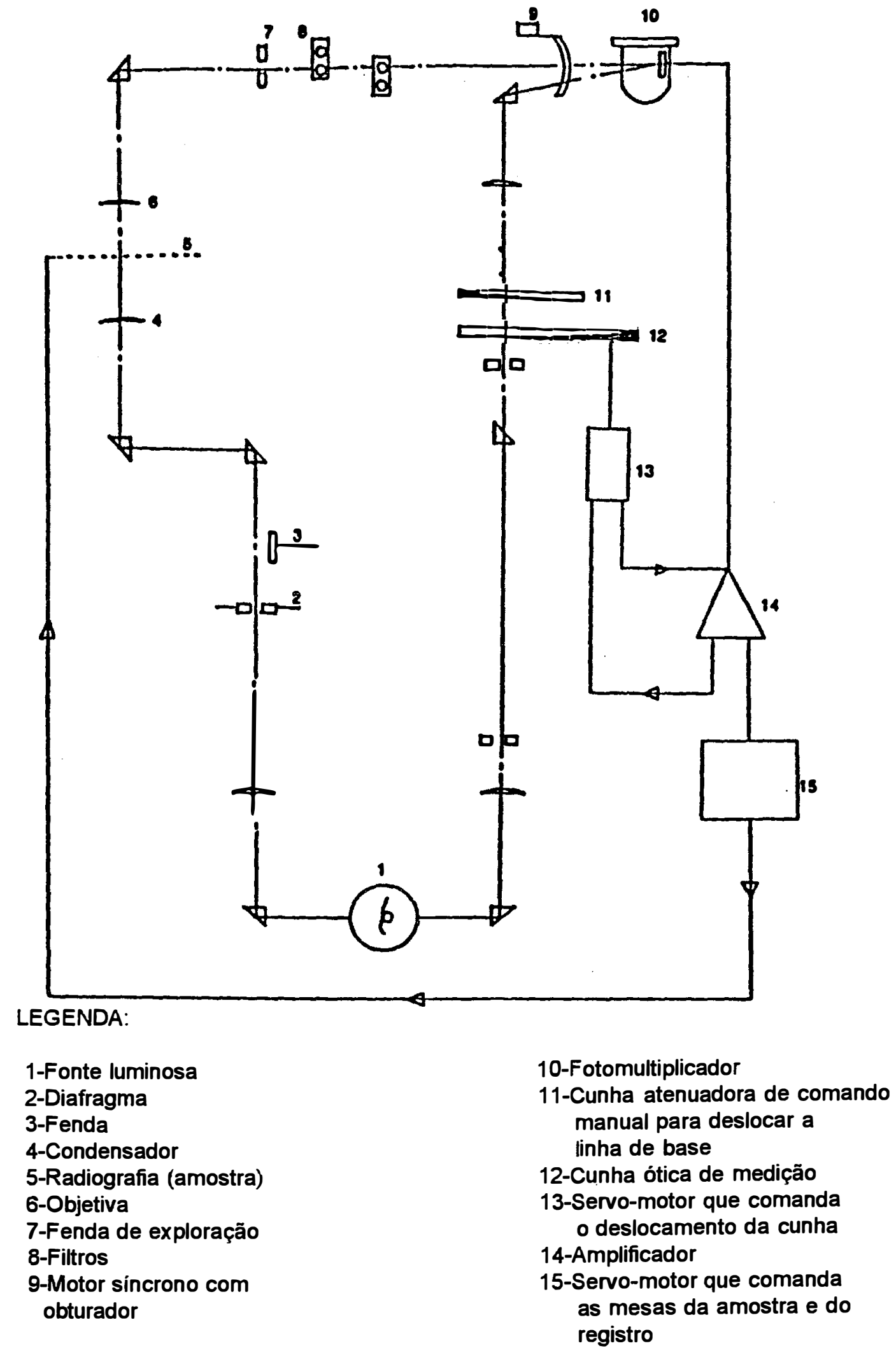


Após a regulagem do condensador e da objetiva, é necessário regular a abertura da fenda de exploração (Figura 9). As dimensões desta fenda dependem do tipo de amostra, do tipo do filme e, finalmente, do propósito perseguido.

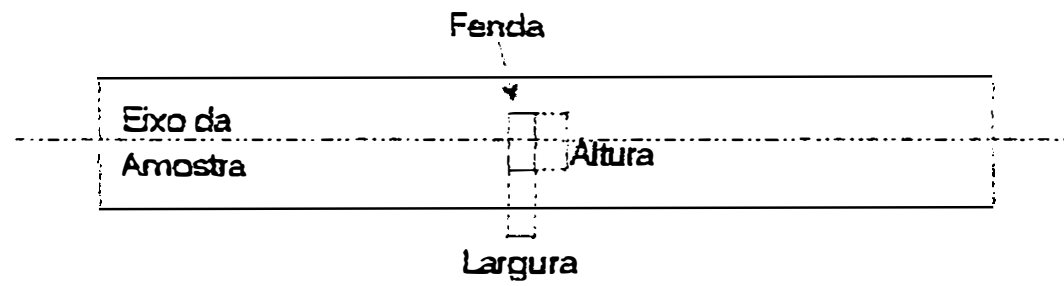

Figura 9. Esquema fornecedor das noções de largura e altura da fenda em relação à radiografia de uma amostra.

Dimensōes no sentido radial (largura): Quanto menor for a largura, maior será a precisão no que diz respeito às variações da densidade ótica. Entretanto, receia-se que os resultados sejam distorcidos por causa das microvariações de escurecimento devido as irregularidades de granulação das radiografias. Em nosso trabalho, foi adotada uma largura de fenda de 0,1 $\mathrm{mm}$. Para maior precisão é possivel trabalhar com emulsões de granulação muito fina, como as usadas para microradiografias, utilizando-se de fendas de exploração de superfícies mínimas, por exemplo, de $5 \times 5$ microns. 
Dimensões no sentido tangencial (altura): É interessante que ela seja suficientemente grande para a obtenção de um registro das variações médias de densidade em diversas filas de células. Em nosso trabalho adotou-se uma altura de 0,3 mm. Em casos de madeira muito heterogênea, pode-se usar uma altura de $0,8 \mathrm{~mm}$ a $1,6 \mathrm{~mm}$.

As dimensões da fenda devem ser modificadas em função do tamanho circunferencial dos elementos que constituem a madeira para observar as variações de densidade e não as variáveis de estrutura anatômica. Quanto maiores os elementos mais importantes tornam-se as dimensões da fenda. Quando os anéis são muito estreitos a largura da fenda deve ser reduzida até um mínimo no qual o lenho outonal e o lenho primaveril não sejam integrados. Neste caso, abertura de fendas de 0,03 mm a 0,06 mm parecem ser ideais, POLGE (1966).

\subsection{Calibração}

Os diagramas obtidos através do microdensitômetro permitem observar as variações de densidade de uma amostra, mas não permitem quantificar a densidade absoluta de um ponto qualquer da curva, porque é necessário calibrar cada radiografia através da colocação de pelo menos duas amostras homogêneas de densidades diferentes e conhecidas. Entretanto, é praticamente impossivel encontrar pedaços de madeira bruta que tenham densidades suficientemente homogêneas para servir de base de comparação. 
Na prática, a solução encontrada por diversos pesquisadores foi a utilização de padrões fabricados com materiais que tivessem um coeficiente de absorção de massa igual ao da madeira e por conseqüência uma composição química muito próxima dela.

Dentre os diversos materiais testados, aqueles que mais se aproximaram da madeira foram o Kematol e o acetato de celulose. Embora o Kematol dê um resultado mais preciso, ele é mais difícil de ser encontrado, sendo o acetato de celulose mais utilizado.

A confecção do padrão ou cunha, pode ser feita de duas maneiras, ou seja, através da trabalhabilidade muito precisa de um bloco de acetato cuja espessura decresce linearmente de uma extremidade a outra, ou através da superposição de um número de folhas de acetato cujo comprimento diminui exatamente de 1,0 ou $2,0 \mathrm{~cm}$ quando se passa de um degrau para o degrau superior. Diversas cunhas devem ser feitas, pois elas devem se adaptar às variações de densidade das amostras a serem analisadas.

Para o nosso trabalho foi utilizada uma cunha em acetato de celulose (Rhodophane 400) tendo o aspecto de uma escada com 12 degraus. 0 primeiro é constituído de duas folhas de $0,12 \mathrm{~mm}$ de espessura, os degraus de 2 a 12 possuem cada um uma espessura de 2 folhas a mais que o precedente. A gramatura $\left(\mathrm{g} / \mathrm{m}^{2}\right)$ do acetato foi calculada através de medições e pesagens, chegando-se a um valor de $157,5 \mathrm{~g} / \mathrm{m}^{2}$. A partir deste valor calculou-se a gramatura para cada degrau da cunha, que dividido pela espessura da amostra fornece a 
densidade da madeira. Este procedimento foi feito baseando-se numa fórmula (a) aceita em densitometria de raio- $X$ onde $x_{a} \cdot d_{a}=x_{m} \cdot d_{m}$ e portanto:

$$
d_{m}=\frac{x_{a} \cdot d_{a}}{x_{m}}
$$

onde:

$$
\begin{aligned}
& x_{a}=\text { espessura do acetato de celulose; } \\
& d_{a}=\text { densidade do acetato de celulose; } \\
& x_{m}=\text { espessura da madeira; } \\
& d_{m}=\text { densidade da madeira }
\end{aligned}
$$

A Tabela 6 , fornece valores em $\mathrm{g} / \mathrm{dm}^{3}$ da densidade da madeira em função da espessura das amostras radiografadas e do número do degrau da cunha de rhodophane 400, que apresenta o mesmo escurecimento.

Esta cunha foi radiografada juntamente com as amostras de madeira e forneceu a curva de calibração necessária para a transformação da densidade ótica em densidade real da madeira. Ela serviu também para compensar qualquer variação na intensidade da exposição ou processamento do filme de radiografia para radiografia. 
Tabela 6. Densidade da madeira $\left(\mathrm{g} / \mathrm{dm}^{3}\right)$ em função da sua espessura e do número do degrau.

\begin{tabular}{|c|c|c|c|c|c|}
\hline \multirow{3}{*}{$\begin{array}{c}\text { No } \\
\text { do } \\
\text { degrau }\end{array}$} & \multirow{3}{*}{$\begin{array}{c}\text { Peso } \\
\text { superficial } \\
\left(\mathrm{g} / \mathrm{m}^{2}\right)\end{array}$} & \multicolumn{4}{|c|}{ Densidade $\left(\mathrm{g} / \mathrm{dm}^{3}\right)$} \\
\hline & & \multicolumn{4}{|c|}{ Espessura (mm) } \\
\hline & & 1,5 & 2,0 & 3,0 & 3,2 \\
\hline 1 & 315 & 210,0 & 157,5 & 105,0 & 98,0 \\
\hline 2 & 630 & 420,0 & 315,0 & 210,0 & 196,0 \\
\hline 3 & 945 & 630,0 & 472,5 & 315,0 & 294,0 \\
\hline 4 & 1260 & 840,0 & 630,0 & 420,0 & 392,0 \\
\hline 5 & 1575 & 1050,0 & 787,5 & 525,0 & 490,0 \\
\hline 6 & 1890 & 1260,0 & 945,0 & 630,0 & 588,0 \\
\hline 7 & 2205 & 1470,0 & 1102,5 & 735,0 & 686,0 \\
\hline 8 & 1520 & 1680,0 & 1260,0 & 840,0 & 784,0 \\
\hline 9 & 1833 & 1890,0 & 1417,5 & 945,0 & 882,0 \\
\hline 10 & 3150 & 2100,0 & 1575,0 & 1050,0 & 980,0 \\
\hline 11 & 3465 & 2310,0 & 1732,5 & 1155,0 & 1078,0 \\
\hline 12 & 3788 & 2520,0 & 1890,0 & 1260,0 & 1176,0 \\
\hline
\end{tabular}

\subsection{Fator de correção}

Ao aceitarmos a fórmula $x_{a} \cdot d_{a}=x_{m} \cdot d_{m}$ partimos da premissa que o acetato de celulose é idêntico à madeira no que diz respeito ao seu comportamento quanto a absorção de raios-X. Entretanto, isto não é verdadeiro e 
o que ocorre é que a densidade real volu-gravimétrica (determinada através da relação entre peso e volume) é sempre menor que a densidade radiótica (densidade da madeira obtida através da densidade ótica). Desta forma, é preciso corrigir a densidade radiótica. Para tanto, é necessário determinar a densidade radiótica de algumas amostras assim como a sua densidade volu-gravimétrica. A relação:

média da densidade volu-gravimétrica

média da densidade radiótica

nos dá um fator de correção que é empregado, seja para corrigir os valores dos degraus da cunha, desta forma utilizando-se a fórmula (b):

$$
d_{m}=\frac{x_{a} \cdot d_{a} \cdot f}{x_{m}}
$$

ou então, utilizando o fator diretamente nos dados de densidade radiótica, obtidos com os degraus da cunha sem correção.

Por esta razão, a densidade volu-gravimétrica (obtida pelo método de deslocamento do $\mathrm{Hg}$ ) foi determinada, assim como a densidade radiótica de algumas amostras (ver Apêndice), chegando-se à um fator igual a 0,8949.

Este fator foi usado para corrigir os dados da densidade radiótica da madeira, obtidos com os valores dos degraus não corrigidos. 


\subsection{Definição do lenho outonal}

A definição do lenho outonal é um problema fundamental nos estudos de densidade intra-anel, e muitos autores concordam que não existe uma definição adequada e universal dos limites entre lenho outonal e lenho primaveril.

Muitos pesquisadores engajados nas pesquisas de densidade intra-anéis optaram por dividir o anel em zonas de níveis de densidade. Neste caso, decisões devem ser tomadas segundo as alternativas:

a) Selecionar um nível de densidade que resulte em um limite primaveril/outonal semelhante à definida por Mork;

b) Selecionar um nível de densidade que dê resultados similares aos de uma inspeção visual de um grande número de amostras;

c) selecionar um nível padrão para todas as espécies;

d) selecionar um nível padrão para cada espécie;

e) selecionar um nível para cada conjunto de árvores (de um

sítio);

f) selecionar um nível para cada amostra de madeira;

g) Selecionar um nivel para cada anel;

h) usar um nível móvel;

i) usar a média, moda, mediana ou um certo nível de porcentagem da densidade;

j) uṣar um nível ou vários níveis. 
Para nosso estudo foi fixado um nível único de $500 \mathrm{~g} / \mathrm{dm}^{3}$ para a separação do lenho outonal do lenho primaveril para todas as amostras, por ser este o nível mais utilizado para coníferas (COWN \& PARKER, 1978; JOSZA et al., 1987).

\subsection{Sistema computacional}

A saída do densitômetro é diretamente lida e registrada por um microcomputador. Como o volume de dados é enorme (leituras de 0,01 mm), um sistema computadorizado é essencial neste tipo de análise.

O sitema computacional foi desenvolvido no Laboratório de Métodos Quantitativos do Departamento de Ciências Florestais - ESALQ/USP e é dividido em dois sistemas auxiliares: um para a coleta dos dados, o Read; e outro, o Analysis, responsável pelo tratamento dos dados, ou seja, a estimativa dos parâmetros de regressão, determinação das características de cada anel (densidades, comprimentos, CV, textura) e a densidade ponderada para a amostra.

\subsubsection{O sistema Read}

Este sistema, cujo fluxograma pode ser observado na Figura 10 é responsável pela coleta das informações de densidade ótica que é gerada pelo 
microdensitômetro e cuja comunicação fica por conta de uma porta de comunicação paralela, modificada para estabelecer este protocolo.

Descrevemos abaixo os passos fundamentais do sistema de coleta das informações.

1) Estabelecer e verificar a comunicação microcomputador/microdensitômetro;

2) Para o início das leituras faz-se necessário informar ao sistema qual é o comprimento da amostra e a velocidade de leitura do microdensitômetro via teclado;

3) A partir daí, dá-se início à leitura da densidade ótica que é medida através do deslocamento da pena em função da passagem de luz. As leituras vão sendo feitas e armazenadas em vetores até que a mesa do microdensitômetro percorra a distância igual ao comprimento da amostra;

4) À medida que as informações de densidade ótica vão sendo transmitidas ao microcomputador, um gráfico é plotado no monitor do mesmo para que o usuário possa ter um acompanhamento visual da amostra (Figura 11). 


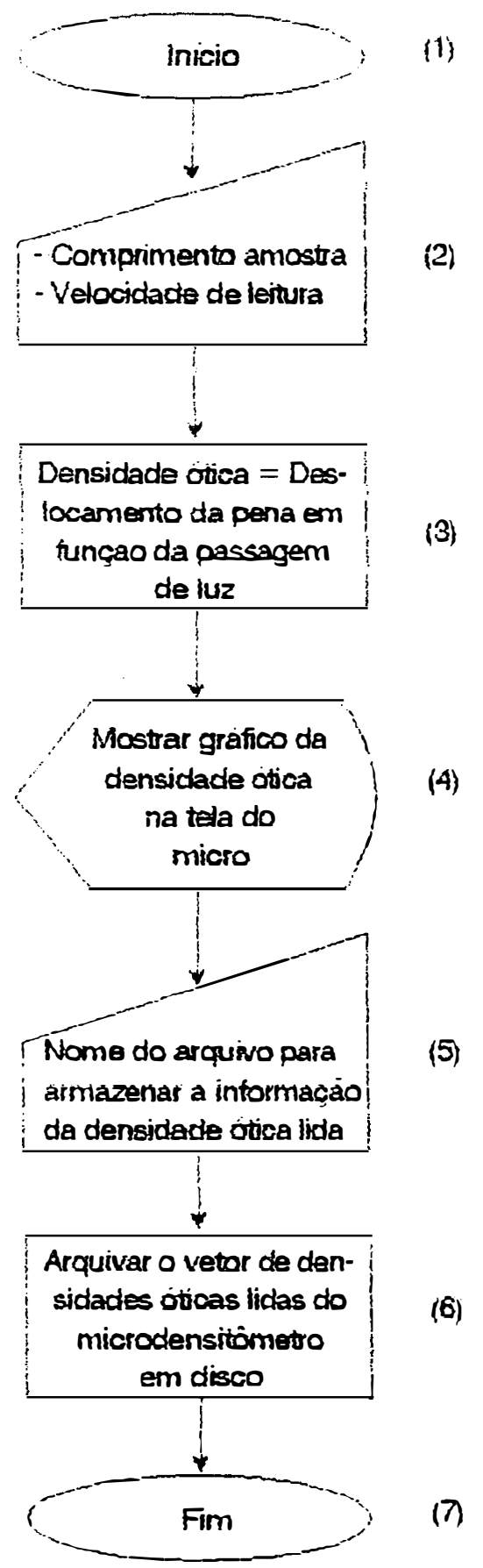

Figura 10. Fluxograma do sistema "READ". 


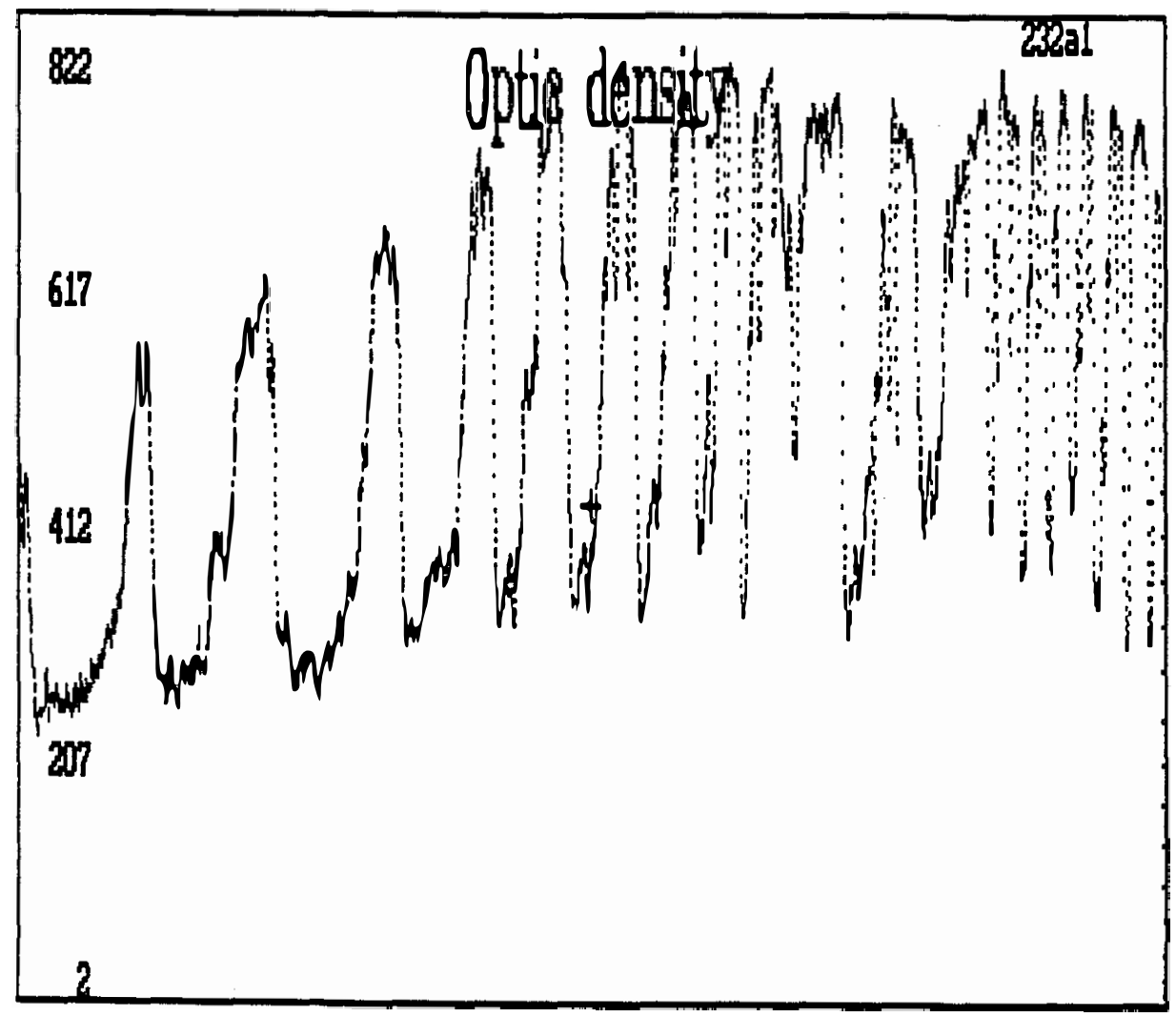

Figura 11. Curvas da variação da densidade ótica de uma amostra de madeira.

5) O sistema solicita ao usuário o nome do arquivo de saída para armazenamento das informações que é gerado em código ASCII.

6) O último passo é arquivar todas as informações para que esta amostra possa ser submetida ao sistema de tratamento dos dados (Analysis).

7) Finaliza operações.

Este sistema tem algumas outras funções auxiliares, como recuperação de informações de arquivo em disco, plotar o gráfico na tela ou impressora. 


\subsubsection{O sistema Analysis}

Este sistema, cujo fluxograma pode ser observado na Figura 12, é responsável pelo setor mais importante do sistema computacional deste método de estudo. Toda base de cálculo, transformações de dados, ajustes, estimativas e gráficos necessários para interpretação dos resultados são gerados por ele. 0 sistema é responsável também por gerar as informações que posteriormente serão submetidas às analises estatísticas.

A seguir são demonstradas as etapas do funcionamento do sistema Analysis.

1) Definição do ambiente de trabalho tais como tipo de vídeo, configuração gráfica entre vídeo e impressora;

2) Leitura da curva de calibracão através de arquivo em disco;

3) O sistema solicita o número de transição entre degraus da cunha de calibração e também o comprimento dos degraus da cunha;

4) Exclusão de dados de transição entre degraus da cunha de calibração (Figura 13); 

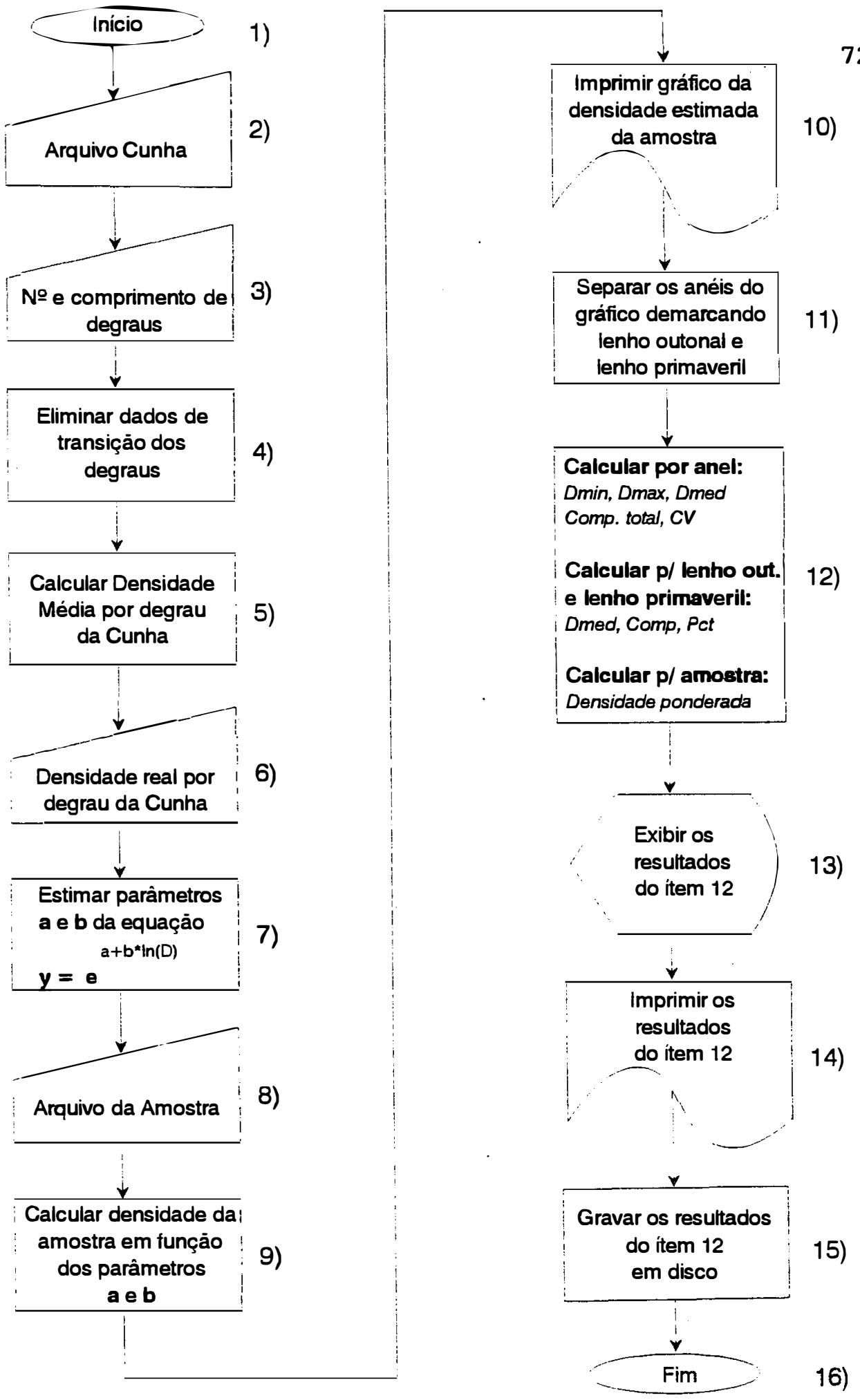

Figura 12. Fluxograma do sistema "ANALISYS". 

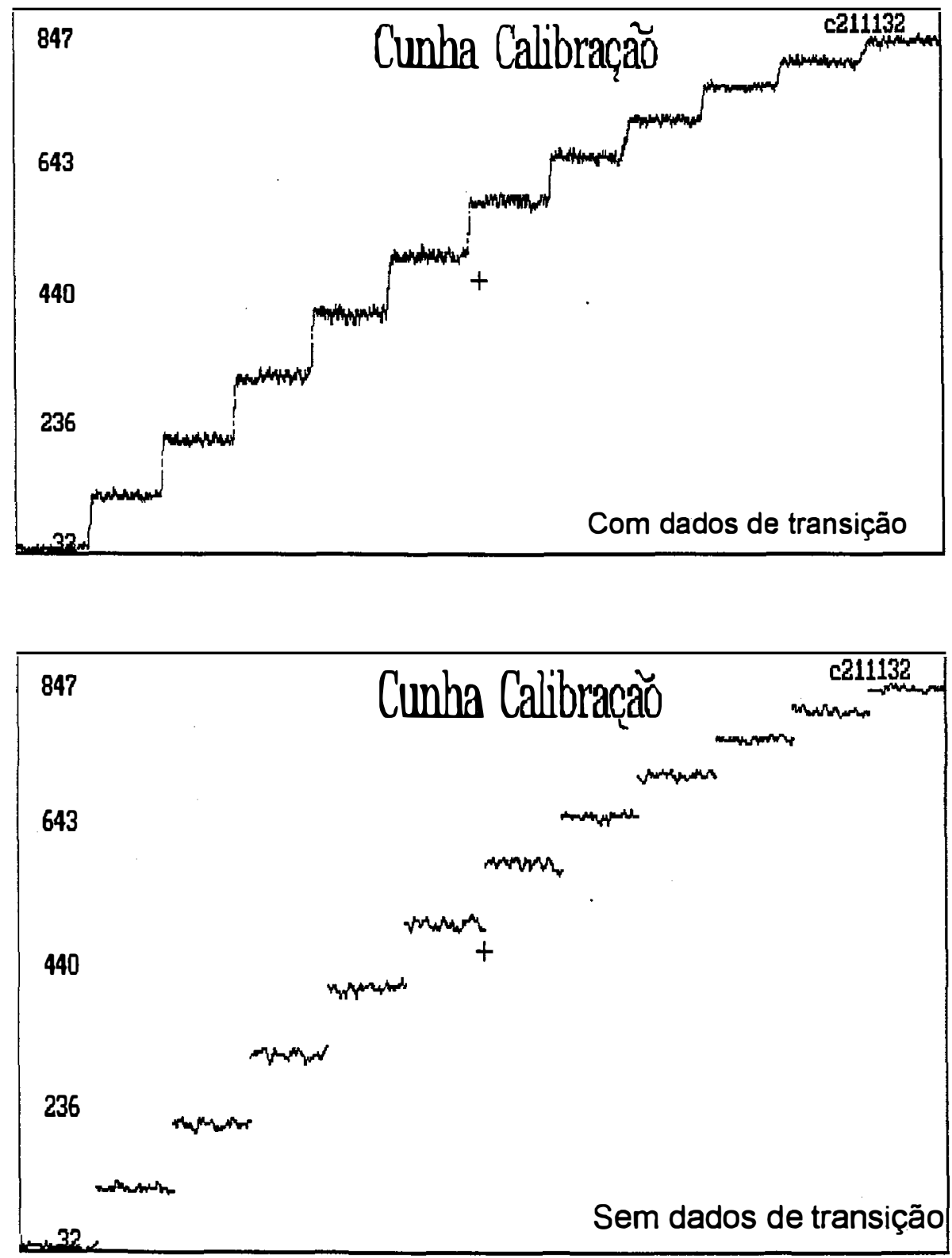

Figura 13. Ilustração da exclusão de dados de transição entre os degraus da cunha de calibração. 
5) Calcular a densidade ótica média por degrau da cunha de calibração;

6) Informar ao sistema a densidade real calculada para cada degrau da cunha de calibração;

7) Estimar os parâmetros da regressão que futuramente serão utilizados para computar a densidade real estimada da amostra. Os parâmetros estimados são a e b da equação:

$$
Y=e^{a+b^{*} \operatorname{Ln}(D)}
$$

$$
\text { onde: } \quad \begin{aligned}
Y & =\text { densidade real estimada; } \\
a & =\text { intercepto da regressão; } \\
b & =\text { coeficiente angular da regressão; } \\
D & =\text { densidade ótica; }
\end{aligned}
$$

8) Uma vez estimado os parâmetros de regressão, faz-se a leitura da amostra em disco;

9) Com as informacões da amostra computa-se a densidade real da mesma, utilizando-se da equação citada no item 7;

10) Uma vez calculada a densidade real em função da densidade ótica, produz-se um gráfico para fazer a pré-seleção dos anéis de crescimento (Figura 14). Este gráfico pode ser tanto da densidade ótica quanto da densidade real e pode ser no padrão de uma ou duas páginas, dependendo da facilidade visual e complexidade dos anéis de crescimento; 
Amostra 211a1

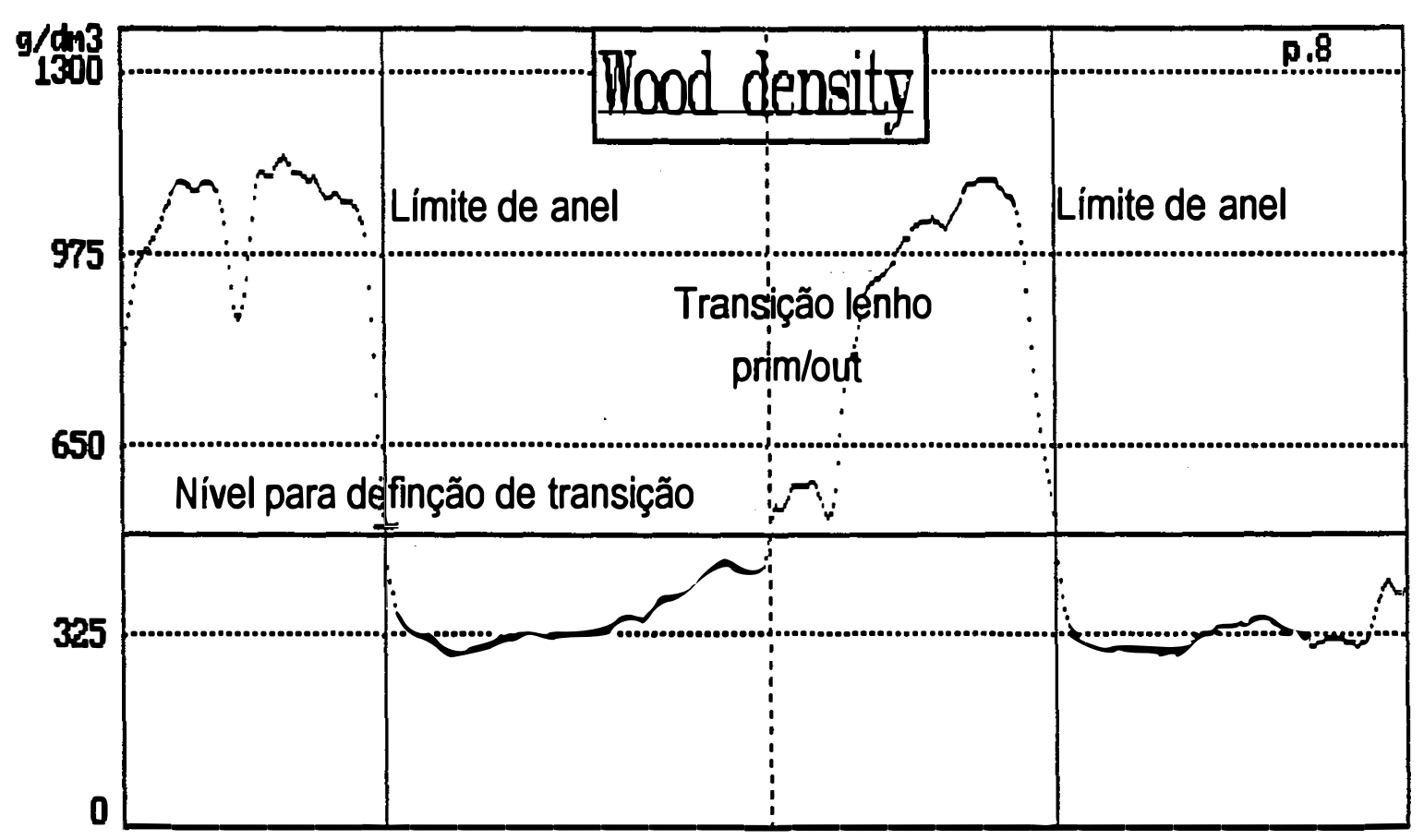

Figura 14. Delimitação dos anéis de crescimento.

11) Utilizando-se de gráfico já com os anéis demarcados previamente, podemos separar na tela do computador, utilizando-se de recursos de movimentação associados à teclas de velocidade, definição de mudança de anel, transição de lenho primaveril para outonal e paginação (uma amostra de $65 \mathrm{~mm}$ possui aproximadamente 10 páginas em Zoom). Por "default", utiliza-se o nível de $500 \mathrm{~g} / \mathrm{dm}^{3}$ para definir a textura de cada anel. Este nível pode ser pré-definido em dois ou mais níveis, de acordo com a necessidade; 
12) Uma vez definida as transições de lenhos primaveril e outonal, faz-se a estimativa dos parâmetros: a) densidade média do anel; b) densidade mínima do anel; c) densidade máxima do anel; d) comprimento do lenho primaveril do anel; e) comprimento do lenho outonal do anel; f) comprimento total do anel; g) coeficiente de variação da densidade do anel; $h$ ) textura do anel (\% de lenho outonal); i) densidade média do lenho outonal de cada anel; e j) densidade média do lenho primaveril de cada anel.

Um exemplo do "output" destas informações pode ser observado na Tabela 7;

13) Exibe os resultados calculados no item 12, na tela;

14) Imprime os resultados calculados no item 12;

15) Arquiva os resultados calculados no item 12, juntamente com a identificação da amostra. Estas informações serão as mesmas a serem analisadas pelo sistema estatístico de análise.

Outros recursos disponiveis também neste sistema são a junção de diversos arquivos de uma mesma amostra e exclusão de partes da amostra que por algum motivo possam ser desinteressantes ou apresentam problemas que possam afetar os resultados finais. 
Tabela 7. Formato do "OUTPUT" gerado na analise de dados do program a "ANALYSIS".

Sample number: $211 \mathrm{lal}$

\begin{tabular}{||c|c|c|c|c|c|c|c|c|c|c|c||}
\hline \multirow{2}{*}{ Ring } & \multirow{2}{*}{ Min } & Max & Mean & Spring & Autumnal & Total & Spring & Autumnal & CV\% & SPR & AUT \\
\hline \hline 2 & 252 & 712 & 382 & 940 & 250 & 1190 & 78.99 & 21.01 & 27.65 & 322 & 607 \\
\hline 3 & 271 & 884 & 418 & 1070 & 280 & 1350 & 79.26 & 20.74 & 27.74 & 326 & 772 \\
\hline 4 & 263 & 896 & 393 & 1100 & 270 & 1370 & 80.29 & 19.71 & 28.10 & 305 & 752 \\
\hline 5 & 262 & 912 & 429 & 880 & 320 & 1200 & 73.33 & 26.67 & 25.67 & 311 & 753 \\
\hline 6 & 312 & 994 & 529 & 390 & 210 & 600 & 65.00 & 35.00 & 22.75 & 367 & 830 \\
\hline 7 & 275 & 1088 & 507 & 440 & 190 & 630 & 69.84 & 30.16 & 24.44 & 355 & 857 \\
\hline 8 & 261 & 1043 & 530 & 530 & 280 & 810 & 65.43 & 34.57 & 22.90 & 352 & 866 \\
\hline 9 & 277 & 1148 & 618 & 390 & 270 & 660 & 59.09 & 40.91 & 20.68 & 361 & 988 \\
\hline 10 & 299 & 1105 & 580 & 420 & 200 & 620 & 67.74 & 32.26 & 23.71 & 401 & 955 \\
\hline 11 & 301 & 1079 & 695 & 300 & 620 & 920 & 32.61 & 67.39 & 11.41 & 347 & 863 \\
\hline 12 & 276 & 1037 & 303 & 480 & 450 & 930 & 51.61 & 48.39 & 18.06 & 371 & 850 \\
\hline 13 & 317 & 955 & 640 & 430 & 530 & 960 & 44.79 & 55.21 & 15.68 & 417 & 821 \\
\hline 14 & 406 & 937 & 676 & 240 & 650 & 890 & 26.97 & 73.03 & 9.44 & 459 & 756 \\
\hline 15 & 348 & 937 & 599 & 320 & 410 & 730 & 43.84 & 56.16 & 15.34 & 397 & 756 \\
\hline 16 & 317 & 784 & 504 & 530 & 320 & 850 & 62.35 & 37.65 & 21.82 & 405 & 669 \\
\hline 17 & 356 & 780 & 529 & 420 & 380 & 800 & 52.50 & 47.50 & 18.38 & 419 & 652 \\
\hline 18 & 330 & 854 & 533 & 510 & 480 & 990 & 51.52 & 48.48 & 18.03 & 381 & 695 \\
\hline 19 & 324 & 915 & 609 & 330 & 640 & 970 & 34.02 & 65.98 & 11.91 & 389 & 722 \\
\hline 20 & 337 & 858 & 585 & 440 & 560 & 1000 & 44.00 & 56.00 & 15.40 & 421 & 713 \\
\hline \hline
\end{tabular}

Weighted average: 533 


\section{RESULTADOS E DISCUSSÃO}

A principal finalidade do presente trabalho foi 0 desenvolvimento e implantação da metodologia da densitometria de raios- $X$ em madeira. Com a finalidade de serem visualizados os resultados obtidos através desta técnica foram analisadas as amostras de madeira retiradas da base de árvores de Pinus taeda com 20 anos, coletadas em 5 classes de diâmetros, descritos a seguir.

\subsection{Radiografia das amostras de madeira}

Os procedimentos adotados (item 4.5), possibilitaram a obtenção de radiografias das amostras de madeiras com nitidez e contraste, permitindo a distinção de todos os seus anéis de crescimento e posterior varredura no micro-densitômetro. Um exemplo pode ser visto na Figura 15 , onde é 
apresentada a imagem positiva de uma radiografia contendo as amostras de madeira de 5 árvores de Pinus taeda, com seus dois raios $\left(R_{1}\right.$ e $\left.R_{2}\right)$, em ordem decrescente de classes de diâmetro, e a cunha de calibração. Em todas as amostras de madeira foi possível detectar, através da radiografia, a formação de 19 anéis de crescimento anuais e a medula somando 20 anos, correspondendo à idade das árvores de Pinus taeda. Através do exame da radiografia pode-se, também, verificar semelhanças e diferenças entre as amostras radiais de madeira de uma mesma árvore ou de árvores de diferentes classes de diâmetro, com relação às características dos anéis de crescimento. O efeito dos desbastes das árvores de Pinus taeda também é notório, principalmente o primeiro, efetuado aos 11 anos, verificado pelo aumento da largura dos anéis de crescimento, formados após o desbaste.

\subsection{Análise das radiografias}

A varredura das radiografias das amostras de madeira de Pinus taeda no microdensitômetro, foi realizada de acordo com a metodologia descrita nos ítens 4.6. à 4.8. Os dados obtidos da leitura das radiografias foram aplicados nos programas especialmente desenvolvidos (item 4.10) produzindo-se os perfis densitométricos das amostras de madeira. 


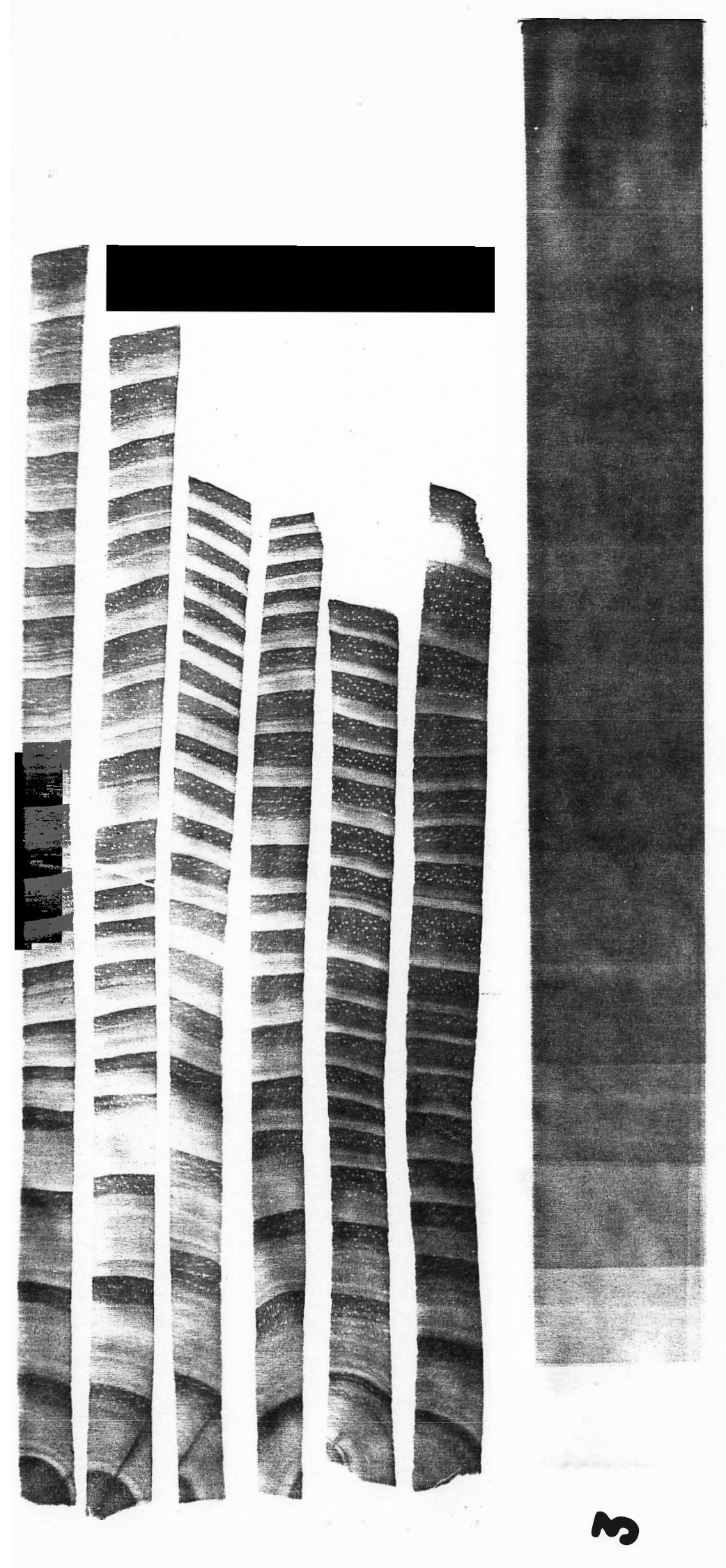

80

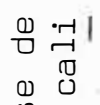

$\begin{array}{ll}0 & 0 \\ 0 & 0 \\ 0 & 0 \\ 0 & 0\end{array}$

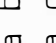

贺 $\frac{0}{5}$

$\begin{array}{ll}\pi & 0 \\ 0 & 0\end{array}$

㕝 0

¿ै

(1)

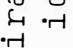

웜

है

ํํㅁ

กำ

중

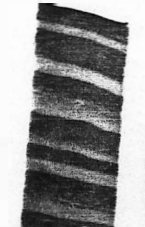

도

का
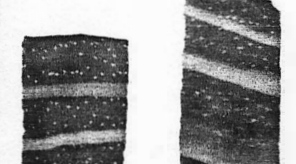

5

……

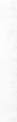
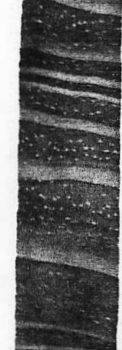

5
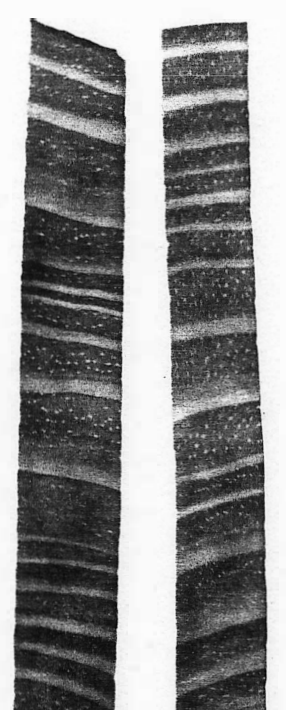

.

筦

4 \&

का

4.

on

号 임

ำ 00

$\begin{array}{cc}0 \\ 0 \\ 0 \\ 0 \\ -1 & 0 \\ 0\end{array}$

$4-1$

00

임ำ

皆

4

艼 密

霓

.

$\pm 0$

0.

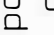

$\varepsilon \stackrel{0}{0} \dot{0}$

of 0 un

.

$\stackrel{n}{\sim}$

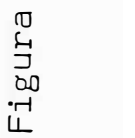




\subsection{Perfis densitométricos radiais das amostras de madeira}

A varredura das radiografias das amostras de madeira forneceu os seus perfis densitométricos que foram utilizados para a identificação e separação dos anéis anuais de crescimento (lenhos primaveril + outonal) necessários para a obtenção dos dados quantitativos.

Os perfis densitométricos das árvores de maior e menor classe de diâmetro, juntamente com as respectivas imagens da madeira, são apresentados nas Figuras 16 e 17. É interessante notar as diferenças na forma dos perfis densitométricos dos anéis de crescimento que, devido às quantidades de lenhos outonal e primaveril, aparecem de forma bastante diversa. Essas diferenças são resultado da morfologia dos traqueídeos que, segundo PANSHIN \& de ZEEUW (1970) apresentam-se com maior largura e diâmetro do lúmen e de parede delgada no lenho primaveril e com menor largura e diâmetro do lúmen e parede espessa no lenho outonal.

É possivel determinar também a idade das árvores pela contagem do número de valores de baixalalta densidade (picos e vales) dos anéis de crescimento. Observa-se uma maior variabilidade na largura dos anéis de crescimento das árvores menores, quando comparadas as de maior diâmetro, mostrando que são mais sensitivas. Esta reação das árvores suprimidas, respondendo de forma mais intensa à competição dos diferentes fatores que influenciam no crescimento, pode indicar este padrão fenotípico para estudos 
dendroclimatológicos e dendrocronológicos. Segundo FRITTS (1976), as árvores localizadas nos limites de sua distribuição natural, portanto, árvores estressadas, são as recomendadas para estudos dendrocronológicos e dendroclimatológicos.

Nessas árvores de menor porte aéreo e subterrâneo, em comparação com as dominantes, a atividade das células do meristema cambial é fortemente influenciada pelas variações de disponibilidade de água e sais minerais no solo (transportados pelo xilema) e pela produção de hormônios e carboidratos pelas acículas novas e pelo processo fotossintético (transportados pelo floema), durante as estações climáticas (LARSON, 1969).

O perfil densitométrico, é da mesma forma, fundamental para a definição dos métodos de manejo de povoamentos florestais e de análise da produtividade e da qualidade da madeira das árvores, além de outros fatores que afetam o crescimento das árvores como ataque de pragas, poluição, fogo, etc. (DUPONT, 1978; JOSZA et alii, s/d, MOSCHLER et alii, 1989, POLGE, 1966). 

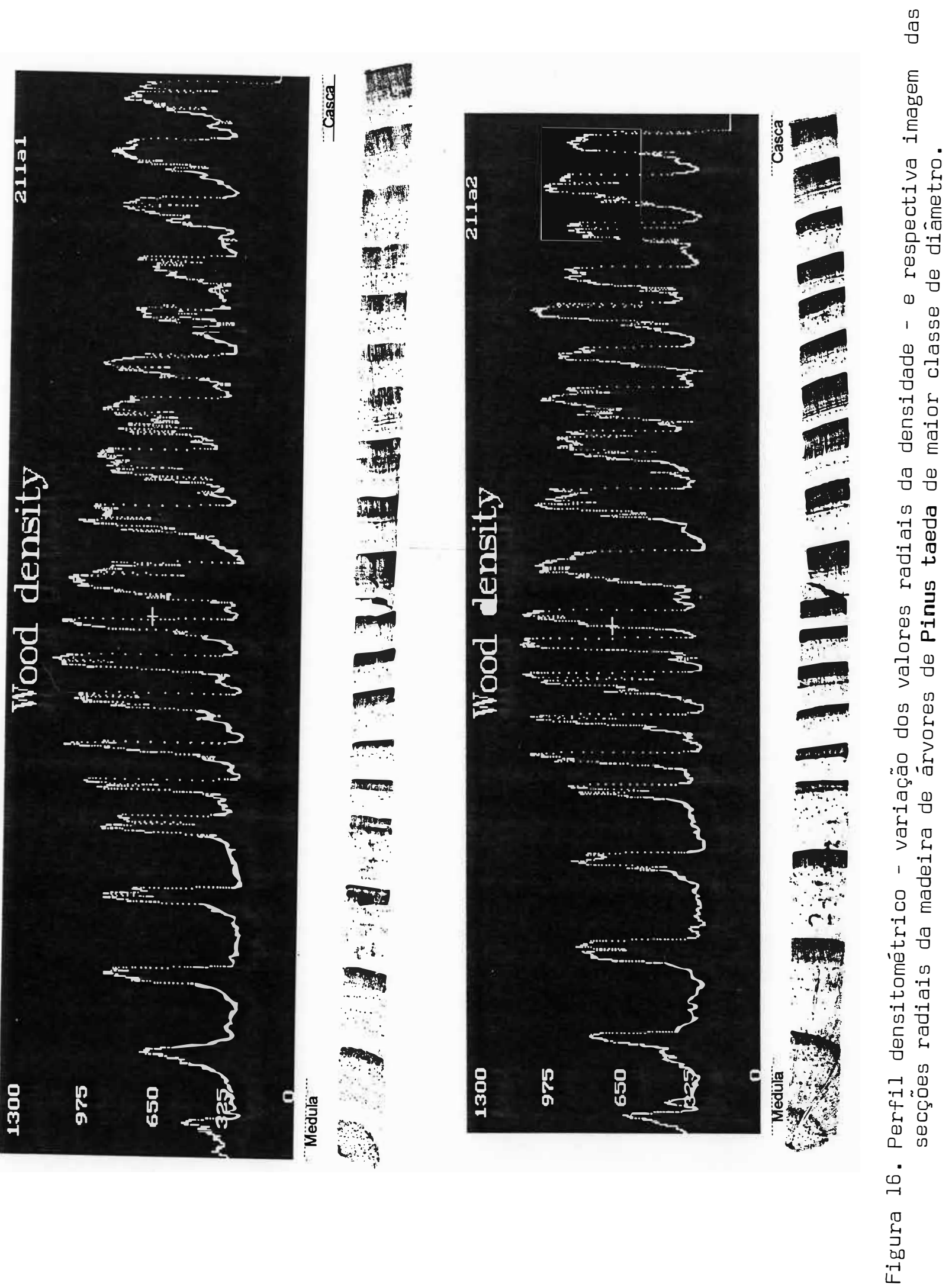

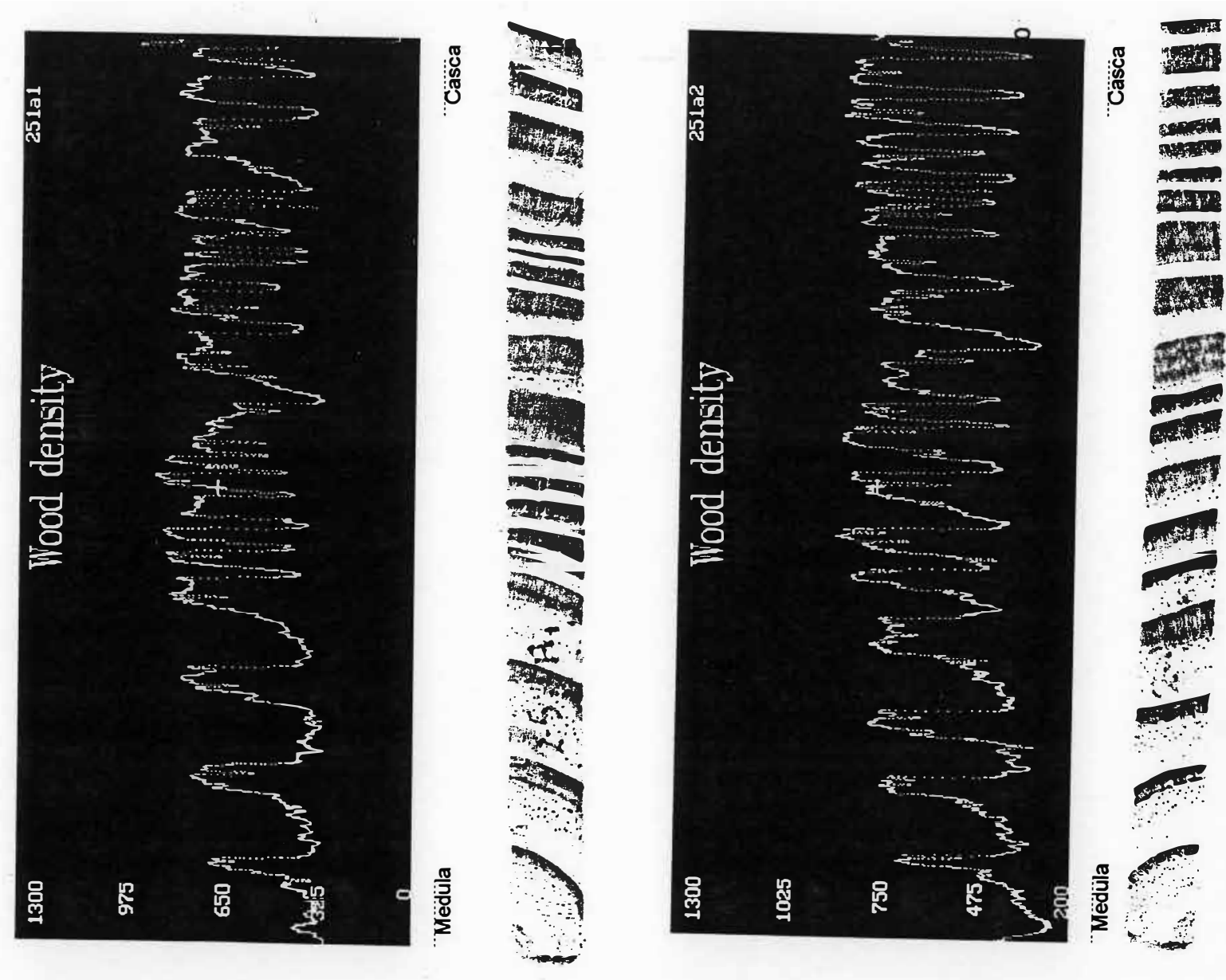

ก

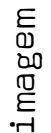

त

.

苟

ㄴ.

응ㄷㅁㅁ

นิ

(1)

10

ำ

गु

.

of

वे वे

뭄

o $\pi$

.

管

40

क 들

담

뭉

종

ก

음

况它

ㅁำ

年

1.0

O $\stackrel{\mathbb{E}}{E}$

त्

$4 \frac{\pi}{\square}$

'哭

ㄷํำ

닫

एक

$\rightarrow 0$

70

40

$\begin{array}{lll}0 & 0 \\ 0 & 0 \\ 0 & 0\end{array}$

ने

告 


\subsection{Parâmetros analisados nos anéis de crescimento}

Os parâmetros analisados e os dados quantitativos da madeira dos anéis de crescimento, tomando como exemplo o de número 9 da amostra de madeira da árvore 211, raio 1 de Pinus taeda obtidos por densitometria, são apresentados na Figura 18 e Tabela 8.

Na Figura 18 verifica-se que a delimitação dos anéis de crescimento é feita através de linhas paralelas traçadas à partir dos pontos de densidade máxima do lenho outonal (ponto superior do anel). A transição do lenho outonal (densidade máxima) de um ano para o lenho primaveril (densidade mínima) do ano seguinte é abrupta e aparece no perfil densitométrico como uma reta perpendicular ao eixo das abcissas, possibilitando separar facilmente o limite dos anéis de crescimento. A transição do lenho primaveril para o outonal de um mesmo ano, ao contrário, se faz de forma gradual, sendo demarcada através de um nível de densidade previamente estabelecido (discutido no item 4.9). A inclinação da reta que une os pontos de densidade mínima e máxima caracteriza o tipo de transição entre os lenhos primaveril e outonal: pode ser abrupta, devido à forte inclinação desta reta como a encontrada para o Pinus taeda no presente trabalho e por RUDMAN (1968), ou branda, com uma inclinação mais suave, como mostra LOUZADA (1990) para o Pinus pinaster. 
Amostra 211a1

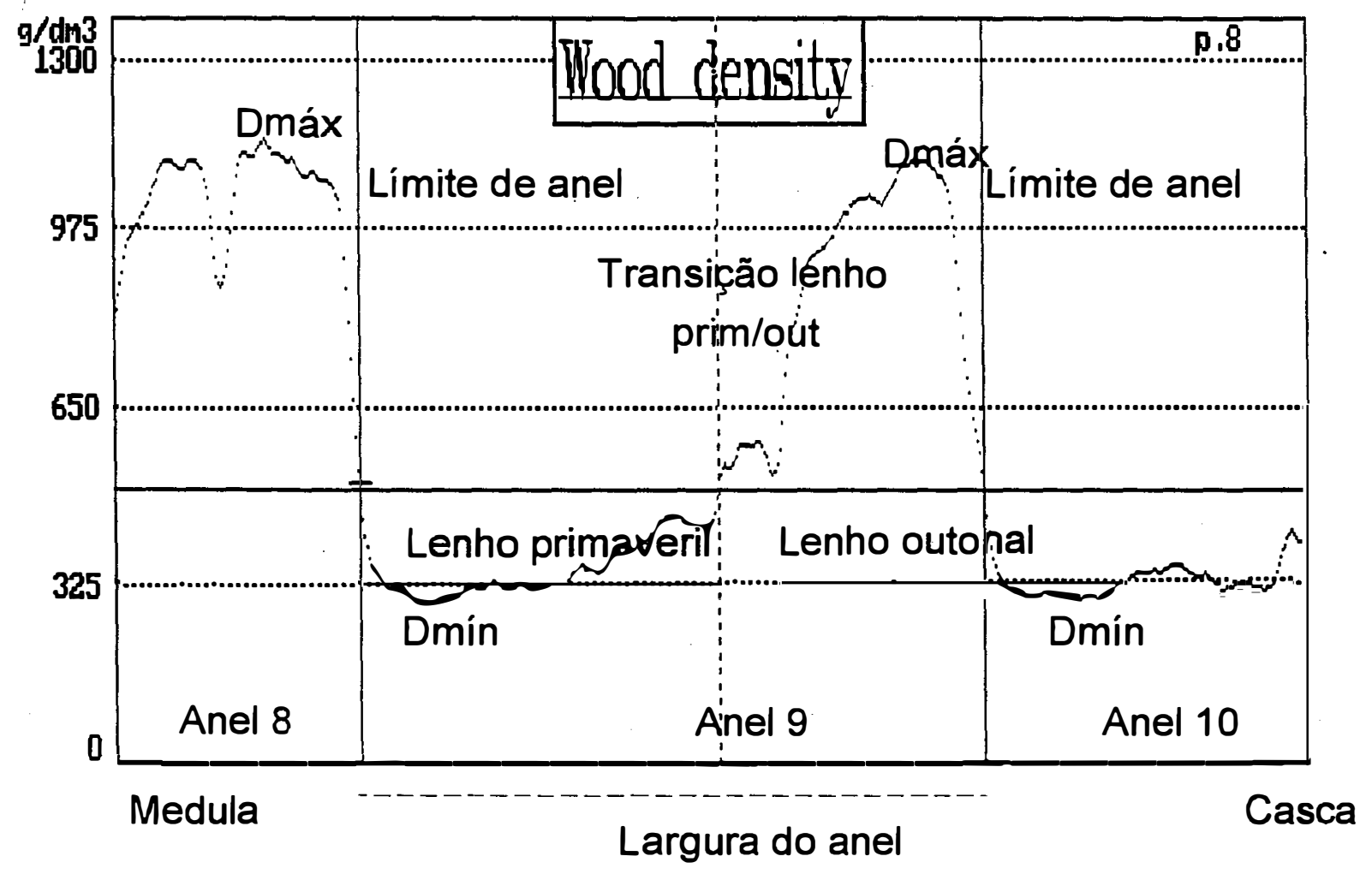

Figura 18. Parâmetros analisados nos anéis de crescimento da madeira de Pinus taeda. 


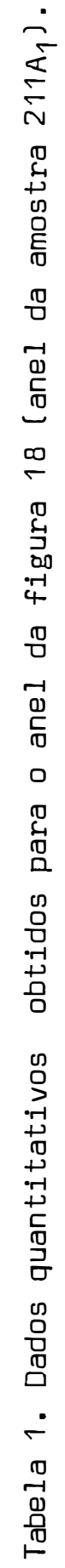

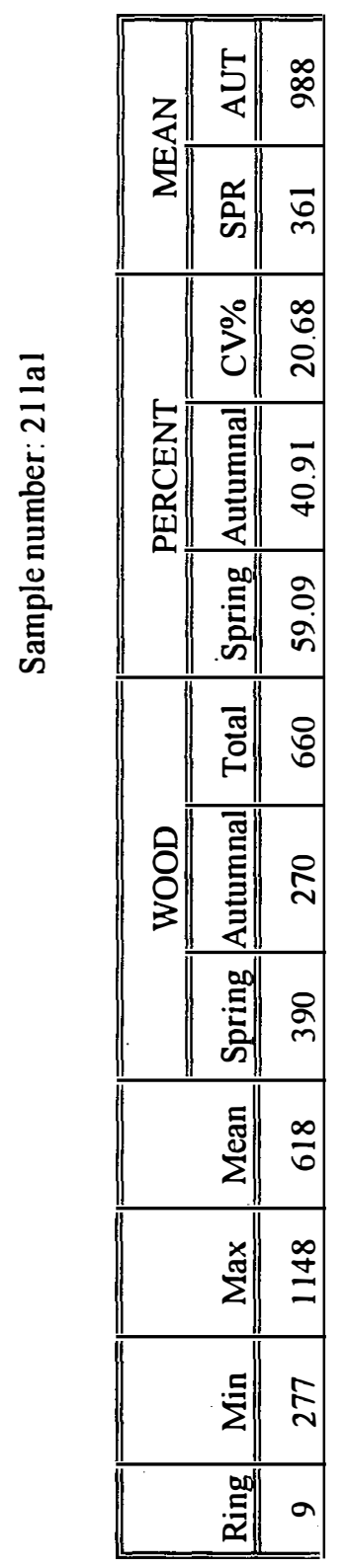


A transição dos anéis de crescimento gradual e abrupta pode ser explicada pelas respostas do meristema cambial à redução gradativa dos fatores de crescimento na estação da primavera para o outono e a rápida disponibilidade destes fatores, ativando as células do câmbio, na passagem da estação do inverno para a primavera (LARSON, 1969).

A sensibilidade da análise densitométrica da madeira através dos raios-X é destacada por SCHWEINGRUBER (1988), possibilitando obter informações não disponíveis pelas demais metodologias (POLGE, 1978). Atualmente têm sido testadas novas técnicas de análise de anéis de crescimento utilizando-se dos raios laser e de análise de imagens, com resultados comparáveis aos dos raios-X (LESNINO, 1992).

\subsection{Caracterização dos anéis de crescimento das árvores}

Os dados quantitativos de densidade e da largura de cada um dos anéis de crescimento das amostras radiais da madeira das árvores de Pinus taeda, dos 5 padrões fenotípicos, são apresentadas nas Tabelas 11 a 25 do Apêndice. Os valores médios obtidos por classe constam das Figuras 19 a 28.

Com base nesses dados dos anéis de crescimento, foram determinados os incrementos em massa e volume, apresentados nas Figuras 30 a 34 . 


\subsubsection{Densidades mínimas e médias dos lenhos primaveris}

As densidades mínimas e médias dos lenhos primaveris obedeceram a um mesmo padrão de variação dentro de cada árvore, nas várias classes de DAP (Figuras 19 a 23).

Com relação aos valores numéricos, nas árvores de maior diâmetro (classe 1), as densidades médias do lenho primaveril apresentaram variações de 275 a $440 \mathrm{~g} / \mathrm{dm}^{3}$, com menor amplitude de variação. Esses valores tendem a aumentar com a redução do diâmetro das árvores atingindo a faixa de 331 a $811 \mathrm{~g} / \mathrm{dm}^{3}$ e com maior amplitude de variação.

O alto valor da densidade média do lenho primaveril encontrado em alguns anéis de crescimento, deve-se à necessidade de atender a exigência do programa de análise. Na realidade estes anéis não possuem lenho primaveril, ou seja, lenho com densidades abaixo de $500 \mathrm{~g} / \mathrm{dm}^{3}$.

Para quaisquer classes de diâmetro - embora mais nítido nas classes menores - houve um aumento dos valores das densidades médias e mínimas dos lenhos primaveris até o $9^{\circ}-10^{\circ}$ ano, seguindo-se uma tendência de estabilização ou de menor flutuação. Esse modelo de variação está relacionado com a formação da madeira juvenil, madeira de transição, e adulta no lenho das árvores de Pinus taeda. Verifica-se também, na maioria das árvores com destaque para as de classes 3,4 e 5, aumentos nos valores de densidade para os anéis de crescimento $11^{\circ}, 14^{\circ}$ e $17^{\circ}$, seguidos de uma redução. 


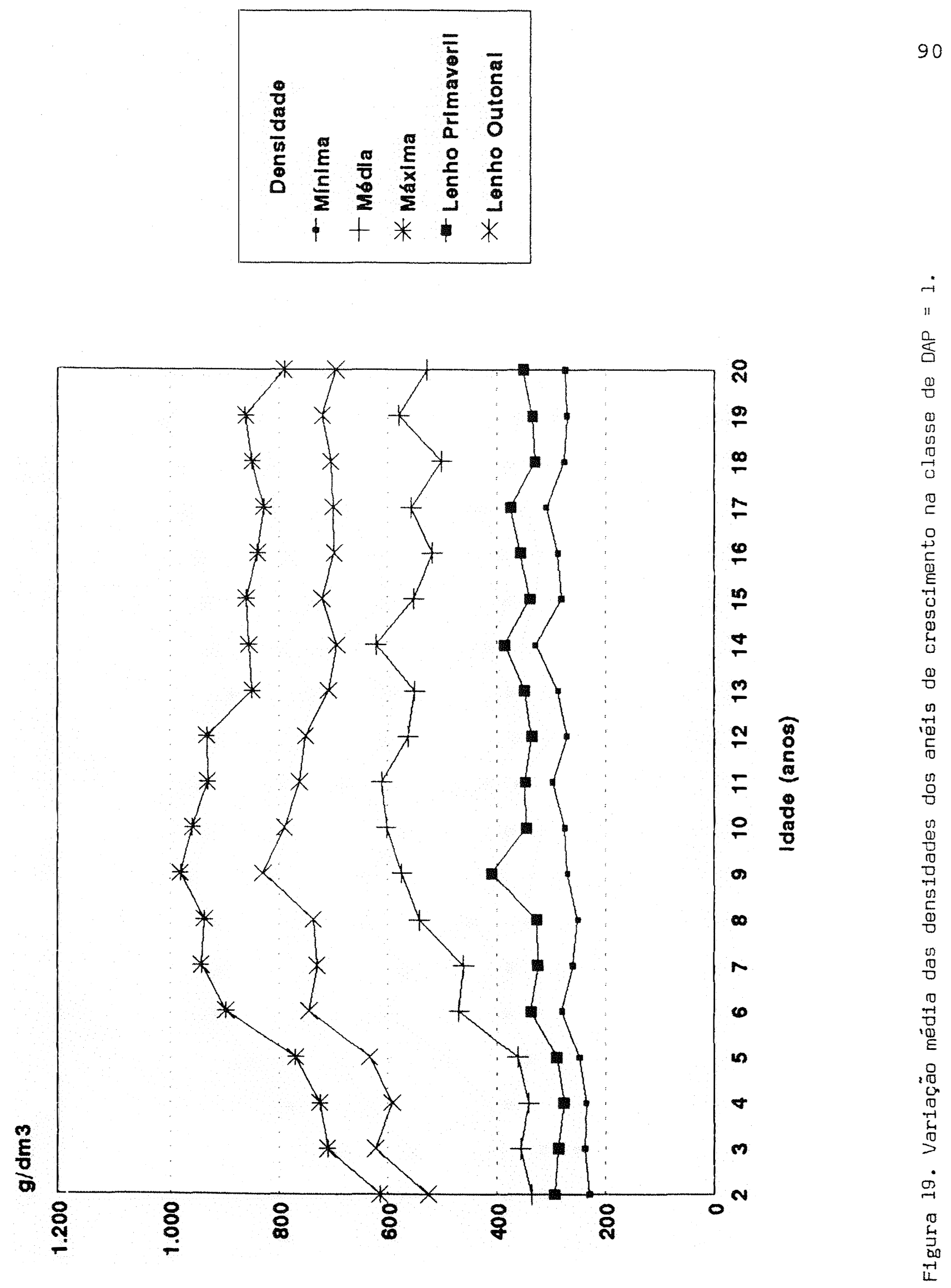




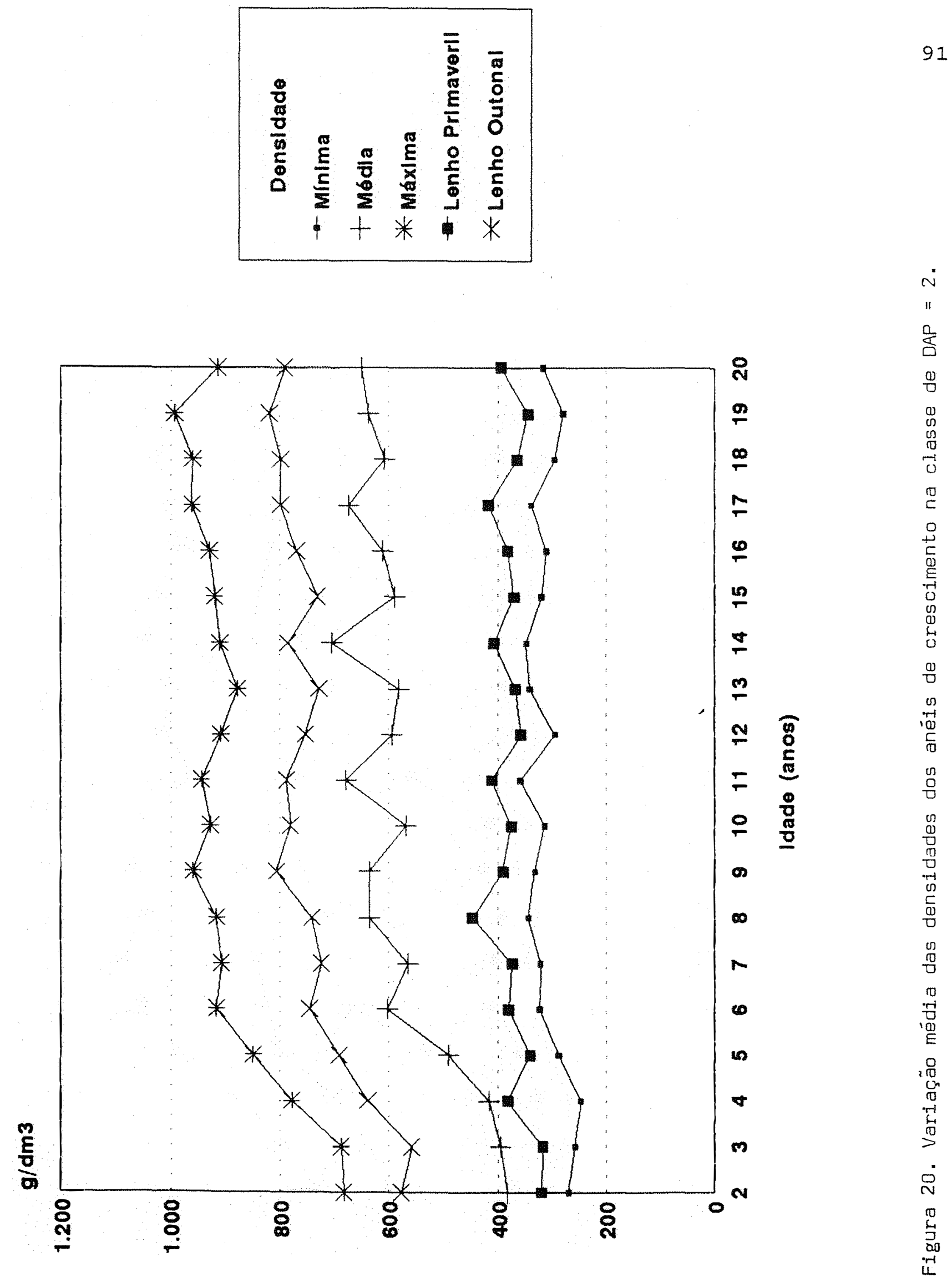




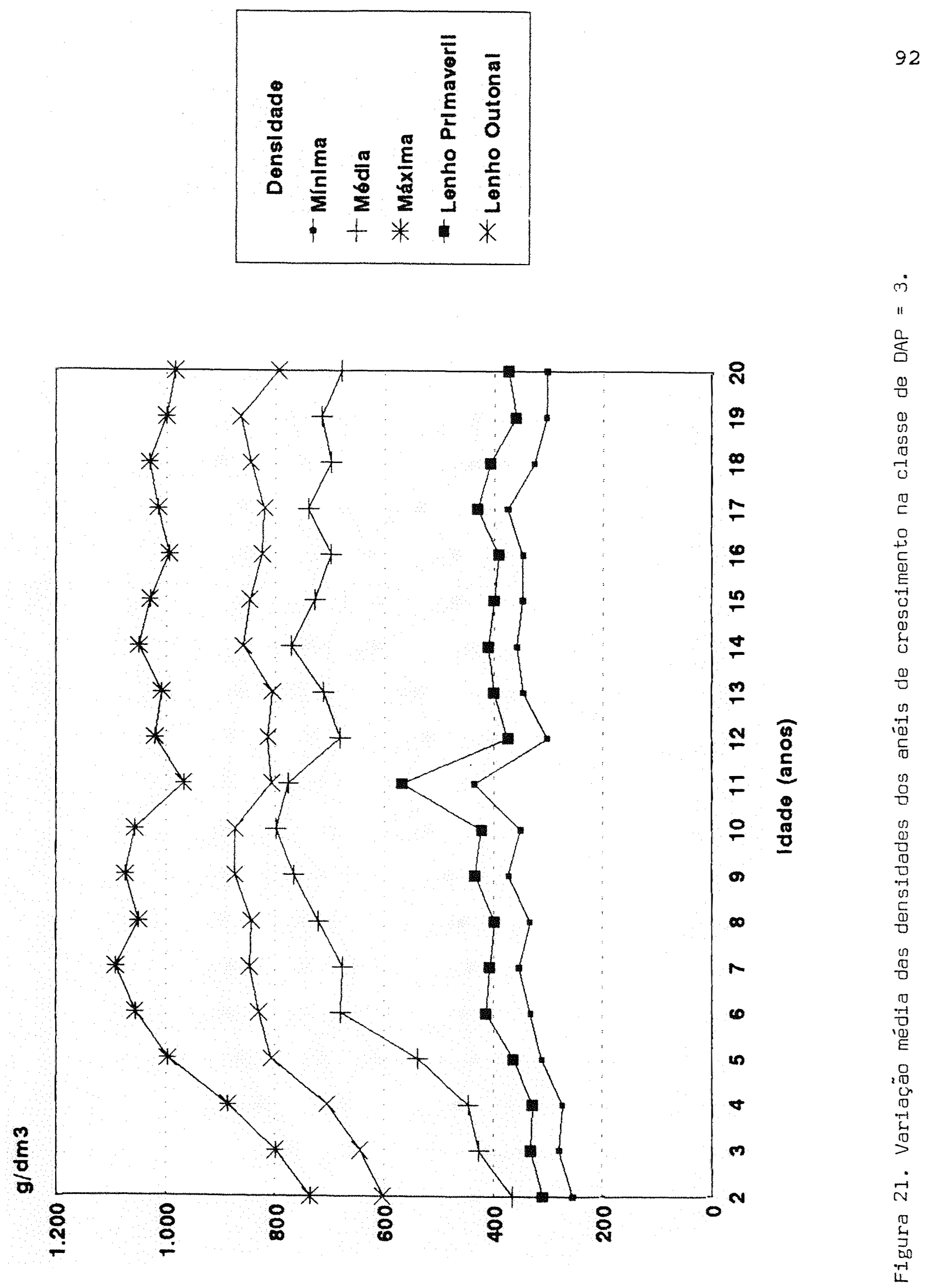




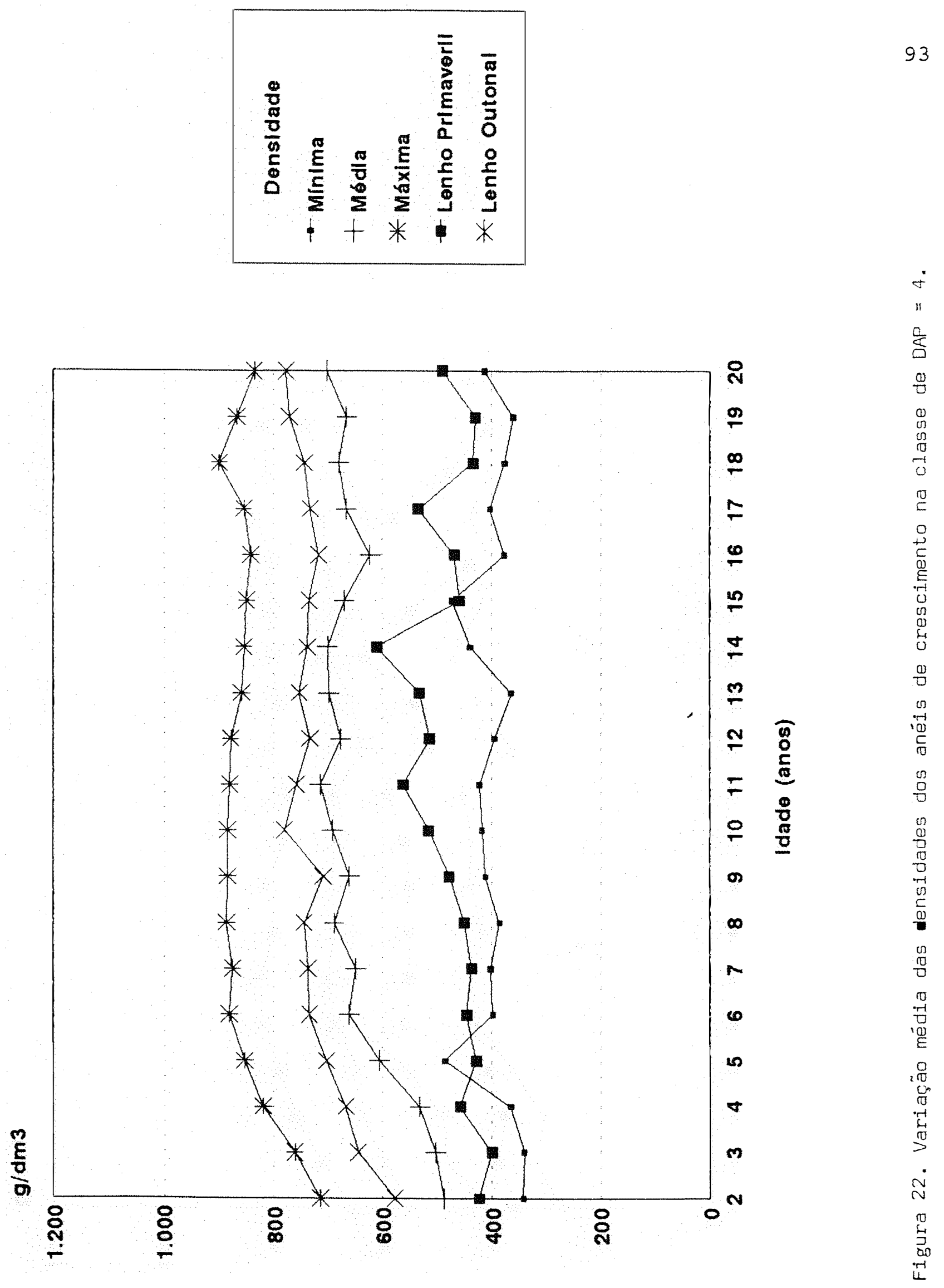




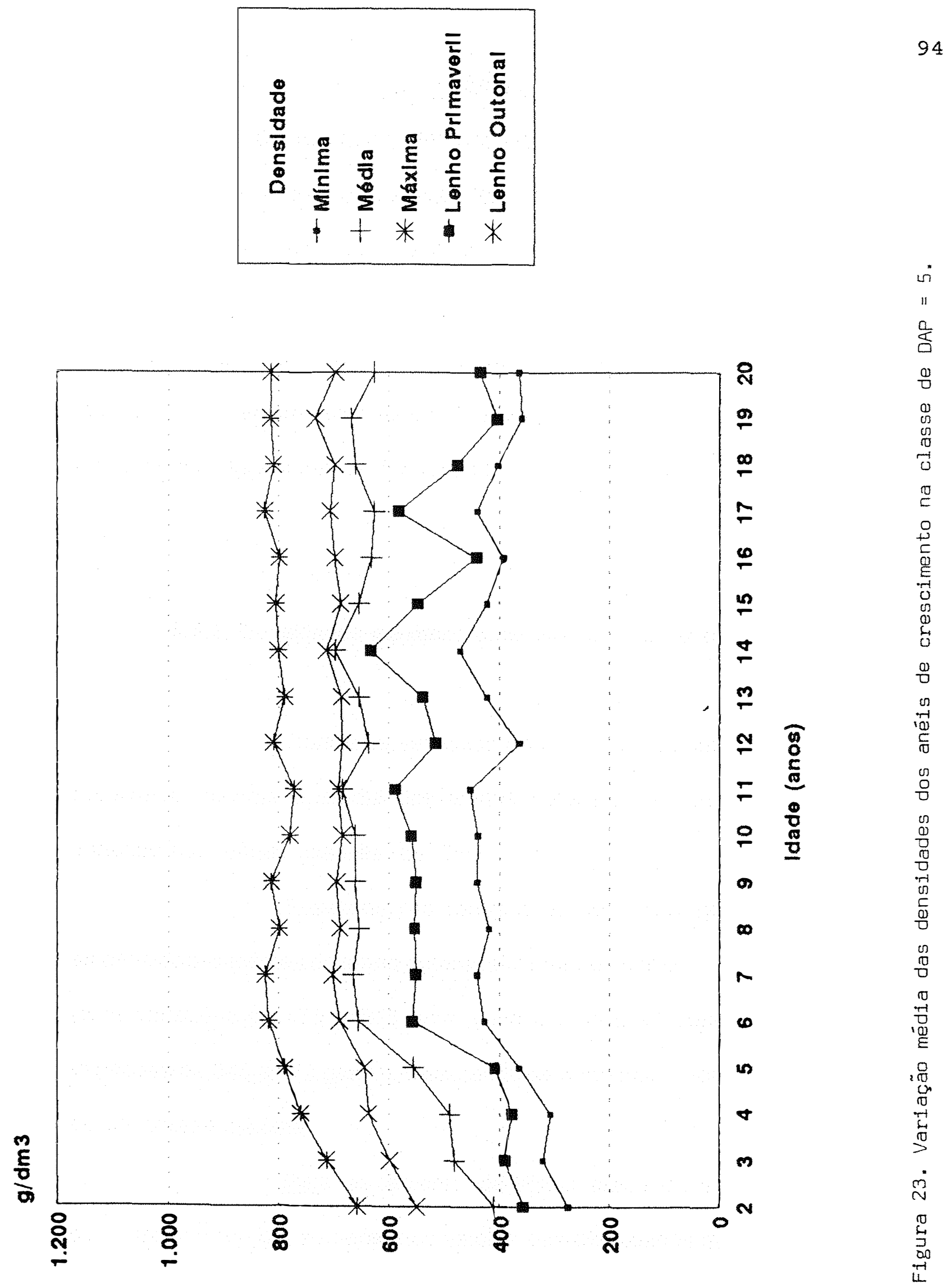


Esse comportamento é resultado da competição entre as árvores seguida de desbastes efetuados aos 11 e 17 anos, conforme histórico de manejo da população de Pinus taeda, estando de acordo com os resultados obtidos por MOSCHLER et alii (1989), que encontraram uma diminuição da densidade da madeira primaveril em árvores de Pinus taeda após desbaste pesado e moderado. O alto valor da densidade no $14^{\circ}$ anel, seguido de redução no $15^{\circ}$ anel pode estar relacionado a algum fator externo, de natureza climática, que influenciou no crescimento das árvores de Pinus taeda.

\subsubsection{Densidades máximas e médias dos lenhos outonais}

Conforme verificado para os lenhos primaveris, os valores de densidade máxima e média dos lenhos outonais têm um mesmo padrão de variação nas várlas classes de DAP.

Entretanto, ao contrário do observado nos lenhos primaveris, as densidades médias do lenho outonal são maiores nas classes de maior diâmetro (com variações de 475 a $875 \mathrm{~g} / \mathrm{dm}^{3}$ ) em comparação com as de menor (com variações de 545 a $772 \mathrm{~g} / \mathrm{dm}^{3}$ ), detectando-se a mesma tendência para os valores de densidade máxima.

Para as árvores de Pinus taeda de todas as classes de diâmetro ocorreu um aumento nos valores das densidades máxima e médias dos 
lenhos outonais até $06^{\circ}-7^{\circ}$ anel, com estabilização após $010^{\circ}$ ano e tendência de queda nas árvores de maior classe de diâmetro. Conforme discutido no item anterior (5.5.1), essas variações estão relacionadas com a formação da madeira juvenil e adulta.

Não foram verificadas nítidas influências dos desbastes nos valores de densidades máximas e médias dos lenhos outonais das árvores de Pinus taeda das várias classes de diâmetro, ao contrário do observado para os lenhos primaveris.

As flutuações encontradas parecem, portanto, estar mais ligadas as condições climáticas do ano de crescimento do que à prática do desbaste.

\subsubsection{Densidades médias dos anéis de crescimento anuais}

As densidades médias dos anéis de crescimento variaram nas classes de diâmetro das árvores quanto a amplitude de variação, com valores de 311 a $624 \mathrm{~g} / \mathrm{dm}^{3}$ nas árvores da classe 1 , chegando a $700-800 \mathrm{~g} / \mathrm{dm}^{3}$ em alguns anéis de crescimento, nas classes 3,4 e 5 .

A densidade média dos anéis de crescimento atinge valores mínimos próximo à medula, crescentes até o 9-10ªnel e com oscilações até o $20^{\circ}$ anel, com aumentos nos $11^{\circ}, 14^{\circ}$ e $17^{\circ}$ anéis de crescimento, seguidos de 
valores mais baixos. Conforme discutido anteriormente, essas condições estão relacionadas com a formação da madeira juvenil e adulta e com as práticas de desbaste, executadas no $11^{\circ}$ e $17^{\circ}$ anos.

\subsubsection{Largura dos anéis de crescimento anuais e dos lenhos primaveris e outonais}

De acordo com as Figuras 24 a 28 pode-se notar que a largura dos anéis de crescimento e a dos lenhos primaveris, para todas as classes de diâmetro, decrescem de forma acentuada até $06^{\circ}$ ano, em função do início da competição pelos fatores de crescimento; apresentam um menor decréscimo até ○ $10^{\circ}$ ano, quando a competição já está instalada no povoamento e daí até o $20^{\circ}$ ano apresentam oscilações resultantes principalmente dos desbastes efetuados.

Menor amplitude de variação foi encontrada para a largura dos lenhos outonais em comparação a dos primaveris, independente da classe de diâmetro, apresentando, no entanto, maiores oscilações nos primeiros anéis, nas árvores das classes de menor diâmetro. 


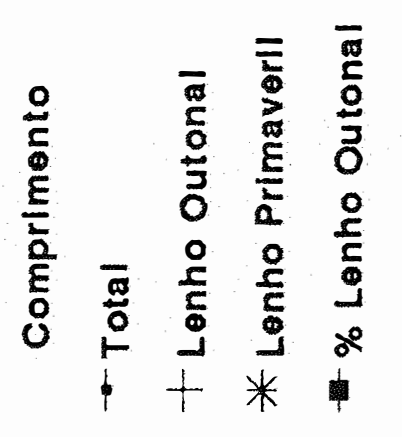

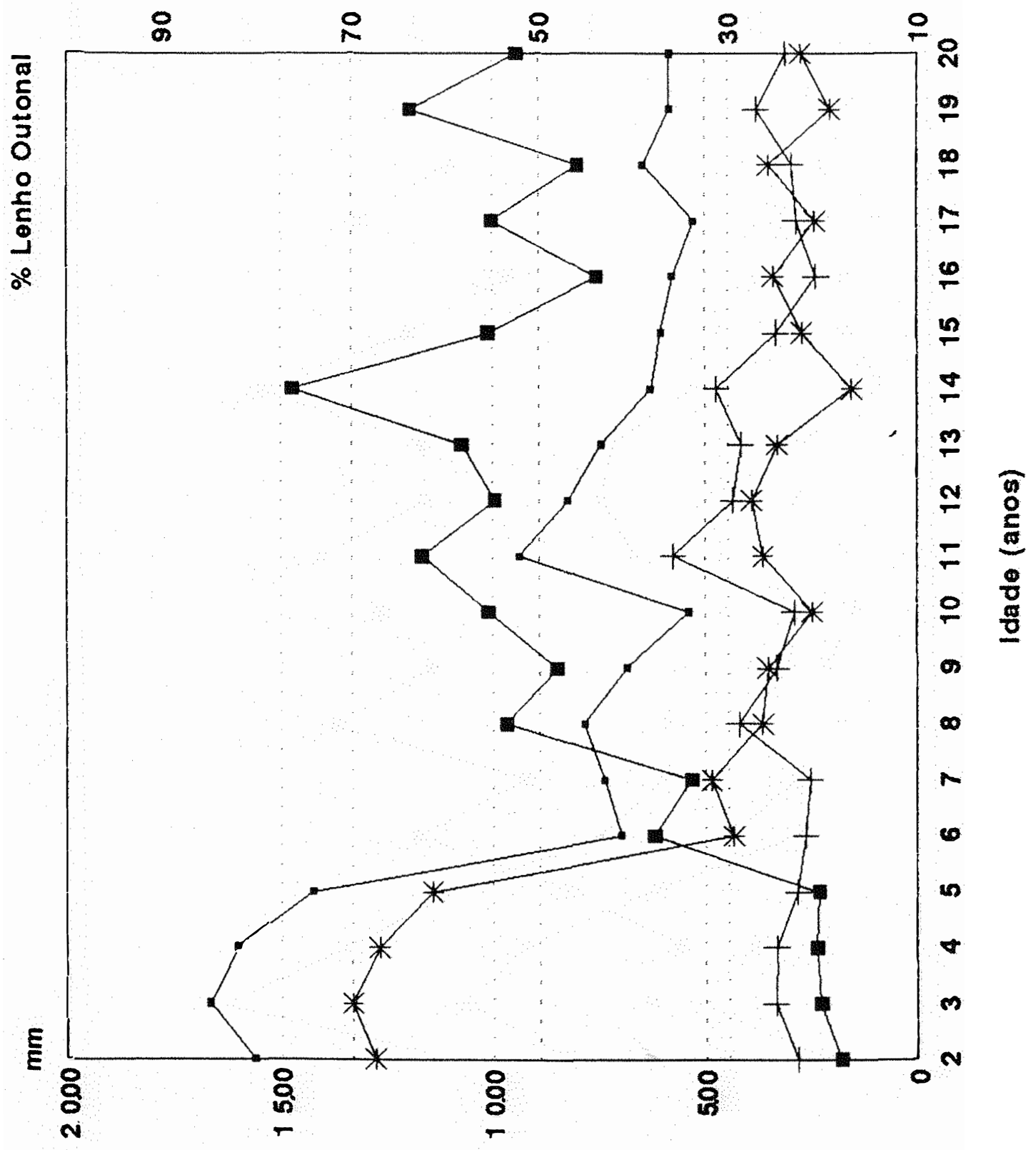




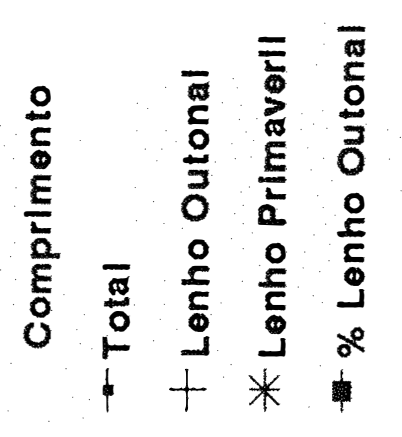

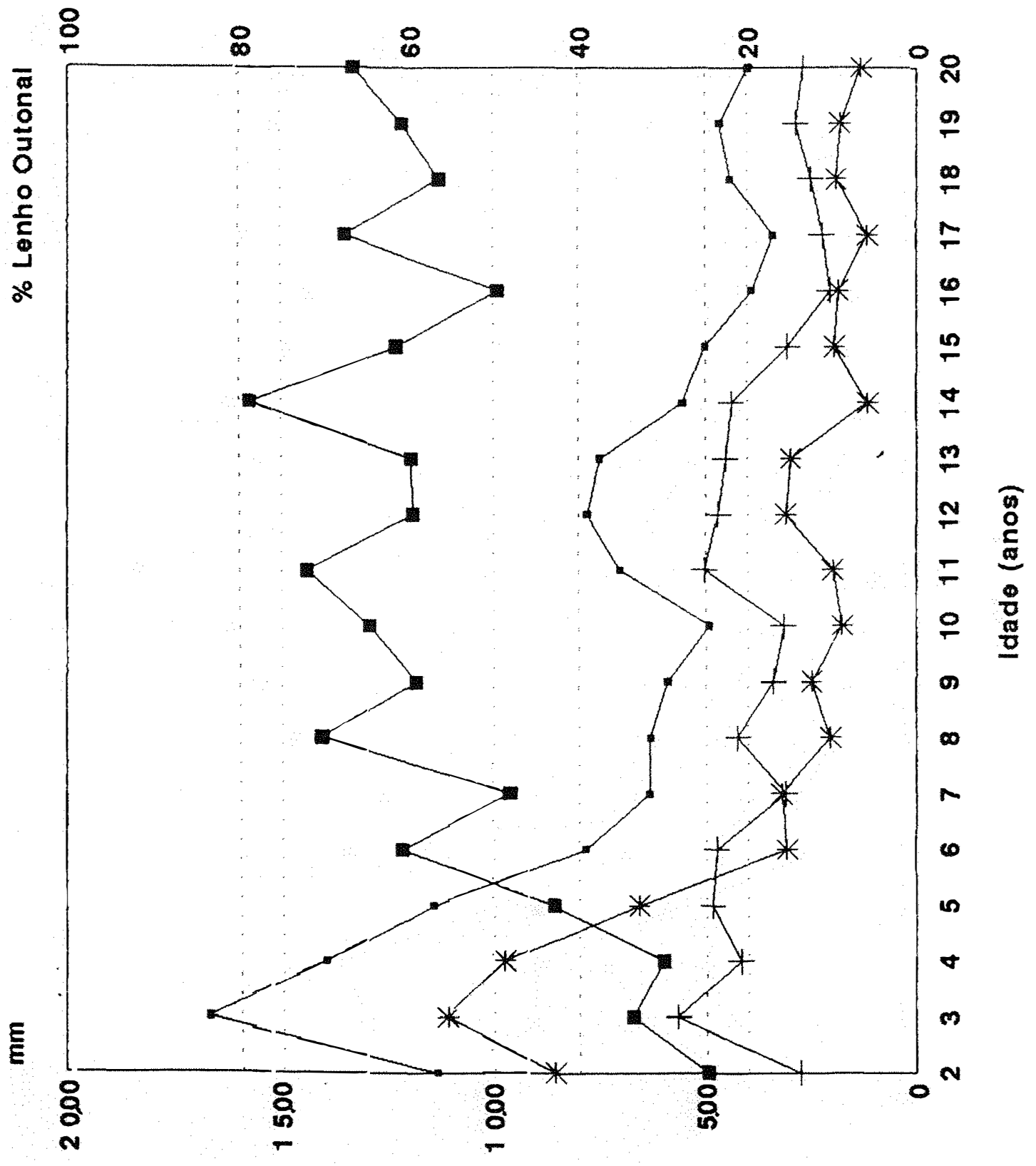

$J$
0
0
$\frac{9}{c}$
0
-1
0
0
$\frac{1}{0}$
0
0
0
+
0
0
0
0
0
0

T)

(2)

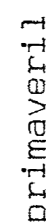

(3)

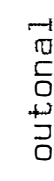

on

ㅇำำ

元

足

담익

을

0
0

은

吕

苗

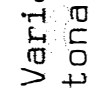

$\stackrel{n}{\sim}$

告 


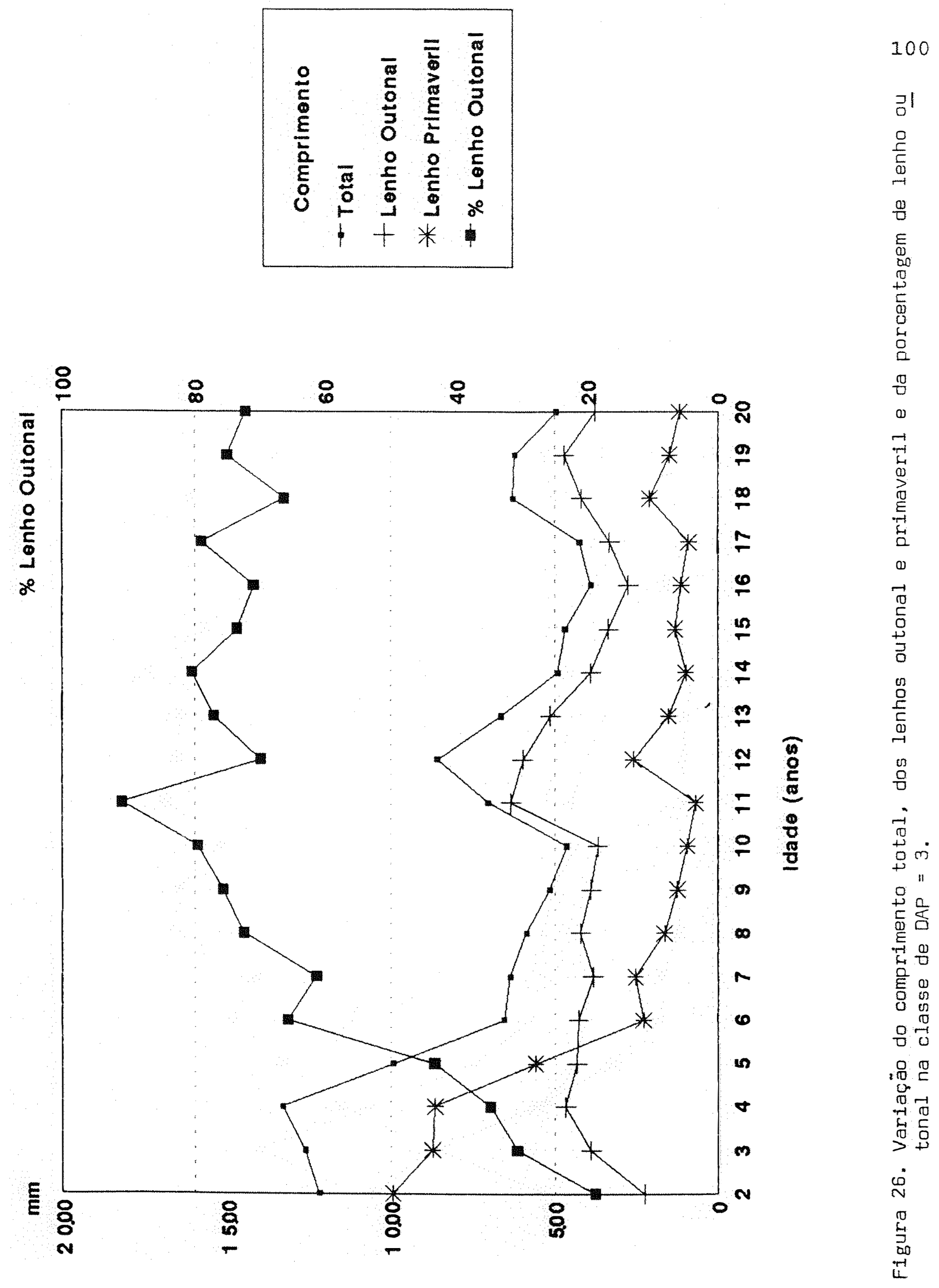




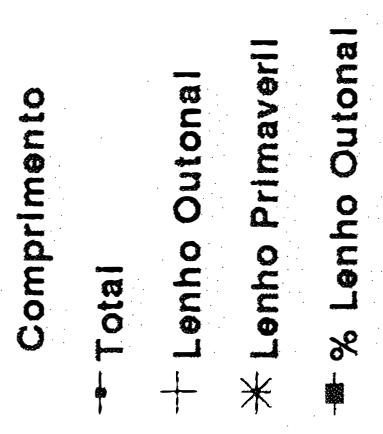

ว

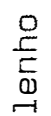

밈

$E$
0
0
0
0
0
$ᄃ$
0
0
0
0
0
0

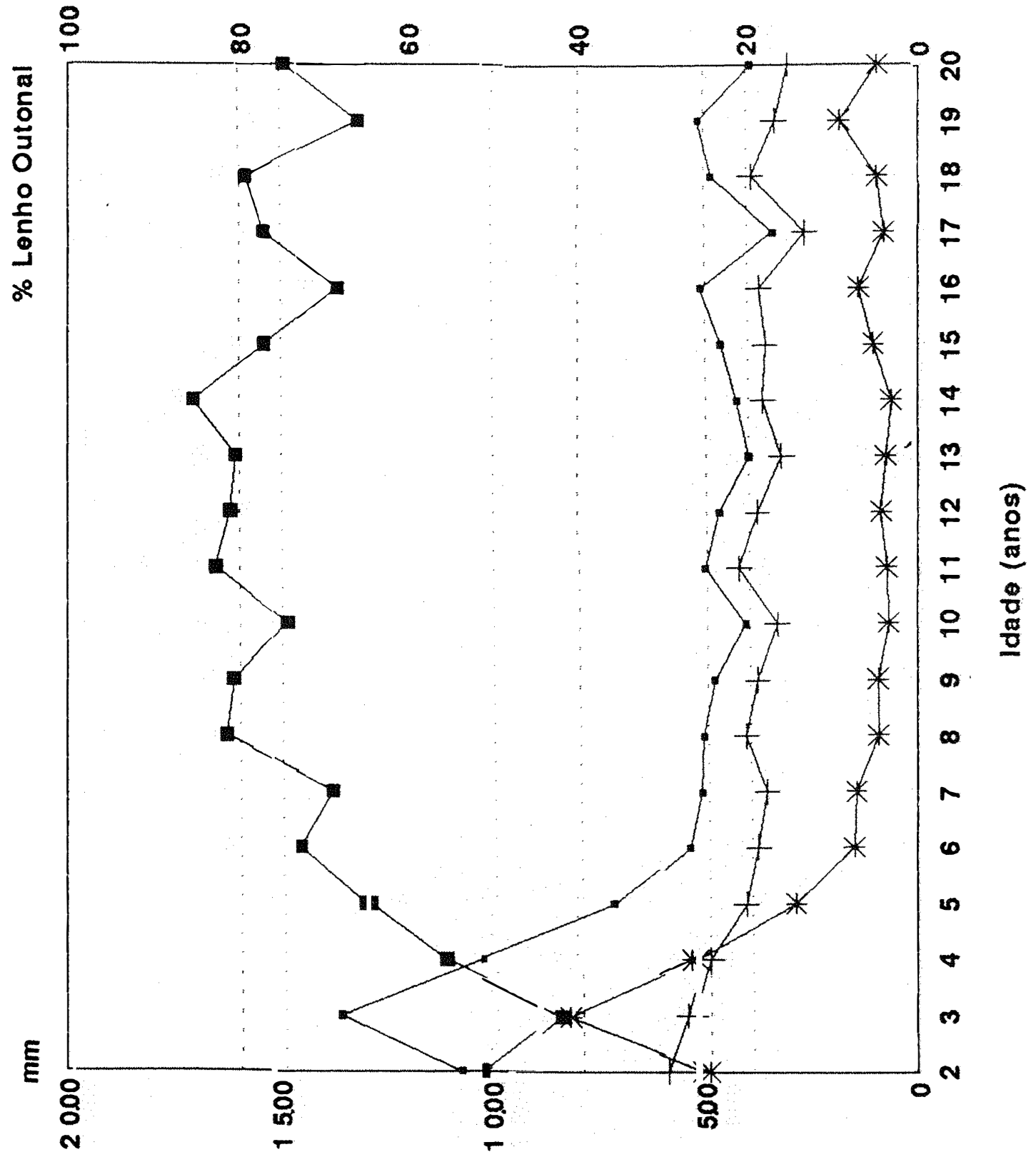

๑

a)

:

S

离

a)

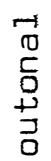

足

옴

盛

$+11$

웅

峦

है

० 每

움

吕

崩

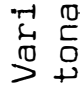

$\therefore$

0
3
3
0
-1
4 


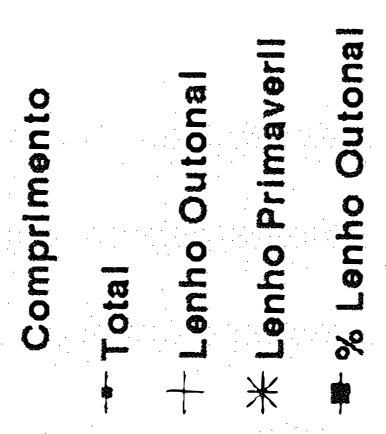

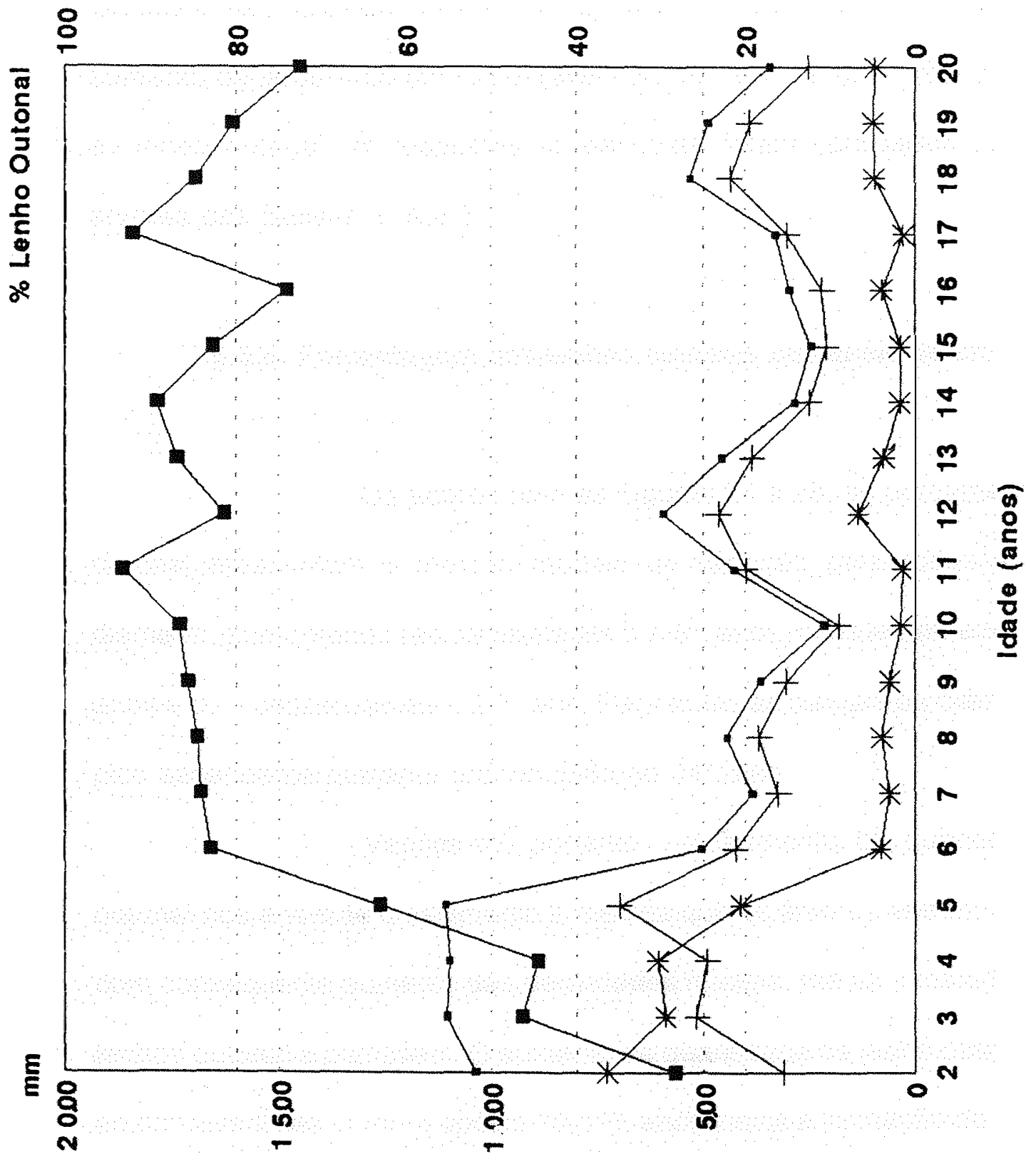

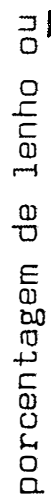

ए

(1)

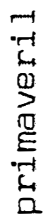

\begin{tabular}{l}
0 \\
0 \\
0 \\
0 \\
0 \\
\hline \\
0
\end{tabular}

$\stackrel{0}{\stackrel{0}{c}}$

윰

藏

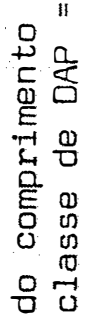

品

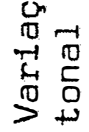

$\stackrel{\infty}{\sim}$

苟 
O $11^{\circ}$. anel de crescimento, notadamente o seu lenho outonal, apresentou um grande alargamento em resposta ao primeiro desbaste, realizado no final da formação do lenho primaveril ou início do lenho outonal. O seu efeito no próprio ano indica que no outono-inverno não existem limitações com relação aos fatores de crescimento, principalmente disponibilidade de água às plantas. $02^{\circ}$. desbaste foi realizado no final ou após a formacão do $17^{\circ}$. anel refletindo no aumento da largura do lenho primaveril do $18^{\circ}$ anel de crescimento. Com relação ao lenho outonal, as respostas ao desbaste foram verificadas somente pra as árvores das classes 3,4 e 5.

\subsubsection{Porcentagem dos lenhos outonais nos anéis de crescimento}

De acordo com as Figuras 24 a 28 , as porcentagens de lenho outonal apresentam o mesmo modelo de variação para todas as classes de diâmetro, aumentando rapidamente até o $7-8^{\circ}$. anos, mais lentamente até o $10-11^{\circ}$. anos e com oscilações até $020^{\circ}$. ano. Para todas as classes de diâmetro houve um pico ascendente bastante pronunciado no $14^{\circ}$. ano.

Verifica-se, portanto, um aumento da quantidade de lenho outonal nos anéis de crescimento à medida que as árvores entram em competição com consequente aumento das densidades mínima, média e máxima e média dos lenhos outonal e primaveril. O aumento da quantidade de lenho outonal em relação ao primaveril nas árvores após o $10-11^{\circ}$. anos indica a formação de madeira adulta 
e a instalação da competição na população. A inexistência de déficit hídrico no outono-inverno proporciona disponibilidade de água para as árvores, que seria limitante para a formação do lenho outonal. Com a aplicação do desbaste no 11 e $17^{\circ}$. anos, a competição entre árvores é reduzida ocasionando a formação de lenho primaveril mais largo e diminuição da porcentagem de lenho outonal e dos valores das densidades.

\subsubsection{Médias das densidades, largura e porcentagem de lenhos outonais dos anéis de crescimento}

Os valores médios da densidades, largura e porcentagem de lenho outonal de todos os anéis de crescimento das árvores das 5 classes de diâmetro são apresentados na Figura 29.

A média da porcentagem de lenhos outonais - em relação aos primaveris - está abaixo de $30 \%$ nos primeiros anos, aumentando respectivamente até o $10-11^{\circ}$. ano, com flutuações até o $20^{\circ}$. ano. É caracterizada a formação da madeira juvenil pela atividade cambial nesse primeiro período da árvore - até $010^{\circ}$. ano - e o estabelecimento da competição entre as árvores na população. Esses aspectos podem ser verificados pela largura dos anéis de crescimento, inicialmente largos, seguidos de significativa redução até $\circ 10^{\circ}$. ano, com flutuações até o $20^{\circ}$. ano. Conforme discutido anteriormente, a porcentagem de lenho outonal aponta valores máximos nos 11,14 e $17^{\circ}$. anos, em resposta aos desbastes efetuados na 
plantação de Pinus taeda. A variação dos valores de porcentagem de lenho outonal está relacionada com a das densidades média, mínima e média mínima dos anéis de crescimento.

A maior porcentagem de lenho outonal na madeira adulta, formada em condições de competição pelos fatores de crescimento é determinada pela espécie e condições climáticas no período outono-inverno. Conforme destaca LARSON (1969), o lenho primaveril é formado no início da estação de crescimento (primavera-verão) quando são produzidas maiores quantidades de hormônios pelos brotos (na porção terminal dos ramos) em relação aos carboidratos (pelas acículas maduras). No período outono-inverno, quando a relação hormônio/ carboidrato é menor e não ocorrendo limitação da disponibilidade de água o meristema cambial produz lenhos outonais mais largos, principalmente para as árvores das classes de diâmetro maior. A compreensão dos mecanismos de formação dos lenhos nos anéis de crescimento e sua dependência pelos fatores climáticos e edáficos e pelas técnicas de manejo dos povoamentos florestais pode constituir-se em metodologia para a producão de madeira com porcentagens variadas de lenhos primaveris e outonais, com reflexos na sua qualidade. 


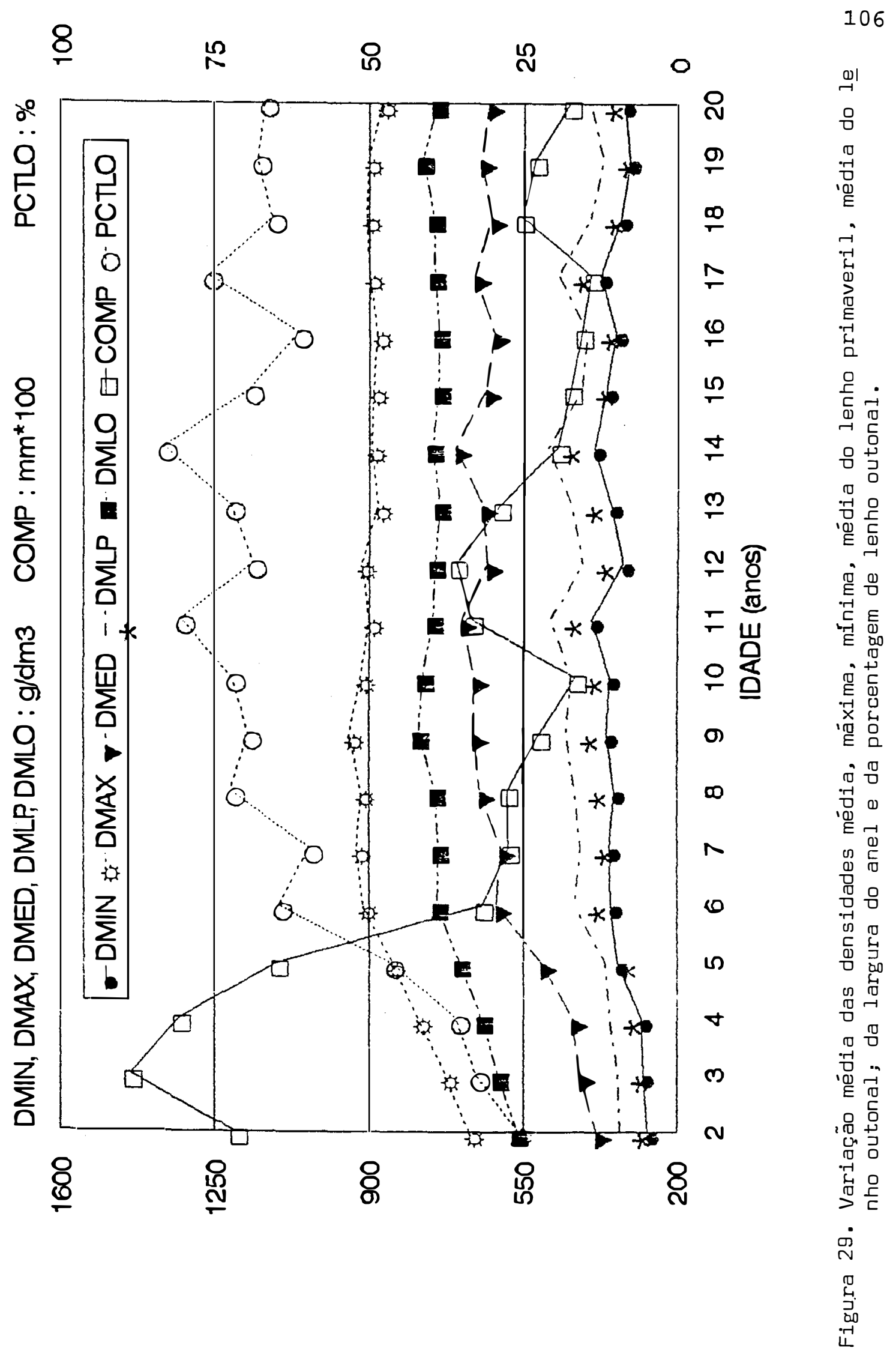


As variações das médias dos demais parâmetros seguem a mesma tendência verificada nas árvores individuais, conforme discutido em 5.5.1, $5.5 .2,5.5 .3$ e 5.5 .4

\subsubsection{Densidades médias das amostras radiais de madeira}

O "out-put" da análise dos dados quantitativosforneceu a média ponderada da densidade das amostras radiais das árvores de Pinus taeda, apresentados na Tabela 9.

Tabela 9. Densidade da madeira de Pinus taeda aos 20 anos de idade, segundo a classe de diâmetro, árvore e o raio amostrados.

\begin{tabular}{|c|c|c|c|c|c|}
\hline \multirow{2}{*}{$\begin{array}{c}\text { Árvore } \\
n^{0}\end{array}$} & \multirow{2}{*}{$\begin{array}{l}\text { Classe } \\
\text { de } \\
\text { diâmetro }\end{array}$} & \multicolumn{3}{|c|}{ Densidade $\left(\mathrm{g} / \mathrm{dm}^{3}\right)$} & \multirow[b]{2}{*}{ Média/classe } \\
\hline & & Raio 1 & Raio 2 & Média/árv & \\
\hline $\begin{array}{l}211 \\
212\end{array}$ & 1 & $\begin{array}{l}477 \\
474\end{array}$ & $\begin{array}{l}482 \\
438\end{array}$ & $\begin{array}{l}479 \\
456\end{array}$ & 467 \\
\hline $\begin{array}{l}221 \\
222\end{array}$ & 2 & $\begin{array}{l}505 \\
551\end{array}$ & $\begin{array}{l}507 \\
606\end{array}$ & $\begin{array}{l}506 \\
578\end{array}$ & 542 \\
\hline $\begin{array}{l}231 \\
232\end{array}$ & 3 & $\begin{array}{l}635 \\
572\end{array}$ & $\begin{array}{l}637 \\
624\end{array}$ & $\begin{array}{l}636 \\
598\end{array}$ & 617 \\
\hline $\begin{array}{l}241 \\
242\end{array}$ & 4 & $\begin{array}{l}585 \\
622\end{array}$ & $\begin{array}{l}603 \\
650\end{array}$ & $\begin{array}{l}594 \\
636\end{array}$ & 615 \\
\hline $\begin{array}{l}251 \\
252\end{array}$ & 5 & $\begin{array}{l}531 \\
609\end{array}$ & $\begin{array}{l}546 \\
645\end{array}$ & $\begin{array}{l}538 \\
627\end{array}$ & 582 \\
\hline
\end{tabular}


A análise da Tabela 9, demonstra que, de um modo geral, as árvores apresentam densidades com valores próximos para as amostras radiais da madeira. As diferenças existentes referem-se aos teores e largura dos lenhos outonais e primaveris dos anéis de crescimento (conforme discutido em $5.5 .4 \mathrm{e}$ 5.5.5), resultado do ritmo diferenciado do crescimento do câmbio nas estações primavera-verão e outono-inverno (DADSWELL, 1960; POLGE \& ILLY, 1967; SLUDER, 1972).

As classes de maiores diâmetros apresentam menores valores de densidade. Apesar de não terem sido feitas análises estatísticas, é de se esperar que as classes 1 e 2 de maior diâmetro e com valores de densidade igual à 467 e $542 \mathrm{~g} / \mathrm{dm}^{3}$ respectivamente, difiram das classes 3,4 e 5 , de menores diâmetros e cujos valores encontrados para a densidade são: 617,615 e 582 g/dm respectivamente.

Analisando a Tabela 9 verificamos que os valores médios de densidade encontrados são altos. Isto se deve ao fato de termos trabalhado com um disco da base, o qual possui uma densidade muito maior do que aqueles localizados mais acima no tronco (MeGRAW, 1985; VAN BUIJTENEN, 1969; GILMORE \& PEARSON, 1969).

Além disso, os valores referem-se à densidade ao ar ou seja, à $12 \%$ de umidade, que é maior que o valor da densidade básica. Para efeito de comparação podemos citar o trabalho de COUTO et alii (no prelo), que num estudo comparativo entre as densidades básica, ao ar (12\% de umidade) e seca ( $0 \%$ de 
umidade), para discos da base de Pinus taeda, aos 25 anos de idade, provenientes de Telêmaco Borba - Parana, obtiveram valores de $510 \mathrm{~g} / \mathrm{dm}^{3}$ para a densidade básica; $601 \mathrm{~g} / \mathrm{dm}^{3}$ para a densidade à $12 \%$ de umidade e $582 \mathrm{~g} / \mathrm{dm}^{3}$ para a densidade à $0 \%$ de umidade (determinadas pelo método gravimétrico).

Os valores encontrados no presente trabalho estão dentro da gama de variação do trabalho mencionado. Se fizermos a média das densidades encontradas na Tabela 9, encontraremos um valor de $565 \mathrm{~g} / \mathrm{dm}^{3}$ para Pinus taeda aos 20 anos, contra $601 \mathrm{~g} / \mathrm{dm}^{3}$ para Pinus taeda aos 25 anos de idade, cultivado em regiões muito semelhantes (Telêmaco Borba e Sengês, ambas no estado do Paraná).

\subsubsection{Produtividade em volume e biomassa da madeira das árvores}

Os incrementos médios anuais (IMA) e periódicos (IP) em volume e massa para cada anel de crescimento das árvores de Pinus taeda das 5 classes de diâmetro das amostrs basais são apresentados nas Figuras 30 a 34, calculados a partir dos seus valores de densidade e de volume. Verifica-se que 0 IMA de massa e volume segue um modelo de variação com aumentos crescentes e uniformes, enquanto o IP apresenta grandes oscilações, em relação ao ano de formação dos anéis de crescimento e, principalmente, dos desbastes realizados na população de Pinus taeda. 


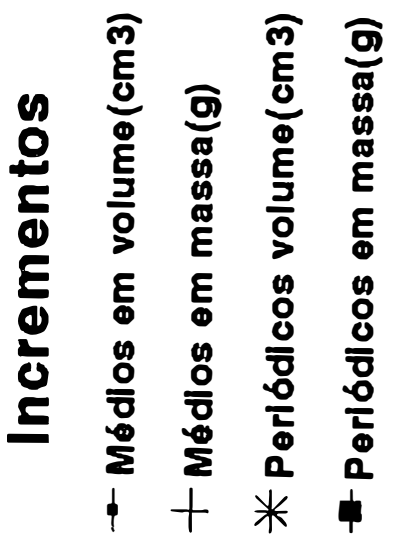

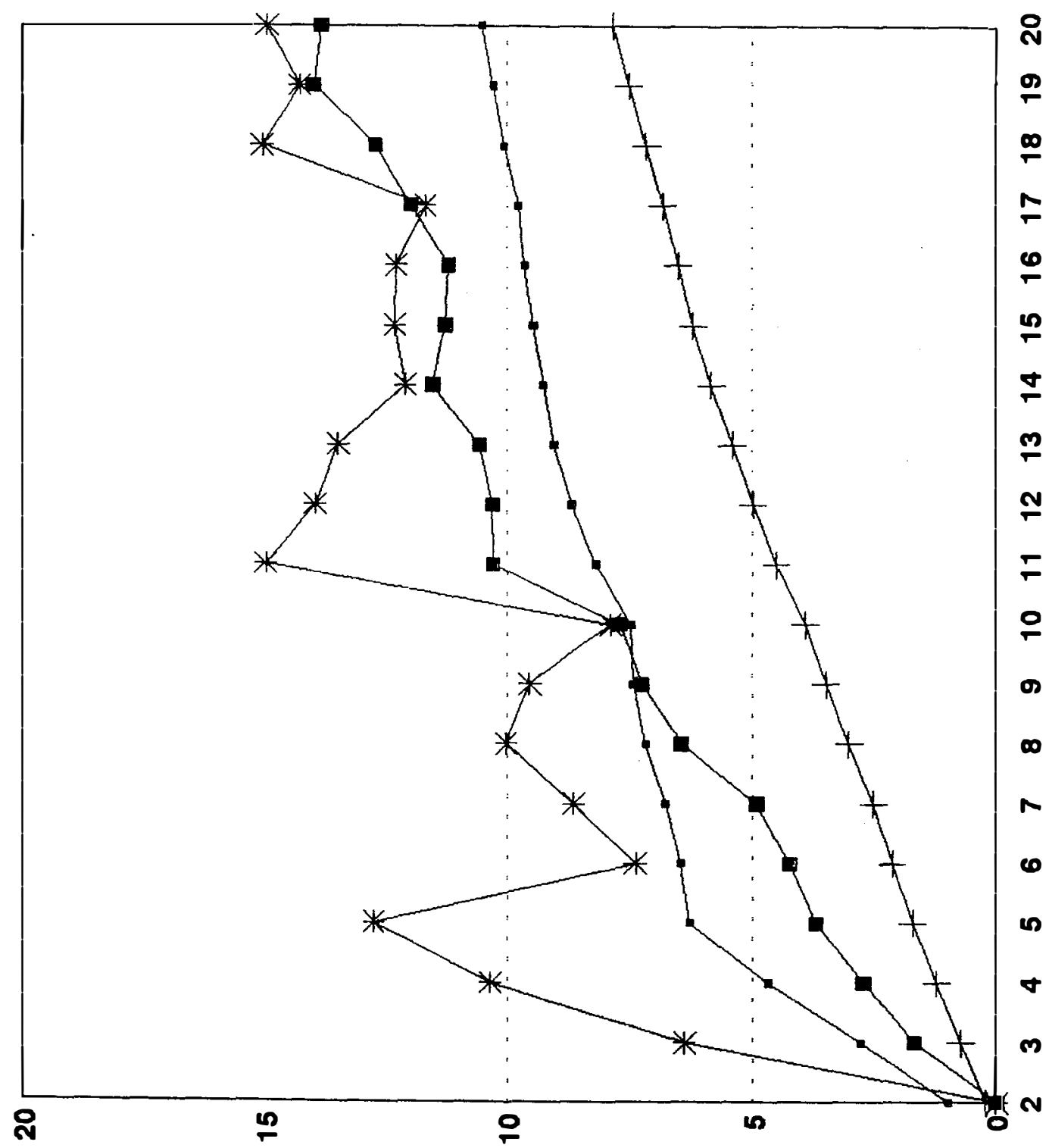

-1
11
0
$\frac{0}{0}$
0
0
0
0
0
0
-1

$\stackrel{0}{ᄃ}$

号

뭉

0
0
0

$\approx$

6

$\underline{\square}$

$\pm$

$m$

N

\%

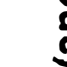

흠

(2)

$\infty$



8
0
0
$0-1$

음

D) 


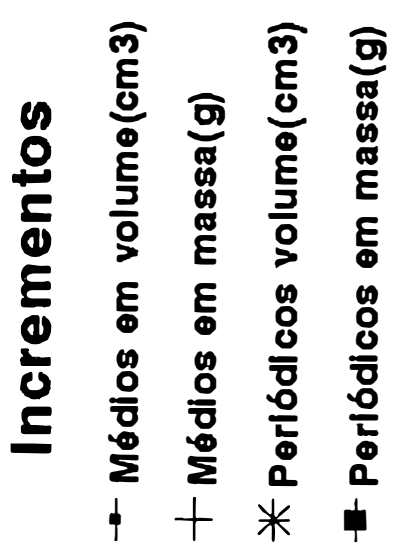

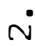

II

옴

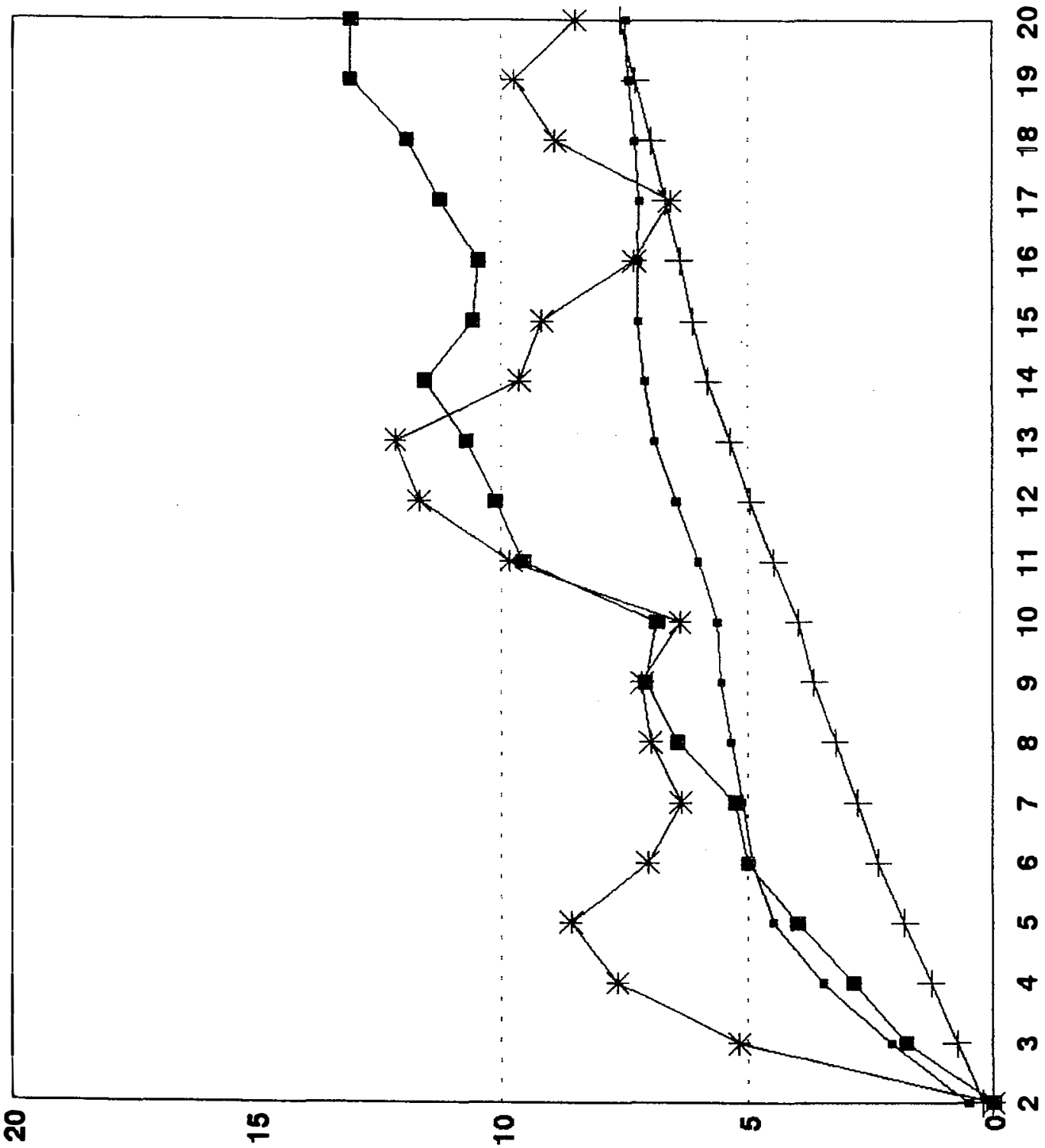

$\stackrel{0}{\square}$

(2)

N

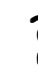

离

0
0
0
-1
0

읃

$=$

으

ช్ำ

$\infty$ 


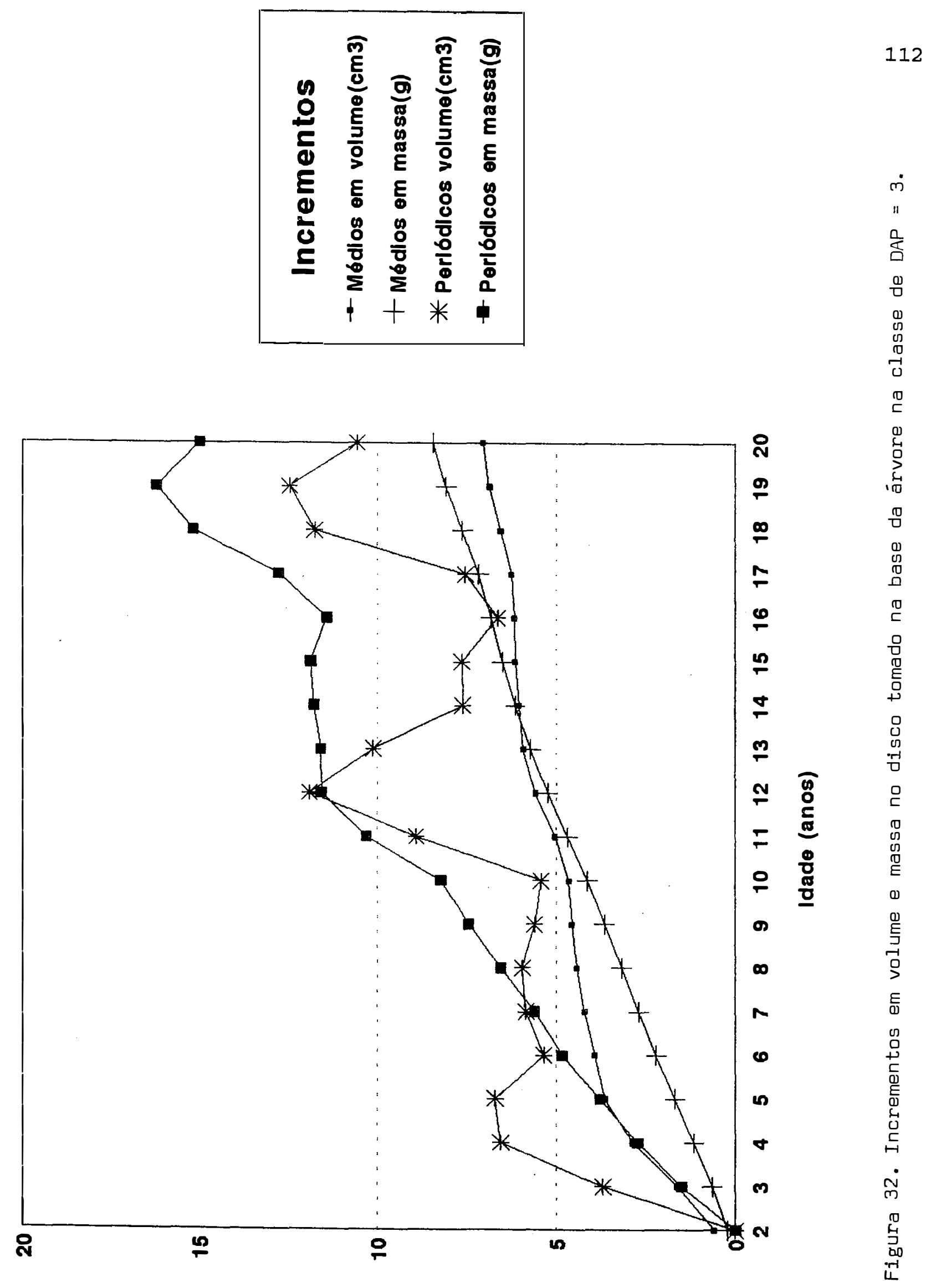




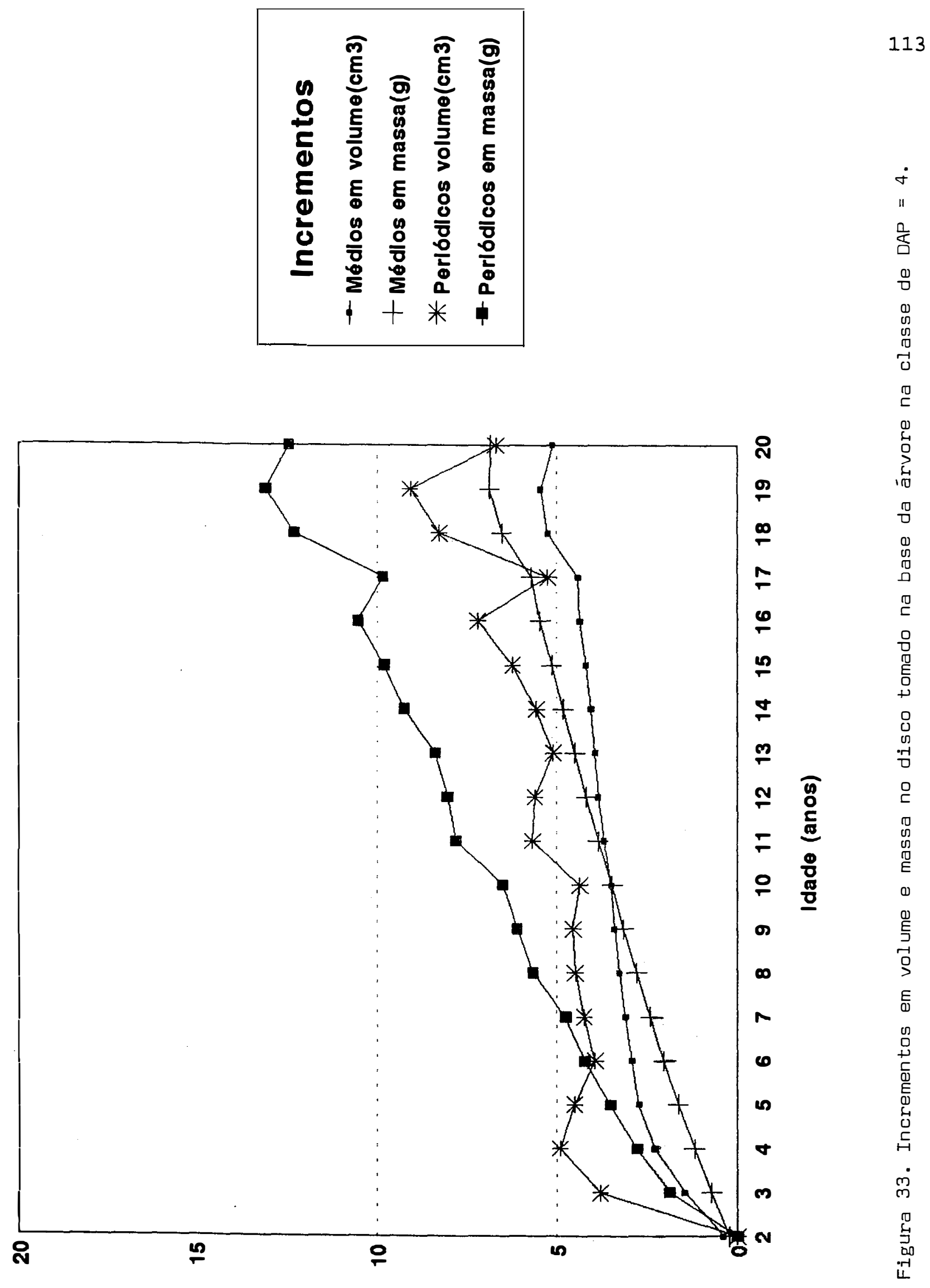




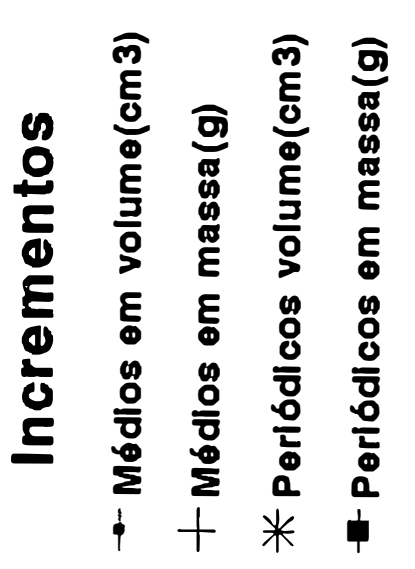

i

足

임

ป

品

묻

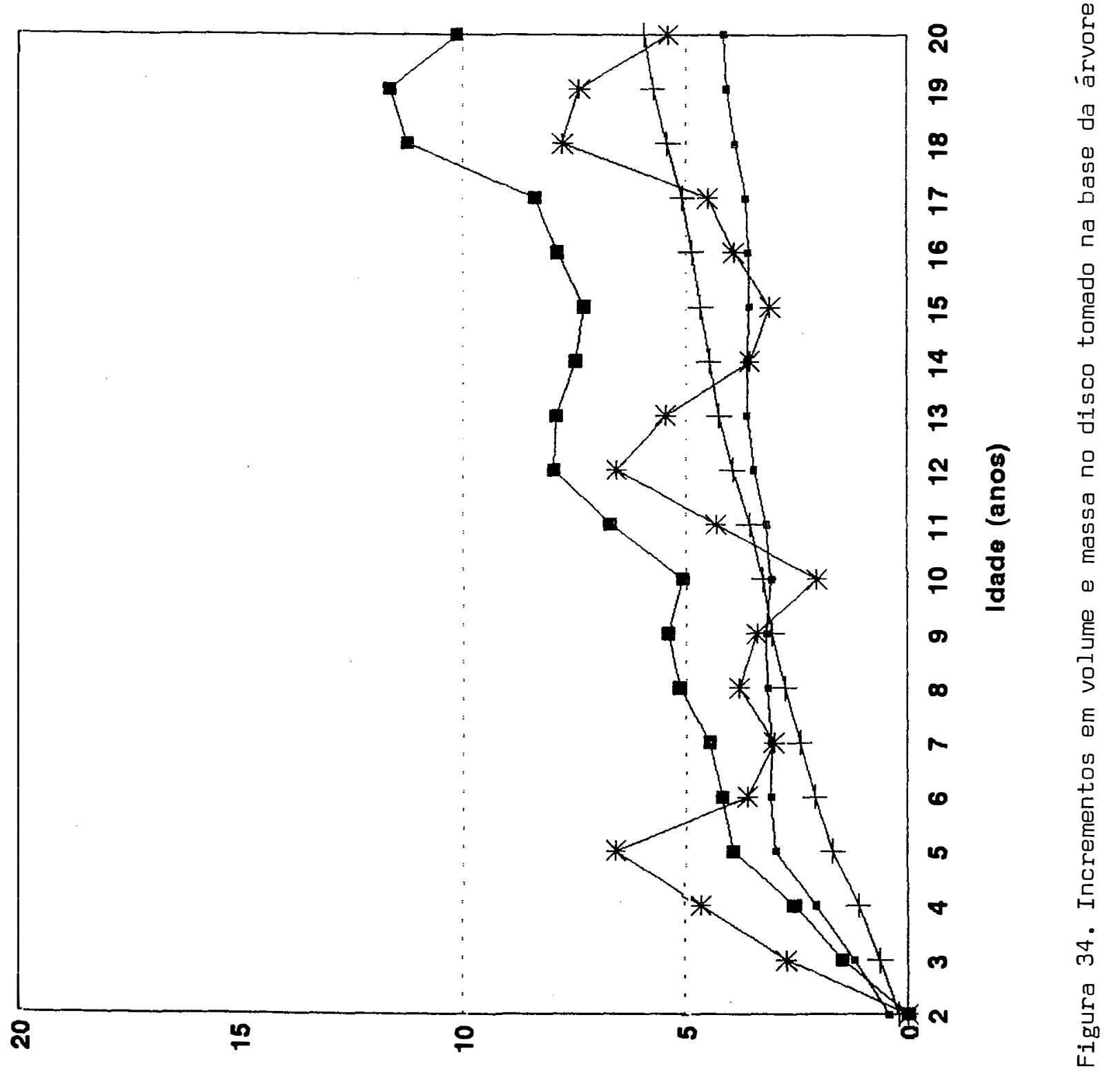


Através destas figuras, podemos notar as diferentes respostas aos desbastes segundo as classes de diâmetros. Enquanto que as de maior classe respondem mais ao primeiro desbaste com relação ao volume, as de menor respondem mais ao segundo desbaste. Em relação ao peso, as tendências se invertem. Pode-se observar, ainda, que nas árvores das primeiras classes de diâmetro, as curvas de volume se situam num patamar bem mais elevado que as de massa, sendo que o inverso ocorre com as classes de menores diâmetros, onde as curvas de massa se sobrepõem às de volume.

Os dados de massa e volume obtidos para os anéis individuais permitiram também testar modelos para relacionar a idade do anel com: volume acumulado, massa acumulada, volume do anel e massa do anel. Os modelos testados, assim como suas significâncias, foram relacionados na Tabela 10. Através desta tabela, pode-se verificar que a analise estatística dos modelos testados (linear simples, log-log e quadrático) mostrou uma maior aderência para o modelo log-log, que relaciona o log do volume acumulado e da massa acumulada com o log da idade do anel $\left(R^{2}=0,8347\right.$ e 0,8956 respectivamente). Através desta análise, conclui-se que é impossivel estimar a massa e o volume do anel através da idade ( $R^{2}$ extremamente baixo para todos os modelos testados), enquanto que é perfeitamente possivel se estimar a massa e o volume acumulado através do log da idade. 
Tabela 10. Resultados da análise estatística efetuada para testar modelos de regressão utilizados para relacionar massa e volume dos anéis de crescimento com a idade da árvore.

\begin{tabular}{|c|c|c|c|c|c|}
\hline \multirow{2}{*}{ Equação } & \multirow{2}{*}{$\mathbf{R}^{2}$} & \multicolumn{4}{|l|}{$\mathrm{F}$} \\
\hline & & Modelo & a & $b$ & c \\
\hline $\operatorname{Massa}(\mathrm{g})=-14,375808+4,4575161 \mathrm{D}$ & 0,7691 & ** & ** & $\star \star \star$ & \\
\hline $\operatorname{Vol}\left(\mathrm{cm}^{3}\right)=-19,549361+7,4501181 \mathrm{D}$ & 0,6765 & ** & 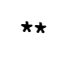 & ** & \\
\hline IMA MAS $=0,513501+0,19778010$ & 0,5546 & ** & ** & ** & \\
\hline IMA VOL $=1,861403+0,2862671 \mathrm{D}$ & 0,3353 & ** & 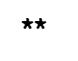 & ** & \\
\hline IPMAS $=2,257291+0,2079491 \mathrm{D}$ & 0,2039 & $\star \star$ & $\star \star$ & $\star \star \star$ & \\
\hline $\mathrm{IPVOL}=5,054130+0,2377271 \mathrm{D}$ & 0,0848 & ** & 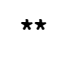 & 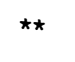 & \\
\hline LMAS $=-1,538108+2,038884$ L(ID) & 0,8956 & *夫 & $\star \star \star$ & $\star \star$ & \\
\hline LVOL $\quad=-0,390207+1,813582 \mathrm{~L}(\mathrm{ID})$ & 0,8347 & ** & ** & ** & \\
\hline LIPMAS $=0,439671+0,417865$ L(ID) & 0,2393 & ** & ** & $\star \star *$ & \\
\hline LIPVOL $=1,385421+0,224526$ (ID) & 0,0654 & 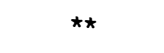 & $\star \star$ & $\star \star$ & \\
\hline LIMAVOL $=-0,390207+0,813582 \mathrm{~L}(\mathrm{ID})$ & 0,5040 & ** & ** & $\star \star$ & \\
\hline LIMAMAS = -1,538108+1,0388884L(ID) & 0,6901 & $\star \star$ & 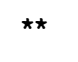 & 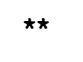 & \\
\hline $\operatorname{MAS}(\mathrm{g})=-5,000707+2,104864 \mid \mathrm{D}+0,112125 \mathrm{ID}^{2}$ & 0,7794 & 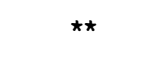 & ns & $* \star$ & ** \\
\hline $\operatorname{Vol}\left(\mathrm{cm}^{3}\right)=-7,993927+4,5503191 \mathrm{D}+0,1382021 \mathrm{D}^{2}$ & 0,6815 & ** & ns & $\star \star$ & $\star \star$ \\
\hline IMAMAS $=0,213184+0,699882|D-0,019712|^{2}$ & 0,3690 & *夫 & ns & $\star \star$ & $\star \star$ \\
\hline IPMAS $=1,506461+0,396371$ ID $-0,008980 \mathrm{ID}^{2}$ & 0,2120 & ** & $\star \star$ & $\star \star$ & ns \\
\hline IPVOL $=5,373163+0,1576661 \mathrm{D}+0,0038161 \mathrm{D}^{2}$ & 0,0853 & 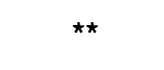 & $\star \star$ & ns & ns \\
\hline \multicolumn{6}{|l|}{ MAS = Massa } \\
\hline \multicolumn{6}{|l|}{ VOL $=$ Volume } \\
\hline \multicolumn{6}{|l|}{$\mathrm{IMA}=$ Incremento médio anual } \\
\hline \multicolumn{6}{|l|}{ IP = Incremento periódico } \\
\hline $\mathrm{L}=\mathrm{Log}$ & & & & & \\
\hline$I D=$ Idade & & & & & \\
\hline
\end{tabular}




\section{Os procedimentos adotados na análise densitométrica de madeiras são:}

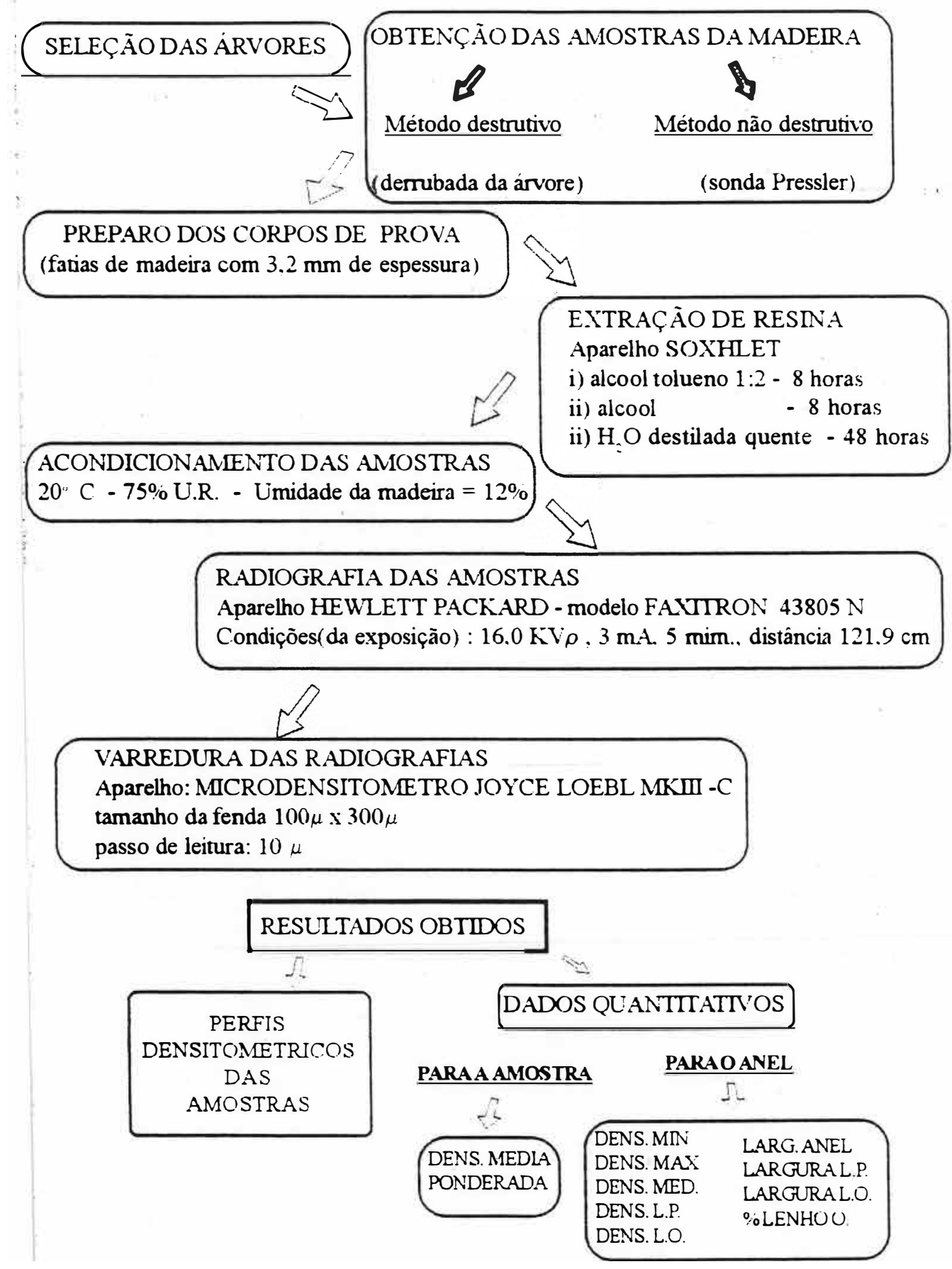




\section{CONCLUSÕES}

1) A metodologia de determinação da densidade através da densitometria de raios- $X$ foi implantada em todas as suas etapas, desde o preparo das amostras, leitura do filme de raios-X, até a interpretação final dos resultados, incluindo o desenvolvimento do programa de análise.

2) Essa metodologia aplicada na análise dos anéis de crescimento de amostras radiais da madeira de Pinus taeda possibilitou:

2.1) calcular a idade das árvores através do exame das radiografias e de sua leitura no microdensitômetro;

2.2) determinar as variações da densidade da madeira, no sentido medula-casca, dentro e entre os lenhos primaveril e outonal nos anéis de crescimento e a densidade média das amostras de madeira;

2.3) determinar outros parâmetros de crescimento das árvores e da qualidade da madeira, como a madeira juvenil e adulta e sua transição, a porcentagem de lenho outonal e os incrementos anuais em massa e volume. 
3) A interpretação dos dados obtidos, através dessa metodologia, para as árvores de Pinus taeda, nas 5 classes de diâmetro possibilitou verificar:

3.1) que as árvores apresentaram o mesmo padrão de variação para as características dos anéis de crescimento, sendo que as dominadas apresentaram maiores niveis de variação.

3.2) respostas aos desbastes com variações nas árvores dominadas e dominantes para as características dos anéis de crescimento;

3.3) modelos para estimar a massa e volume acumulados pelas árvores através de suas idades. 


\section{REFERÊNCIAS BIBLIOGRÁFICAS}

BROCHI, M.A.C. Métodos de simulação computacional para redução da dose em radiodiagnóstico. Ribeirão Preto, 1990. 80p. (Tese Mestrado - FFCL/USP).

BROWN, G.A. A statistical analysis of density variation in Pinus caribaea grown in Jamaica. In: IUFRO CONGRESS, 15, Gainesville, 1971. 17p. (não publicado).

CLARKE, S.H. On estimating the mechanical strength of the wood ash. Forestry, Oxford, 7: 26-31, 1933.

COUTO, H.T.Z.; SPELTZ, R.M.; AMARAL, A.C.B.; MARCOLIN, M. Influência do regime de manejo na qualidade da madeira de Pinus taeda e Pinus elliotti. Densidade da madeira. Revista do IPEF, Piracicaba (no prelo).

COWN, D.J. \& PARKER, M.L. Comparison of annual ring density profiles in hardwoods and softwoods by X-ray densitometry. Canadian joumal of forest research, Ottawa, V(8): 442-9, 1978.

DADSWELL, H.E. Tree growth wood property intemelationship. Raleigh, North Carolina State University, 1960. 86p. 
DUPONT, $P$. Étude de la densité du bois par analyse radiographique et application a l'Epicea de l'est de la Belgique. Gembloux. Faculté de Sciences Agronomiques de L'Etat, 1978. 81p.

ECHOLS, R.M. Moving slit radiography of wood samples for incremental measurements. In: SMITH, J.H.G. \& WORRALL, eds. Tree ring analysis with special reference to north west America. Vancouver, British COlumbia, University, 1970. p.34-36.

ECHOLS, R.M. Patterns of wood density distribution and growth rate in ponderosa pine. In: SUMPOSIUM ON THE EFFECT OF GROWTH ACCELERATION ON PROPERTIES OF WOOD, Madison, 1972. Proceedings, p.H1/H18.

ECHOLS, R.M. Uniformity of wood density assessed from X-rays of increment cores. Wood science and technology, New York, 6(1): 34-44, 1973.

FRITTS, H.C. Tree rings and climate. London, Academic Press, 1976. 567p.

HARRIS, J.M. Wood quality of radiata pine. New Zealand Forestry Service Reprint, Rotorua, (1474): 211-5, 1981.

HEGGER, L. Longitudinal of specific gravity in stems of black spruce, balsan fir and lodgpole pine. Canadian joumal of forestry research, Ottawa, 4: 321-6, 1974.

IFJU, G. Within growth ring variation in some physical properties of southern pine wood. Wood sciences, Madison, 2: 11-9, 1969.

JAYNE, B.A. Effects of site and spacing on the specific gravity of wood plantations grown red pine. TAPPI, Atlanta, 41: 162-6, 1958. 
JOSZA, L.A; RICHARDS, J.E.; JOHNSON, S.G. Calibration of Forintek';s Direct Reading X-ray densitometer. Vancouver, Forintek (Project $n^{\circ}$. 04-55-12-104, CFS no. 362), 1987.

JOSZA, L.A.; RICHARDS, J.E.; JOHNSON, S.G. In: KELLOG, R.M. Second growth Douglas-fir: Its management and convertion value compiled. Vancouver, Forintek Canada Corp., s/d, p.5-27 (B.C. Special Publication n. S.P. 32).

KODAK. Elementos de Radiografia, 1961. 76p.

LARSON, P.R: Microscopic wood characteristics and their variations with tree growth. In: IUFRO MEETING OF THE SECTION 41, 1963. Proceedings, p.113.

LARSON, P.R. Wood formation and concept of wood quality. Yale Univ. Sch. For. Bull. (74): 1-54, 1969.

LARSON, P.R. The physiological basis for wood specific gravity in conifers. In: IUFRO MEETING OF DIVISION, 5, 1973. Proceedings. Capetown and Pretoria.

LENZ, O.; SCHÄR, E.; SCHWEINGRUBER, F.H. Metodische probleme bei der radiographisch densitometrishen Bestimmung der Dichte und der Jahrring breiten von Holz. Holzforschung, Berlin, 30(4): 114-23, 1976.

LESNINO, G. Analyse de cernes de coniferes par procede de sablage et de mesure par rayons laser. In: IUFRO ALL-DIVISION 5 CONFERENCE "FOREST PRODUCTS". Proceedings. Nancy, A.R. BO. LOR., 1992. v.1, p.195. 
LOUZADA, J.L.P.C. Variação nas componentes da densidade da madeira de Pinus pinaster Ait. Vila Real, Univ. de Trás-os-Montes e Alto Douto, 1990, 111p.

McGRAW, R.A. \& NEARN, W.T. Detailed DBH density profiles of several trees from Douglas-fir fertilizer/thinning plots. In: SYMPOSIUM ON EFFECTS OF GROWTH ACCELERATION ON PROPERTIES OF WOOD, Madison, 1972. Proceedings, FPL (p.G1/G24).

MeGRAW, R.A. Wood quality factors in Loblolly Pine. Atlanta, TAPPI PRESS, 1985. 88p.

MOSCHLER, W.W.; DOUGAL, E.F.; McRAE, D.D. Density and growth ring characteristics of Pinus taeda L. folowing thinning. Wood and fiber science, Lawrence, 21(3): 313-9, 1989.

OHTA, S.; KELLER, R.; JANIN, G. Effects de divers modes de fertilization (N, $P$, $\mathrm{K})$ sur certaines caractéristiques physiques, chimiques, mecaniques et proprietés papetières du pin maritime des Landes (Pinus pinaster Ait): 1. Ann. sci. for., Paris, 40(3): 283-98, 1983.

PANSHIN, A.J. \& DE ZEEUW, C. Textbook of wood technology. New York, MacGraw-Hill, 1970. v.1, 105p.

PARKER, M.L. \& MELESKIE, K.R. Preparation of X-ray negatives of tree-ring specimens for dendrochronological analysis. Tree ring bull, Tucson, 30: 1-22, 1970.

PARKER, M.L. \& KENNEDY, W.W. The status of radiation densitometry for measurement of wood specific gravity. In: IUFRO MEETING OF DIVISION 5, 1973, Proceedings. Capetown and Pretoria. 
PARKER, M.L. Improving tree-ring dating in Northern Canada by X-ray densitometry. Syesis, Victoria, 9: 163-72, 1976.

PETERSON, T.A. Variation in radial growth patterns and specific gravity of red pine (Pinus resinosa). For. prod. j., Madison, 18: 62, 1968.

POLGE, $H$. Recherches sur l'utilization de prélèvements effectués a la tarière de Pressler pour l'étude des proprietés physiques et mecaniques des bois. Revue forestière française, Nancy, 1962.

POLGE, $H$. Étude des variations de densité du bois par analyse densitometrique sous cliches radiographiques d'echantillons prélèves a la tarière de pressler. In: IUFRO MEETING OF SECTION 41, 1965. Proceedings, Melbourne, v.2, $18 p$.

POLGE, H. Établissement des courbes de variation de la densité du bois par exploration densitometrique de radiographies d'echantillons prélèves a la tarière sur des arbres vivants. Aplication dans les domaines technologique et physiologique. Ann. sci. for., Paris, 23(1): 1-206, 1966.

POLGE, H. \& ILLY, G. Observations sur l'anisotropie du Pin maritime des Landes. Ann. sci. for., Paris, 24: 205-31, 1967.

POLGE, $H$. Influence of fertilizer application on the wood properties of Pinus pinaster. Ann. sci. for., Paris, 26(1): 45-64, 1969.

POLGE, $H$. Fifteen years of wood radiation densitometry. Wood sci. technol., New York, 12: 187-96, 1978. 
PRONIN, D. Estimating tree specific gravity of major pulp wood species of Wisconsin. U.S.D.A. For. Serv. FPL Res. Paper, Madison, (16): 1-17, 1971.

RUDMAN, P. Growth ring analysis. J. inst. wood sci., 4(2): 58-63, 1968.

SARDINHA, R.M. de A. Variation in density and some structural features of wood of Eucalyptus saligna Sm. from Angola. Oxford, 1974 (Ph.D. Linage College).

SLUDER, E.R. Variation in specific gravity of yellow-poplar in the Southern Appalachians. Wood sci., Madison, 5: 132-8, 1972.

SCHWEINGRUBER, F.H. The X-ray techniques as applied to dendroclimatology. Tree ring bull., Tucson, 38: 61-91, 1978.

SCHWEINGRUBER, F.H. Tree Rings: Basics and Applications of Dendrochronology. Dordrecht, D. Reidel, 1988. 276p.

TALBERT, J.T. \& JETT, J.B. Regional specific gravity values for plantation grown loblolly pine in the Southeastern United States. For. Sci., Madison, 27: 801-7, 1981.

THOMAS, W.R. X-ray analysis of wood increment cores. Clenson, University Clenson, South Carolina, 1972. 61p. (Tese Mestrado-Clenson).

THOMAS, W.R. \& WOTEN, T.E. X-ray analysis of wood increment cores. Dep. of for. res. series, Clenson, (26): 1-16, 1973.

VAN BUIITJENEN, J.P. Controlling wood properties by forest management. TAPPI, Atlanta, 52(2): 257-9, 1969. 
WATSON, A.J. \& DADSWELL, H.E. Influence of fibre morphology on paper properties: part 2 - Early wood and latewood. A.T.I.P., 35817, 1962.

ZOBEL, B.J.; KELLISON, R.C.; MATHIAS, M.F.; HATCHER, A.V. Wood density of Southern pines. Tech bull., Raleigh (208): 1-56, 1972,

ZOBEL, B.J. \& VAN BUIIJTENEN, J.P. Wood variation: its cause and control. Berlin, Springer Verlag, 1989. 
APÊNDICE 
Tabela11-Caracteristicas dos aneis de crescinento de amos tras de madeira de arvores de pinus taeda, obtidas atraves de densitonetria de Raios - $Y$.

Sitio $=2$ Classe de $D ! . \mathrm{P}=1$ Irrore $=1$

\begin{tabular}{|c|c|c|c|c|c|c|c|c|c|c|}
\hline $\begin{array}{l}\text { Idade } \\
\text { (anos) }\end{array}$ & Raio & $\begin{array}{c}\text { Dens. } \\
\text { Min. }(g / d m 3)\end{array}$ & $\begin{array}{l}\text { Dens. } \\
\text { Max. }(a / d n 3)\end{array}$ & $\begin{array}{l}\text { Dens. } \\
\text { Med. }(9 ; d m 31\end{array}$ & $\begin{array}{l}\text { Dens. L.P. } \\
(g / \operatorname{dg} 3)\end{array}$ & $\begin{array}{l}\text { Dens.L.O. } \\
\text { Ig:dm } 31\end{array}$ & $\begin{array}{l}\text { Conp.L.P. } \\
\text { (ng) }\end{array}$ & $\begin{array}{l}\text { Conp.L.O. } \\
\text { (min) }\end{array}$ & $\begin{array}{l}\text { Conp. Total } \\
\text { (a日) }\end{array}$ & L.O. \\
\hline 2 & 1 & 226 & 637 & 342 & 288 & 543 & 9.40 & 2.50 & 11.90 & 21.01 \\
\hline 2 & 2 & 255 & 707 & 377 & 324 & 511 & 10.70 & 2.40 & 13.10 & 13.32 \\
\hline 3 & 1 & 243 & 791 & 374 & 292 & 691 & 10.70 & 2.80 & 13.50 & 20.74 \\
\hline 3 & 2 & 237 & $? 62$ & 387 & 294 & 665 & 12.10 & 4.10 & 16.20 & 25.31 \\
\hline 4 & 1 & 235 & 802 & 352 & 273 & 673 & 11.00 & 2.70 & 13.70 & 19.71 \\
\hline 4 & 2 & 235 & 780 & 349 & 277 & 626 & 11.60 & 3.00 & 14.60 & 20.55 \\
\hline 5 & 1 & 234 & 816 & 384 & 278 & 674 & 8.80 & 3.20 & 12.00 & 26.67 \\
\hline 5 & 2 & 236 & 791 & 351 & 285 & 627 & 9.30 & 2.20 & 11.50 & 19.13 \\
\hline 6 & 1 & 279 & 890 & 384 & 328 & 743 & 3.90 & 2.10 & 6.00 & 35.00 \\
\hline 6 & 2 & 285 & 943 & 517 & 345 & 783 & 3.40 & 2.20 & 5.60 & 39.29 \\
\hline$?$ & 1 & 246 & 974 & 454 & 318 & 767 & 4.40 & 1.90 & 5.30 & 30.16 \\
\hline 7 & 2 & 249 & 943 & 459 & 319 & 733 & 4.30 & 2.20 & 6.50 & 33.85 \\
\hline 8 & 1 & 234 & 933 & 474 & 315 & 775 & 5.30 & 2.80 & 8.10 & 34.57 \\
\hline 8 & 2 & 239 & 974 & 520 & 302 & 721 & 3.50 & 3.80 & 7.30 & 52.05 \\
\hline 9 & 1 & 248 & 1027 & 553 & 565 & 884 & 3.90 & 2.70 & 6.60 & 10.91 \\
\hline 9 & 2 & 247 & 987 & 526 & 315 & 865 & 3.70 & 2.30 & 6.00 & 38.33 \\
\hline 10 & 1 & 268 & 989 & 519 & 359 & 855 & 4.20 & 2.00 & 6.20 & 32.26 \\
\hline 10 & 2 & 273 & 976 & 646 & 339 & 799 & 1.60 & 3.20 & 4.80 & 66.67 \\
\hline 11 & 1 & 269 & 966 & 622 & 311 & 772 & 3.0 & 6.20 & 9.20 & 67.39 \\
\hline 11 & 2 & 277 & 925 & 599 & 331 & 766 & 3.50 & 5.60 & 9.10 & 61.54 \\
\hline 12 & 1 & 247 & 928 & 540 & 332 & 761 & $4.80^{\prime}$ & 4.50 & 9.30 & 48.39 \\
\hline 12 & 2 & 235 & 928 & 515 & 303 & 749 & 5.50 & 5.00 & 10.50 & 47.62 \\
\hline 13 & 1 & 284 & 855 & 573 & 373 & 735 & 4.30 & 5.30 & 9.60 & 55.21 \\
\hline 13 & 2 & 275 & 839 & 532 & 340 & 714 & 4.80 & 5.10 & 9.90 & 51.52 \\
\hline 14 & 1 & 363 & 839 & 605 & $\$ 11$ & 677 & 2.40 & 6.50 & 8.90 & -3.03 \\
\hline 14 & 2 & 287 & 901 & 636 & 375 & -22 & 1.90 & 5.80 & -.70 & -5.32 \\
\hline .15 & 1 & 311 & 839 & 536 & 355 & 677 & 3.20 & 4.10 & 7.30 & 56.16 \\
\hline 15 & 2 & 243 & 832 & 509 & 319 & 699 & 3.50 & 3.50 & $? .00$ & 50.00 \\
\hline 16 & 1 & 284 & 702 & 451 & 362 & 599 & 5.30 & 3.20 & 8.50 & 37.65 \\
\hline 16 & 2 & 276 & 948 & 555 & 366 & 752 & 3.80 & 2.62 & 6.42 & 10.81 \\
\hline $1 ?$ & 1 & 319 & 698 & 473 & 375 & 583 & 4.20 & 3.80 & 8.00 & $\$ 7.50$ \\
\hline 17 & 2 & 326 & 805 & 571 & 375 & 698 & 2.38 & 3.70 & 6.08 & 50.86 \\
\hline 18 & 1 & 295 & 764 & 477 & 341 & 622 & 5.10 & 4.80 & 9.90 & 18.18 \\
\hline 18 & 2 & 260 & 797 & 458 & 317 & 678 & 4.50 & 2.90 & 7.40 & 39.19 \\
\hline 19 & 1 & 290 & 819 & .545 & 348 & 646 & 3.30 & 6.40 & 9.70 & 65.98 \\
\hline 19 & $\begin{array}{l}1 \\
2\end{array}$ & 251 & 890 & 575 & 303 & 714 & 2.30 & 5.50 & 3.30 & $56.2^{x}$ \\
\hline 20 & 1 & 302 & 768 & 524 & 377 & 638 & 4.40 & 5.60 & 10.00 & 56.00 \\
\hline 20 & 2 & 260 & 793 & 515 & 339 & 700 & 3.70 & 3.50 & 7.20 & 48.61 \\
\hline
\end{tabular}


Tabela 12 - Caracteristicas dos aneis de crescimento de amos tras de madeira de arvores de pinus taeda, obtiaas atraves de densitometria de Raios - $!$.

Sitio $=2$ Classe de $D \leq P=1$ arrore $=2$

\begin{tabular}{|c|c|c|c|c|c|c|c|c|c|c|}
\hline $\begin{array}{l}\text { Idade } \\
\text { ( anos) }\end{array}$ & Raio & $\begin{array}{l}\text { Dens. } \\
\text { Min. }(q / d \operatorname{dn} 31\end{array}$ & $\begin{array}{c}\text { Dens. } \\
\text { Max. } \mid \mathrm{g}: \mathrm{d} n 31\end{array}$ & $\begin{array}{l}\text { Dens. } \\
\text { Hed. } \mid \mathrm{g} \text { d } 31\end{array}$ & $\begin{array}{l}\text { Dens.L.P. } \\
|\mathrm{g} / \mathrm{dm} 3|\end{array}$ & $\begin{array}{l}\text { Dens.L.0. } \\
\text { (g.dm } 31\end{array}$ & $\begin{array}{l}\text { Conp.L.P. } \\
(\operatorname{and})\end{array}$ & $\begin{array}{l}\text { Conp.L.O. } \\
(\mathrm{an})\end{array}$ & $\begin{array}{l}\text { Conp.Total } \\
|\operatorname{lag}|\end{array}$ & L.O. \\
\hline 2 & 1 & 216 & 570 & 335 & 294 & 484 & 16.00 & 4.40 & 20.40 & 21.57 \\
\hline 2 & 2 & 220 & 544 & 288 & 265 & 465 & 15.10 & 2.00 & 17.10 & 11.70 \\
\hline 3 & 1 & 241 & 648 & 347 & 292 & 582 & 15.20 & 3.60 & 18.80 & 19.15 \\
\hline 3 & 2 & 231 & 642 & 318 & 273 & 553 & 15.30 & 2.90 & 18.20 & 15.93 \\
\hline 4 & 1 & 241 & 614 & 339 & 286 & 532 & 15.50 & 4.30 & 19.80 & 21.72 \\
\hline f & 2 & 230 & 704 & 327 & 268 & 539 & 12.60 & 3.30 & 15.90 & 20.75 \\
\hline 5 & 1 & 263 & 735 & 346 & 304 & 628 & 15.90 & 2.40 & 18.30 & 13.11 \\
\hline 5 & 2 & 257 & 737 & 364 & 291 & 609 & 11.70 & 3.50 & 15.20 & 23.03 \\
\hline 6 & 1 & 282 & 887 & 502 & 346 & 749 & 4.90 & 3.10 & 8.00 & 38.75 \\
\hline 6 & 2 & 273 & 873 & +72 & 327 & 703 & 5.10 & 3.20 & 3.30 & 38.55 \\
\hline$?$ & 1 & 263 & 997 & 472 & 328 & 740 & 5.20 & 2.80 & 8.00 & 35.00 \\
\hline$?$ & 2 & 281 & 857 & 460 & 331 & 681 & 5.50 & 3.20 & 8.70 & 36.78 \\
\hline$\delta$ & 1 & 260 & 951 & 610 & 347 & 769 & 3.30 & 5.50 & 8.80 & 62.50 \\
\hline$\delta$ & 2 & 273 & 391 & 564 & 338 & 684 & 2.50 & 4.70 & 7.20 & 55.28 \\
\hline 9 & 1 & 306 & 1010 & 648 & 387 & 816 & $2.1 \theta$ & 3.70 & 6.10 & 60.66 \\
\hline 9 & 2 & 277 & 898 & 570 & 368 & 751 & 4.10 & 4.60 & 8.70 & 52.87 \\
\hline 10 & 1 & 300 & 976 & 681 & 365 & 856 & 1.50 & 2.70 & 4.20 & 64.29 \\
\hline 10 & 2 & 258 & 396 & 566 & 319 & 651 & 2.60 & 3.70 & 6.30 & 58.73 \\
\hline 11 & 1 & 340 & 1002 & 723 & 403 & 854 & 2.20 & 5.40 & 7.60 & 71.05 \\
\hline 11 & 2 & 301 & 830 & 500 & 345 & 656 & 5.80 & 5.80 & 11.60 & 50.00 \\
\hline 12 & 1 & 320 & 969 & 701 & 381 & 795 & 1.30 & 4.40 & 5.70 & 77.19 \\
\hline 12 & 2 & 280 & 907 & 496 & 323 & 699 & 4.00 & 3.40 & 7.40 & 45.95 \\
\hline 13 & 1 & 306 & 844 & 621 & 352 & 697 & .90 & 3.20 & 4.10 & 78.05 \\
\hline 13 & 2 & 285 & 857 & 480 & 328 & 692 & 3.20 & 3.00 & 6.20 & 48.39 \\
\hline 14 & 1 & 352 & 907 & 682 & 393 & 745 & .60 & 2.80 & 3.40 & 32.35 \\
\hline 14 & 2 & 310 & 72 & 551 & 360 & 630 & 1.30 & 3.80 & 5.10 & 74.51 \\
\hline 15 & 1 & 280 & 947 & 629 & 335 & 789 & 1.80 & 3.30 & 5.10 & 54.71 \\
\hline 15 & 2 & 291 & 322 & 536 & 347 & 718 & 2.30 & 24.0 & 4.70 & 51.06 \\
\hline 16 & 1 & 311 & 906 & 605 & 353 & 756 & 1.20 & 2.00 & 3.20 & 62.50 \\
\hline 16 & 2 & 280 & 301 & 463 & 345 & 684 & 3.20 & 1.70 & 1.90 & 34.69 \\
\hline 17 & 1 & 284 & 957 & 624 & 359 & 812 & 1.70 & 2.40 & 4.10 & 58.54 \\
\hline 17 & 2 & 308 & 850 & 561 & 391 & 709 & 1.30 & 1.50 & 2.80 & 53.57 \\
\hline 18 & 1 & 275 & 939 & 542 & 338 & 779 & 2.20 & 1.90 & 4.10 & 46.34 \\
\hline 18 & 2 & 272 & 896 & 528 & 321 & 736 & 2.20 & 2.20 & 4.40 & 50.00 \\
\hline 19 & 1 & 276 & 887 & 609 & 322 & 762 & .70 & 1.30 & 2.00 & 65.00 \\
\hline 19 & 2 & 269 & 848 & 592 & 364 & 759 & 1.40 & 1.90 & 3.30 & 57.58 \\
\hline 20 & 1 & 270 & 807 & 524 & 343 & 754 & 1.40 & 1.10 & 2.50 & 44.00 \\
\hline 20 & 2 & 264 & 790 & 556 & 347 & 688 & 1.40 & 2.20 & 3.60 & 61.31 \\
\hline
\end{tabular}


Tabela 13- Caracteristicas dos aneis de crescimento de amos tras de nadeira de arvores de Pinus taeda, obtidas atraves de densitometria de Raios - .

\begin{tabular}{|c|c|c|c|c|c|c|c|c|c|c|}
\hline $\begin{array}{l}\text { Idade } \\
\text { (anos }\end{array}$ & Raio & $\begin{array}{l}\text { Dens. } \\
\text { Min. }(a / d n\})\end{array}$ & $\begin{array}{l}\text { Dens. } \\
\text { Max. }(9 \cdot \operatorname{dn} 3)\end{array}$ & $\begin{array}{c}\text { Dens. } \\
\text { Hed. }(g / d n 3)\end{array}$ & $\begin{array}{l}\text { Dens.L.P. } \\
\lg / \operatorname{dn} 3)\end{array}$ & $\begin{array}{c}\text { Dens.L. } 0 . \\
(\mathrm{g} d \mathrm{~d} 3)\end{array}$ & $\begin{array}{l}\text { Comp.L.P. } \\
\text { inni }\end{array}$ & $\begin{array}{l}\text { Comp.L.O. } \\
\text { (nn) }\end{array}$ & $\begin{array}{l}\text { Conp.Total } \\
\text { (no) }\end{array}$ & L.O. \\
\hline 2 & 1 & 304 & 664 & 413 & 345 & 572 & 5.60 & 2.80 & 9.40 & 29.79 \\
\hline 2 & 2 & 232 & 697 & 362 & 277 & 519 & 8.10 & 3.70 & 11.80 & 31.36 \\
\hline 3 & 1 & 217 & 577 & 354 & 287 & 515 & 12.60 & 5.32 & 17.92 & 29.69 \\
\hline 3 & 2 & 236 & 724 & 382 & 277 & 600 & 10.98 & 5.30 & 16.28 & 32.56 \\
\hline 4 & 1 & 215 & 707 & 383 & 294 & 612 & 10.28 & 4.00 & 14.28 & 28.01 \\
\hline 4 & 2 & 226 & 716 & 396 & 288 & 634 & 8.30 & 3.80 & 12.10 & 31.40 \\
\hline 5 & 1 & 268 & 834 & 476 & 329 & 700 & 7.80 & 5.10 & 12.90 & 39.53 \\
\hline 5 & 2 & 249 & 789 & 430 & 303 & 657 & 7.90 & 4.40 & 12.30 & 35.77 \\
\hline 6 & 1 & 317 & 830 & 538 & 369 & 678 & 3.90 & 4.70 & 8.60 & 54.65 \\
\hline 5 & 2 & 290 & 879 & 582 & 345 & 736 & 3.00 & 4.60 & 7.60 & 60.53 \\
\hline 7 & 1 & 323 & 745 & 527 & 373 & 642 & 3.20 & 1.30 & 4.50 & 28.89 \\
\hline$?$ & 2 & 266 & 354 & 193 & 328 & 692 & 4.30 & 3.60 & 7.90 & 45.57 \\
\hline 8 & 1 & 273 & 832 & 526 & 345 & 663 & 3.10 & 4.10 & 7.20 & 56.94 \\
\hline 8 & 2 & 272 & 864 & 543 & 322 & 730 & 3.40 & 4.00 & 7.40 & 54.05 \\
\hline$Q$ & 1 & 314 & 892 & 581 & 383 & 758 & 3.30 & 3.70 & 7.00 & 52.86 \\
\hline 9 & 2 & 295 & 872 & 558 & 342 & 743 & 3.00 & 3.50 & 6.50 & 53.85 \\
\hline$\therefore 10$ & 1 & 299 & 918 & 591 & 362 & 795 & 2.50 & 2.80 & 5.30 & 52.83 \\
\hline 10 & 2 & 254 & 851 & 535 & 313 & 719 & 2.40 & 2.90 & 5.30 & 54.72 \\
\hline 11 & 1 & 326 & 965 & 623 & 369 & 789 & 2.50 & 3.80 & 6.30 & 60.32 \\
\hline 11 & 2 & 323 & 892 & 670 & 368 & 788 & 2.00 & 5.12 & 7.12 & 71.91 \\
\hline 12 & 1 & 324 & 813 & 543 & 354 & 700 & 2.40 & 2.90 & 5.30 & 54.72 \\
\hline 12 & 2 & 275 & 897 & 589 & 334 & 767 & 3.40 & 4.90 & 8.30 & 59.04 \\
\hline 13 & 1 & 294 & 838 & 535 & 336 & 728 & 2.90 & 3.00 & 5.90 & 50.85 \\
\hline 13 & 2 & 273 & 851 & 600 & 376 & 713 & 2.70 & 5.38 & 8.08 & 56.58 \\
\hline 14 & $I$ & 350 & 948 & 716 & 400 & 838 & 1.20 & 3.10 & 4.30 & 72.09 \\
\hline$\therefore i$ & 2 & 351 & 392 & 567 & 110 & 771 & 1.30 & 4.40 & 5.20 & -0.97 \\
\hline 15 & 1 & 298 & 905 & 526 & 345 & 733 & 2.40 & 2.10 & 4.50 & 46.67 \\
\hline 15 & 2 & 239 & 831 & 536 & 336 & 707 & 2.90 & 3.40 & 6.30 & 53.97 \\
\hline 16 & 1 & 294 & 892 & 605 & 406 & 776 & 2.20 & 2.92 & 5.12 & 57.03 \\
\hline 16 & 2 & 299 & 844 & 549 & 354 & 738 & 2.50 & .26 & 2.76 & 9.42 \\
\hline 17 & 1 & 310 & 892 & 603 & 369 & 772 & 1.80 & 2.50 & 4.30 & 58.14 \\
\hline 17 & 2 & 268 & 866 & 572 & 368 & 722 & 1.52 & 2.10 & 3.62 & 58.01 \\
\hline 18 & 1 & 286 & 890 & 576 & 339 & 757 & 1.90 & 2.50 & 4.40 & 56.82 \\
\hline 18 & 2 & 268 & 897 & 553 & 328 & 803 & 2.10 & 1.90 & 4.00 & $\$ 7.50$ \\
\hline 19 & 1 & 263 & 884 & 548 & 350 & 756 & 2.40 & 2.28 & 4.68 & 48.72 \\
\hline 19 & 2 & 270 & 918 & 583 & 322 & 763 & 1.60 & 2.30 & 3.90 & 58.97 \\
\hline 20 & 1 & 299 & 897 & 625 & 356 & 822 & 1.90 & 2.60 & 4.50 & 57.78 \\
\hline 20 & 2 & 311 & 862 & 567 & 350 & 754 & 1.38 & 1.60 & 2.98 & 53.69 \\
\hline
\end{tabular}


Tabela 14-Caracteristicas dos aneis de crescinento de anos tras de tadeira de arrores de Pinus taeda, obtidas atraves de densitonetria de Raios - . .

Sitio=2 Classe de $D \leq P=2$ arvore $=2$

\begin{tabular}{|c|c|c|c|c|c|c|c|c|c|c|}
\hline $\begin{array}{l}\text { Idade } \\
\text { (anos) }\end{array}$ & Raio & $\begin{array}{l}\text { Dens. } \\
\operatorname{Min} .(9 ; d n 3)\end{array}$ & $\begin{array}{l}\text { Dens. } \\
\operatorname{Max} .(9 / \mathrm{dn} 3)\end{array}$ & $\begin{array}{l}\text { Dens. } \\
\text { Med. }(a / d n 3)\end{array}$ & $\begin{array}{l}\text { Dens .L.P. } \\
|q / \operatorname{dn} 3|\end{array}$ & $\begin{array}{l}\text { Dens . L.O. } \\
\text { ig.don3i }\end{array}$ & $\begin{array}{l}\text { Conp.L.P. } \\
\text { (nn) }\end{array}$ & $\begin{array}{l}\text { Comp.L.O. } \\
\text { inni }\end{array}$ & $\begin{array}{l}\text { Conp. Total } \\
\text { (nni }\end{array}$ & $\therefore$ L.O. \\
\hline 2 & 1 & 273 & 683 & 378 & 327 & 578 & 9.10 & 2.30 & 11.40 & 20.18 \\
\hline 2 & 2 & 272 & 685 & 378 & 328 & 608 & 10.50 & 2.30 & 12.80 & 17.97 \\
\hline 3 & 1 & 272 & 717 & 379 & 319 & 566 & 12.00 & 3.80 & 15.80 & 27.05 \\
\hline 3 & 2 & 305 & 730 & 465 & 385 & 550 & 8.80 & 8.20 & 17.00 & 48.24 \\
\hline 4 & 1 & 271 & Ti1 & 404 & 570 & 615 & 10.70 & 3.82 & 14.52 & 26.31 \\
\hline 4 & 2 & 278 & 919 & 485 & 376 & 691 & 9.60 & 5.10 & 14.70 & 34.69 \\
\hline 5 & 1 & 296 & 825 & 183 & 346 & 634 & 5.00 & 4.50 & 9.50 & 97.37 \\
\hline 5 & 2 & 339 & 947 & 575 & 385 & 774 & 5.60 & 5.40 & 11.00 & 49.09 \\
\hline 5 & 1 & 334 & 959 & 627 & 388 & 90 & 2.70 & 4. 30 & 7.00 & 51.43 \\
\hline 5 & 2 & 348 & 996 & 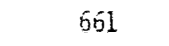 & 413 & 736 & 2.70 & 5.40 & 3.10 & 606.67 \\
\hline 7 & 1 & 349 & 1032 & 652 & 404 & 823 & 2.40 & 3.50 & 5.90 & 59.32 \\
\hline$?$ & 2 & 345 & 996 & 589 & 386 & 734 & 2.92 & 4.08 & 7.00 & 58.29 \\
\hline 0 & 1 & 332 & 932 & 642 & 390 & 739 & 1.60 & 4.10 & 5.70 & 71.93 \\
\hline 3 & 2 & 500 & 1037 & 830 & 728 & 333 & .12 & 4.80 & 4.92 & 07.56 \\
\hline 9 & 1 & 365 & 1004 & 664 & 404 & 770 & 1.10 & 2.70 & 3.80 & $=1.05$ \\
\hline 9 & 2 & 353 & 1069 & 737 & 430 & 952 & 2.60 & 3.70 & 6.30 & 58.73 \\
\hline 10 & 1 & 340 & 991 & 416 & 410 & 777 & .80 & 2.38 & 3.18 & 74.84 \\
\hline 10 & 2 & 358 & 947 & 730 & 415 & 829 & 1.40 & 4.50 & 5.90 & 75.27 \\
\hline 11 & 1 & $\$ 20$ & 959 & 742 & 498 & 780 & .80 & 5.10 & 5.90 & 86.44 \\
\hline 11 & 2 & 364 & 954 & 675 & 409 & 791 & 2.68 & 6.10 & 8.78 & 69.48 \\
\hline 12 & 1 & 278 & 957 & 626 & 373 & 754 & 3.20 & 6.30 & 9.50 & 66.32 \\
\hline 12 & 2 & 299 & 967 & 614 & 368 & 793 & 3.40 & 4.70 & 8.10 & 58.02 \\
\hline 13 & 1 & 319 & 803 & 574 & 379 & 693 & 3.10 & 5.10 & 8.20 & 62.20 \\
\hline 13 & 2 & 478 & 1016 & 615 & 378 & 70 & 3.20 & 4.60 & 7.80 & 58.97 \\
\hline 14 & 1 & 335 & 909 & 722 & 405 & 779 & .72 & 4.00 & 4.72 & 84.75 \\
\hline 24 & $\begin{array}{l}1 \\
2\end{array}$ & 351 & 890 & -08 & 411 & -53 & .80 & 6.00 & 5.90 & 36.96 \\
\hline 15 & 1 & 348 & 919 & 609 & 383 & 698 & .90 & 2.30 & 3.20 & 71.88 \\
\hline 15 & 2 & 340 & 970 & 685 & 117 & -32 & 1.60 & 4.42 & 6.02 & $-3 . \$ 2$ \\
\hline 16 & 1 & 323 & 1007 & 677 & 375 & 806 & .90 & 2.10 & 3.00 & 70.00 \\
\hline 16 & 2 & 322 & 973 & 615 & 390 & 754 & 1.80 & 2.90 & $\$ .70$ & 51.70 \\
\hline 17 & 1 & 430 & 1018 & 716 & 481 & 784 & .40 & 1.38 & 1.78 & 7.53 \\
\hline 17 & 2 & 346 & 1066 & 803 & 448 & 913 & .90 & 2.90 & 3.80 & 76.32 \\
\hline 18 & 1 & 330 & 996 & 607 & 410 & 737 & 1.20 & 1.80 & 3.00 & 60.00 \\
\hline 18 & 2 & 294 & $105 ?$ & 694 & 379 & 894 & 2.10 & 3.78 & 6.18 & 5.. $1^{?}$ \\
\hline 19 & 1 & 313 & 1084 & 710 & 369 & 888 & 1.20 & 2.30 & 3.50 & 65.71 \\
\hline 19 & 2 & 268 & 1084 & 204 & 336 & 868 & 2.00 & 4.50 & 6.50 & 69.23 \\
\hline 20 & 1 & 334 & 926 & 694 & 484 & 780 & .90 & 3.00 & 3.90 & 76.92 \\
\hline 20 & 2 & 322 & 967 & 710 & 383 & 304 & 1.00 & 3.50 & 4.50 & 77.78 \\
\hline
\end{tabular}


Tabela 15- Caracteristicas dos aneis de crescimento de amos tras de madeira de arvores de Pinus taeda, obtidas atraves de densitonetria de Raios - $\ldots$.

Sitio $=2$ Classe de $D A P=3$ Arvore $=$

\begin{tabular}{|c|c|c|c|c|c|c|c|c|c|c|}
\hline $\begin{array}{l}\text { Idade } \\
\text { (anos) }\end{array}$ & Raio & $\begin{array}{c}\text { Dens. } \\
\text { Min. }(g / d \operatorname{dn} 3)\end{array}$ & $\begin{array}{c}\text { Dens. } \\
\operatorname{Max} .(9 / \mathrm{dn} 3)\end{array}$ & $\begin{array}{l}\text { Dens. } \\
\text { Med. }(g / d n 3)\end{array}$ & $\begin{array}{l}\text { Dens.L.P. } \\
(\mathrm{g} / \mathrm{d} \mathbf{n} 3 \mid\end{array}$ & $\begin{array}{l}\text { Dens.L.O. } \\
|g / d \mathrm{~d} 3|\end{array}$ & $\begin{array}{l}\text { Conp.L.P. } \\
\text { (nD) }\end{array}$ & $\begin{array}{l}\text { Comp.L.O. } \\
\text { (nn) }\end{array}$ & $\begin{array}{c}\text { Comp.Total } \\
\mid \text { nn } \mid\end{array}$ & L.O. \\
\hline 2 & 1 & 265 & 788 & 378 & 334 & 625 & 11.28 & 2.00 & 13.28 & 15.06 \\
\hline 2 & 2 & 274 & 825 & 408 & 336 & 654 & 6.80 & 2.00 & 8.80 & 22.73 \\
\hline 3 & 1 & 300 & 889 & 194 & 355 & 681 & 8.60 & 3.20 & 11.80 & 27.12 \\
\hline 3 & 2 & 305 & 856 & 464 & 355 & 698 & 7.68 & 3.60 & 11.28 & 31.91 \\
\hline 4 & 1 & 294 & 9.57 & 489 & 353 & 738 & 7.00 & 3.80 & 10.80 & 35.19 \\
\hline 4 & 2 & 279 & 918 & 464 & 340 & 726 & 8.00 & 6.80 & 14.80 & 45.95 \\
\hline 5 & 1 & 324 & 1058 & 609 & 391 & 850 & 4.30 & 3.90 & 8.20 & 47.56 \\
\hline 5 & 2 & 345 & 1041 & 591 & 384 & 809 & 4.00 & 6.80 & 10.80 & 62.96 \\
\hline 6 & 1 & 341 & 1081 & 723 & 488 & 873 & 1.70 & 3.60 & 5.30 & 67.92 \\
\hline 6 & 2 & 367 & 1033 & 731 & 429 & 323 & 1.50 & 4.90 & 6.40 & 36.56 \\
\hline 7 & 1 & 411 & 1087 & 752 & 459 & 887 & 1.30 & 2.80 & 4.10 & 68.29 \\
\hline 7 & 2 & 353 & 1047 & 713 & 408 & 838 & 1.92 & 4.70 & 6.62 & 71.00 \\
\hline 8 & 1 & 346 & 1052 & 756 & 404 & 885 & 1.20 & 3.30 & 4.50 & 3.33 \\
\hline 8 & 2 & 336 & 1030 & 769 & 404 & 864 & 1.20 & 4.58 & 5.78 & 79.24 \\
\hline 9 & 1 & 395 & 1076 & 801 & 434 & 904 & 1.12 & 3.98 & 5.10 & 78.04 \\
\hline 9 & 2 & 391 & 1010 & 796 & 441 & 856 & .72 & 4.20 & 4.92 & 85.37 \\
\hline 10 & 1 & 379 & 1081 & 816 & 445 & 919 & 1.02 & 3.70 & 4.72 & 78.39 \\
\hline 10 & 2 & 404 & 928 & 767 & 459 & 741 & .70 & 3.40 & 4.10 & 82.93 \\
\hline 11 & 1 & 406 & 969 & 744 & 453 & 782 & .70 & 5.28 & 5.98 & 88.29 \\
\hline 11 & 2 & 480 & 869 & 735 & 573 & 740 & .20 & 6.18 & 6.38 & 96.87 \\
\hline 12 & 1 & 290 & 1067 & 712 & 368 & 822 & 1.90 & 6.00 & 7.90 & 75.95 \\
\hline 12 & 2 & 308 & 889 & 641 & 370 & 716 & 1.90 & 6.82 & 8.72 & 78.21 \\
\hline 13 & 1 & 342 & 991 & 725 & 383 & 818 & 1.20 & 4.40 & 5.60 & 78.57 \\
\hline 13 & 2 & 305 & 908 & 671 & 362 & 755 & 1.40 & 5.20 & 6.60 & 78.79 \\
\hline 14 & 1 & 319 & 1055 & 744 & 380 & 851 & 1.50 & 5.10 & 6.60 & 77.27 \\
\hline 14 & 2 & 350 & 957 & .07 & 403 & 789 & 1.20 & 4.40 & 5.60 & 3.57 \\
\hline 15 & 1 & 317 & 1069 & 647 & 361 & 857 & 2.72 & 3.70 & 6.42 & 57.63 \\
\hline 15 & 2 & 335 & 860 & 624 & 384 & 698 & 1.20 & 3.90 & 5.10 & 76.47 \\
\hline 16 & 1 & 334 & 1013 & 674 & 377 & 847 & 1.70 & 2.90 & 4.60 & 63.04 \\
\hline 16 & 2 & 337 & 848 & 637 & 389 & 729 & 1.30 & 3.50 & 4.80 & 72.92 \\
\hline 17 & 1 & 353 & 1021 & 732 & 415 & 834 & 1.08 & 3.32 & 4.40 & 75.45 \\
\hline 17 & 2 & 353 & 872 & 660 & 426 & 737 & 1.50 & 4.58 & 6.08 & 75.33 \\
\hline 18 & 1 & 323 & 1085 & 701 & 396 & 874 & 2.40 & 4.20 & 6.60 & 63.64 \\
\hline 18 & 2 & 324 & 959 & 685 & 426 & 812 & 3.10 & 6.30 & 9.10 & 57.02 \\
\hline 19 & 1 & 290 & 977 & 697 & 330 & 836 & 1.50 & 3.98 & 5.48 & 72.63 \\
\hline 19 & 2 & 314 & 959 & 719 & 367 & 821 & 2.80 & 9.70 & 12.50 & 77.60 \\
\hline 20 & 1 & 327 & .975 & 719 & 407 & 817 & 1.10 & 3.50 & 4.60 & 76.09 \\
\hline 20 & 2 & 306 & 1041 & 673 & 384 & 754 & 2.40 & 8.50 & 10.90 & 77.98 \\
\hline
\end{tabular}


Tabela 16-Caracteristicas dos aneis de crescimento de amos tras de madeira de arvores de Pinus taeda, obtidas aträes de densitonetria de Raios - :.

\begin{tabular}{|c|c|c|c|c|c|c|c|c|c|c|}
\hline $\begin{array}{l}\text { Idade } \\
\text { (anos) }\end{array}$ & Ra10 & $\begin{array}{c}\text { Dens. } \\
M \ln .19 / \mathrm{dn} 31\end{array}$ & $\begin{array}{c}\text { Dens } \\
\operatorname{Max} .(9 d \mathrm{dn} 31\end{array}$ & $\begin{array}{l}\text { Dens. } \\
\text { Med. (q/dn3) }\end{array}$ & $\begin{array}{l}\text { Dens.L.P. } \\
|g / \operatorname{dn} 3|\end{array}$ & $\begin{array}{l}\text { Dens.L.0. } \\
|g / \operatorname{dn} 3|\end{array}$ & $\begin{array}{l}\text { Comp.L.P. } \\
\text { (nn) }\end{array}$ & $\begin{array}{l}\text { Comp.L.O. } \\
\text { (nn) }\end{array}$ & $\begin{array}{l}\text { Conp.Total } \\
\text { (nn) }\end{array}$ & $\div$ L.O. \\
\hline 2 & 1 & 239 & 582 & 323 & 281 & 509 & 11.50 & 2.60 & 14.10 & 18.44 \\
\hline 2 & 2 & 234 & 744 & 351 & 286 & 623 & 10.20 & 2.40 & 12.60 & 19.05 \\
\hline 3 & 1 & 255 & 680 & 397 & 307 & 577 & 9.52 & 4.80 & 14.32 & 33.52 \\
\hline 3 & 2 & 257 & iil & 102 & 306 & 619 & 9.10 & 4.00 & 13.10 & 30.53 \\
\hline 4 & 1 & 261 & 762 & 406 & 305 & 645 & 10.38 & 4.40 & 14.78 & 29.77 \\
\hline 4 & 2 & 258 & 905 & 425 & 312 & 205 & 9.20 & 3.70 & 12.90 & 28.68 \\
\hline 5 & 1 & 295 & 907 & 439 & 339 & -30 & 6.80 & 4.20 & 11.00 & 38.18 \\
\hline 5 & 2 & 279 & 979 & 464 & 343 & 835 & 7.30 & 2.40 & 9.70 & 24.74 \\
\hline 5 & 1 & 306 & 1062 & 502 & 350 & 75 & 3.50 & 5.10 & 8.60 & 59.30 \\
\hline 2 & 2 & 315 & 1043 & 660 & 389 & 845 & 2.40 & 3.50 & 5.90 & 59.32 \\
\hline 7 & 1 & 319 & 1111 & 609 & 377 & 830 & 3.90 & 4.10 & 8.00 & 51.25 \\
\hline 7 & 2 & 328 & 1113 & 630 & 383 & 830 & 3.00 & 3.70 & 6.70 & 55.22 \\
\hline 3 & 1 & 313 & 1065 & 665 & 386 & 347 & 2.30 & 4.30 & 7.10 & 60.56 \\
\hline 8 & 2 & 335 & 1051 & 691 & 399 & 777 & 1.40 & 4.70 & 6.10 & 77.05 \\
\hline 9 & 1 & 366 & 1102 & 728 & 440 & 880 & 1.30 & 3.40 & 5.20 & 65.38 \\
\hline 9 & 2 & 340 & 1104 & 741 & 420 & 853 & 1.40 & 4.00 & 5.40 & 74.07 \\
\hline 10 & 1 & 315 & 1093 & 779 & 422 & 378 & 1.20 & 4.30 & 5.50 & .8 .18 \\
\hline 10 & 2 & 307 & 1122 & 829 & 367 & 955 & .90 & 3.30 & 4.20 & 78.57 \\
\hline 11 & 1 & 454 & 1032 & 861 & 806 & 362 & .10 & 6.60 & 6.70 & 98.51 \\
\hline 11 & 2 & 405 & 997 & 762 & 442 & 840 & 1.80 & 7.30 & 9.10 & 80.22 \\
\hline 12 & 1 & 300 & 1021 & 605 & 380 & 779 & 3.90 & 5.00 & 8.90 & 56.18 \\
\hline 12 & 2 & 311 & 1102 & 767 & 383 & 937 & 2.70 & 6.10 & 8.80 & 69.32 \\
\hline 13 & 1 & 377 & 1021 & 702 & 124 & 789 & 2.00 & 6.40 & 8.40 & 76.19 \\
\hline 13 & 2 & 361 & 1111 & 750 & 430 & 857 & 1.50 & 4.50 & 6.00 & 75.00 \\
\hline 14 & 1 & 382 & 1090 & 812 & 415 & 364 & .40 & 3.00 & 3.40 & 38.24 \\
\hline 14 & 2 & 380 & 1093 & 816 & 440 & 925 & .90 & 3.10 & 4.00 & 7.50 \\
\hline 15 & 1 & 344 & 1037 & 722 & 404 & 329 & .30 & 2.10 & 3.20 & 7.00 \\
\hline 15 & 2 & 396 & 1148 & 920 & 452 & 1002 & .60 & 3.40 & 4.00 & 85.00 \\
\hline 16 & 1 & 350 & 1048 & 731 & 39.4 & 355 & .70 & 1.90 & 2.60 & 3.08 \\
\hline 16 & 2 & 368 & 1068 & 749 & 405 & 864 & .90 & 2.70 & 3.60 & 75.00 \\
\hline 17 & 1 & 400 & 1037 & 703 & $4+2$ & 775 & .60 & 2.20 & 2.30 & $73.5^{7}$ \\
\hline 17 & 2 & 393 & 1130 & 865 & 439 & 932 & .50 & 3.20 & 3.70 & 86.49 \\
\hline 18 & 1 & 321 & 1005 & 656 & 396 & 804 & 1.30 & 2.30 & 3.60 & 63.89 \\
\hline 18 & 2 & 337 & 1070 & 751 & 409 & 890 & 1.60 & 3.90 & 5.50 & 70.91 \\
\hline 19 & 1 & 293 & 979 & 651 & 380 & 378 & .00 & 2.10 & 2.90 & 72.41 \\
\hline 19 & 2 & 320 & 1081 & 795 & 361 & 921 & .90 & 3.10 & 4.00 & 77.50 \\
\hline 20 & 1 & 298 & 830 & 570 & 361 & 711 & .60 & .90 & 1.50 & 60.00 \\
\hline 20 & 2 & 280 & 1090 & 755 & 345 & 892 & .70 & 2.10 & 2.80 & 75.00 \\
\hline
\end{tabular}


Tabeia 17-Caracteristicas dos aneis de crescimento de anos tras de madeira de arvores de Pinus taeda, obtidas atraves de densitometria de Raios - .

Sitio=2 Classe de $D A P=4$ irrore $=1$

\begin{tabular}{|c|c|c|c|c|c|c|c|c|c|c|}
\hline $\begin{array}{l}\text { Idade } \\
\text { (anos) }\end{array}$ & Raio & $\begin{array}{l}\text { Dens. } \\
\text { Min. }\{Q d \operatorname{dn} 3\}\end{array}$ & $\begin{array}{l}\text { Dens. } \\
\operatorname{Max.} \mid q ; \operatorname{dn} 3\}\end{array}$ & $\begin{array}{l}\text { Dens. } \\
\text { Med. }\{g / d n\})\end{array}$ & $\begin{array}{l}\text { Dens .L.P. } \\
|q / \operatorname{dan} 3|\end{array}$ & $\begin{array}{l}\text { Dens.L.0. } \\
\mid q / \operatorname{dn} 3\}\end{array}$ & $\begin{array}{l}\text { Conp.L.P. } \\
\text { (nn) }\end{array}$ & $\begin{array}{l}\text { Comp.L.O. } \\
\text { (nn) }\end{array}$ & $\begin{array}{l}\text { Conp. Total } \\
\text { (nn) }\end{array}$ & L.O. \\
\hline 2 & 1 & 309 & 678 & 420 & 355 & 581 & 6.60 & 2.60 & 9.20 & 28.26 \\
\hline 2 & 2 & 307 & 668 & 421 & 362 & 567 & 7.10 & 2.80 & 9.90 & 28.28 \\
\hline 3 & 1 & 304 & 770 & 456 & 369 & 666 & 10.70 & 4.40 & 15.10 & 29.14 \\
\hline 3 & 2 & 316 & 727 & 450 & 374 & 610 & 10.70 & 5.10 & 15.80 & 32.28 \\
\hline 4 & 1 & 302 & 770 & 379 & 379 & 631 & 8.70 & 4.90 & 13.60 & 36.03 \\
\hline 4 & 2 & 353 & 788 & 498 & 404 & 653 & 7.20 & 4.40 & 11.60 & 37.93 \\
\hline 5 & 1 & 345 & 823 & 520 & 396 & 308 & 6.10 & 4.00 & 10.10 & 39.60 \\
\hline 5 & 2 & 417 & 860 & 595 & 457 & 725 & 4.40 & 4.70 & 9.10 & 51.65 \\
\hline 6 & 1 & 104 & 865 & 643 & 376 & 762 & 2.70 & 4.10 & 6.80 & 60.29 \\
\hline 5 & 2 & 360 & 920 & 549 & 481 & 710 & 1.40 & 3.90 & 5.30 & 73.58 \\
\hline 7 & 1 & 407 & 869 & 637 & 460 & 735 & 2.50 & 4.50 & 7.00 & 64.29 \\
\hline 7 & 2 & $\$ 23$ & 911 & 624 & 480 & 746 & 1.70 & 2.00 & 3.30 & 54.05 \\
\hline 8 & 1 & 351 & 837 & 614 & 400 & 705 & 2.00 & 4.70 & 6.70 & 70.15 \\
\hline 8 & 2 & 416 & 892 & 701 & 460 & 751 & .70 & 3.40 & 4.10 & 32.93 \\
\hline 9 & 1 & 382 & 883 & 644 & 428 & 744 & 1.70 & 3.70 & 5.40 & 68.52 \\
\hline 9 & 2 & 442 & 887 & 642 & 634 & 543 & .20 & 2.30 & 2.50 & 92.00 \\
\hline 10 & 1 & 345 & 863 & 652 & 429 & 754 & 1.40 & 3.10 & 4.50 & 68.89 \\
\hline 10 & 2 & 379 & 901 & 536 & 454 & 818 & 1.00 & 1.00 & 2.00 & 50.00 \\
\hline 11 & 1 & 442 & 863 & 728 & 597 & 729 & .10 & 6.70 & 6.80 & 98.53 \\
\hline 11 & 2 & 492 & 914 & 805 & 676 & 807 & .10 & 4.60 & 4.70 & 97.87 \\
\hline 12 & 1 & 347 & 917 & 639 & 412 & 746 & 1.70 & 3.60 & 5.30 & 67.92 \\
\hline 12 & 2 & 363 & 390 & 647 & 416 & 745 & 1.40 & 3.30 & 4.70 & 70.21 \\
\hline 13 & 1 & 377 & 878 & 677 & 450 & 737 & 1.20 & 4.60 & 5.80 & 79.31 \\
\hline 13 & 2 & 399 & 387 & 712 & 494 & 790 & 1.00 & 2.80 & 3.80 & -3.68 \\
\hline 14 & 1 & 496 & 881 & 752 & 831 & 750 & .10 & 3.90 & 4.00 & 97.50 \\
\hline 14 & 2 & $4 \hat{1}$ & 392 & .58 & 690 & 760 & .10 & 3.80 & 3.90 & 47.44 \\
\hline 15 & 1 & 663 & 896 & 685 & 466 & 778 & 1.20 & 2.80 & 4.00 & 70.00 \\
\hline 15 & 2 & 404 & 837 & 652 & 447 & 711 & 1.10 & 3.90 & 5.00 & 8.00 \\
\hline 16 & 1 & 350 & 892 & 587 & 415 & 734 & 1.20 & 1.40 & 2.60 & 53.85 \\
\hline 16 & 2 & 407 & 846 & 639 & 471 & 763 & 1.70 & 2.60 & 4.30 & 60.47 \\
\hline 17 & 1 & 423 & 896 & 743 & 477 & 800 & .60 & 2.80 & 3.40 & 82.35 \\
\hline 17 & 2 & 476 & 917 & 726 & 821 & 721 & .10 & 2.00 & 2.10 & 95.24 \\
\hline 18 & 1 & 335 & 917 & 616 & 402 & 715 & 1.30 & 2.80 & 4.10 & 68.29 \\
\hline 18 & 2 & 420 & 911 & 712 & 467 & 769 & .70 & 3.10 & 3.80 & 31.58 \\
\hline 19 & 1 & 286 & 907 & 679 & 364 & 796 & 1.20 & 3.20 & 4.40 & 72.73 \\
\hline 19 & 2 & 366 & 387 & 740 & 455 & 835 & 1.30 & 3.90 & 5.20 & 75.00 \\
\hline 20 & 1 & 409 & 839 & 684 & 485 & 783 & .90 & 1.80 & 2.70 & 66.67 \\
\hline 20 & 2 & 414 & 831 & 721 & 493 & 771 & .90 & 4.20 & 5.10 & 32.35 \\
\hline
\end{tabular}


Iabela 18-Caracteristicas dos aneis de crescinento de amos tras de madeira de arvores de Pinus taeda, obtidas atraves de densitonetria de Raios - $\because$.

\begin{tabular}{|c|c|c|c|c|c|c|c|c|c|c|}
\hline $\begin{array}{l}\text { Idade } \\
\text { (anos })\end{array}$ & Raio & $\begin{array}{l}\text { Dens. } \\
\text { Min. }(g / d n 3)\end{array}$ & $\begin{array}{l}\text { Dens. } \\
\operatorname{Max} .(\mathrm{g} / \mathrm{d} \mathbf{n} 3)\end{array}$ & $\begin{array}{l}\text { Dens. } \\
\text { Med. }(9 ; \mathrm{d} \text { (n) }\end{array}$ & $\begin{array}{l}\text { Dens.L.P. } \\
(\mathrm{g} / \mathrm{d} \mathrm{n} 3 \mid\end{array}$ & $\begin{array}{l}\text { Dens.L.0. } \\
(\mathrm{g} / \mathrm{d} \mathbf{n} 3)\end{array}$ & $\begin{array}{l}\text { Comp.L.P. } \\
\text { (nn) }\end{array}$ & $\begin{array}{l}\text { Conp.L.O. } \\
\text { (nn) }\end{array}$ & $\begin{array}{l}\text { Coap.Total } \\
\text { [Dn] }\end{array}$ & $\therefore 1.0$ \\
\hline 3 & 1 & 362 & 679 & 524 & 508 & 530 & 2.70 & 8.50 & 11.20 & 5.89 \\
\hline 3 & 2 & 389 & 830 & 583 & 467 & 629 & 3.70 & 9.40 & 13.10 & 71.76 \\
\hline 4 & 1 & 309 & 683 & 456 & 385 & 580 & 9.20 & 5.20 & 14.40 & 36.11 \\
\hline$f$ & 2 & 430 & 864 & 650 & 467 & 719 & 2.60 & 6.80 & 9.40 & -2.34 \\
\hline 5 & 1 & 354 & 798 & 543 & 397 & 678 & 5.20 & 5.60 & 10.80 & 51.85 \\
\hline 5 & 2 & 451 & 919 & 704 & 648 & 705 & .10 & 5.00 & 5.10 & 98.04 \\
\hline 6 & 1 & 753 & 784 & 620 & 379 & 643 & .80 & 5.30 & 6.10 & 86.89 \\
\hline 6 & 2 & $\{25$ & 945 & 688 & 481 & 737 & .60 & 2.60 & 3.20 & 31.25 \\
\hline 7 & 1 & 110 & 821 & 625 & 445 & 700 & 1.80 & 4.30 & 6.10 & 70.49 \\
\hline 7 & 2 & 413 & 919 & 726 & 477 & 7066 & .50 & 3.10 & 3.60 & 36.11 \\
\hline 8 & 1 & 400 & 767 & 626 & 381 & 656 & 1.20 & 6.10 & 7.30 & ô. 56 \\
\hline 3 & 2 & 374 & 953 & 706 & 428 & 808 & .70 & 1.90 & 2.60 & 3.08 \\
\hline 9 & 1 & 375 & 924 & 720 & 457 & 757 & .60 & 4.30 & 4.90 & 87.76 \\
\hline 9 & 2 & 396 & 891 & 721 & 484 & 762 & .30 & 4.00 & 4.70 & 35.11 \\
\hline 10 & 1. & 400 & 854 & 708 & 455 & 746 & .80 & 5.30 & 6.10 & 86.89 \\
\hline 10 & 2 & 421 & 914 & 648 & 390 & 702 & 1.30 & $4 \cdot 00$ & 5.30 & 75.47 \\
\hline 11 & 1 & 505 & 823 & 719 & 685 & 720 & .10 & 7.30 & 7.40 & 98.65 \\
\hline 11 & 2 & 439 & 948 & 762 & 493 & 829 & .50 & 2.00 & 2.50 & 30.00 \\
\hline 12 & 1 & 396 & 867 & 609 & 445 & 702 & 2.00 & 3.50 & 5.50 & 63.64 \\
\hline 12 & 2 & 356 & 875 & 717 & 532 & 792 & .90 & 2.20 & 3.10 & 70.97 \\
\hline 13 & 1 & 478 & 878 & 719 & 694 & 719 & .10 & 5.40 & 5.50 & 98.18 \\
\hline 13 & 2 & 388 & 829 & 698 & 528 & 721 & .40 & 2.90 & 3.30 & 87.88 \\
\hline 14 & 1 & 353 & 873 & $i 11$ & 762 & 771 & .10 & 3.50 & 3.60 & 97.22 \\
\hline 14 & 2 & 328 & 796 & 630 & 424 & 712 & .80 & 2.00 & 2.80 & 71.43 \\
\hline 15 & 1 & 432 & 811 & 694 & 501 & 728 & .80 & $4 \cdot 50$ & 5.30 & 84.91 \\
\hline 15 & 2 & 345 & 830 & 600 & 417 & $\lceil 15$ & 1.50 & 2.40 & 3.90 & 51.54 \\
\hline 16 & 1 & 407 & 847 & 651 & 447 & 715 & 1.10 & 3.60 & 4.70 & 76.60 \\
\hline 16 & 2 & 413 & 816 & 691 & $\$ 72$ & 735 & .30 & 4.00 & 4.80 & 33.33 \\
\hline 17 & 1 & $\$ 21$ & 823 & 698 & 587 & 702 & .20 & 7.00 & 7.20 & 97.22 \\
\hline 17 & 2 & 327. & 804 & 565 & 398 & 668 & 2.40 & 3.90 & 6.30 & 61.90 \\
\hline 18 & 1 & 396 & 847 & 656 & 451 & 694 & .80 & 4.30 & 5.10 & 84.31 \\
\hline 13 & 2 & 312 & 755 & 539 & 389 & 711 & 1.60 & 1.40 & 3.00 & 46.67 \\
\hline 19 & 1 & 370 & 870 & 709 & 431 & 746 & .80 & 5.80 & 6.60 & 37.88 \\
\hline 20 & 1 & +28 & 805 & 575 & 469 & 683 & 2.90 & 2.90 & 5.80 & 50.00 \\
\hline
\end{tabular}


Tabela 19-Caracteristicas dos aneis de crescinento de anos tras de nadeira de arvores de Pinus taeda, obtidas atraves de densitonetria de Raios - $Y$.

\begin{tabular}{|c|c|c|c|c|c|c|c|c|c|c|}
\hline $\begin{array}{l}\text { Idade } \\
\text { (anos) }\end{array}$ & Ra1o & $\begin{array}{c}\text { Dens. } \\
\text { M1n.1g:dm } 31\end{array}$ & $\begin{array}{l}\text { Dens. } \\
\operatorname{Max} .19, \mathrm{dm} 31\end{array}$ & $\begin{array}{l}\text { Dens. } \\
\text { Med. }(9 / \mathrm{d} 3)\end{array}$ & $\begin{array}{l}\text { Dens. L.P. } \\
|q / \operatorname{dm} 3|\end{array}$ & $\begin{array}{c}\text { Dens.L.O. } \\
|\mathrm{g} / \mathrm{dm} 3|\end{array}$ & $\begin{array}{c}\text { Conp.L.P. } \\
\text { (吅) }\end{array}$ & $\begin{array}{c}\text { Conp.L. O. } \\
\text { (ani) }\end{array}$ & $\begin{array}{c}\text { Conp. Total } \\
\text { (هi) }\end{array}$ & L.o. \\
\hline 2 & 1 & 300 & 625 & 387 & 343 & 557 & 7.60 & 2.00 & 9.60 & 20.83 \\
\hline 2 & 2 & 226 & 637 & 362 & 319 & 553 & 7.50 & 1.70 & 9.20 & 15.48 \\
\hline 3 & 1 & 291 & 683 & 435 & 353 & 592 & 7.90 & 4.10 & 12.00 & 34.17 \\
\hline 3 & 2 & 291 & 678 & 440 & 367 & 588 & 6.70 & 3.30 & 10.00 & 33.00 \\
\hline 4 & 1 & 285 & 715 & 438 & 337 & 612 & 7.60 & 4.40 & 12.00 & 36.67 \\
\hline 4 & 2 & 287 & 708 & 468 & 349 & 619 & 4.70 & 3.70 & 8.40 & 14.05 \\
\hline 5 & 1 & 322 & 749 & 504 & 378 & 641 & 5.80 & 5.40 & 11.20 & 48.21 \\
\hline 5 & 2 & 337 & 711 & 510 & 380 & 608 & 5.00 & 6.60 & 11.60 & 56.90 \\
\hline 6 & 1 & 362 & 761 & 596 & 414 & 679 & 1.00 & 2.20 & 3.20 & 68.75 \\
\hline 0 & 2 & 373 & 753 & 555 & 435 & 619 & 2.00 & 4.00 & 6.00 & 56.67 \\
\hline 7 & $i$ & 382 & 774 & 607 & 425 & 698 & .90 & 1.80 & 2.70 & 60.67 \\
\hline 7 & 2 & 390 & 803 & 615 & 433 & 676 & 1.30 & 3.90 & 5.20 & 7.00 \\
\hline 8 & 1 & 339 & 719 & 580 & 414 & 666 & 1.40 & 2.70 & 4.10 & 65.85 \\
\hline 8 & 2 & 358 & 763 & 583 & 400 & 634 & 1.50 & 5.40 & 6.90 & 8.26 \\
\hline 9 & 1 & 383 & 800 & 644 & 435 & 711 & .70 & 2.20 & 2.90 & 75.86 \\
\hline 9 & 2 & 377 & 789 & 609 & 417 & 675 & 1.50 & 4.30 & 5.80 & 74.14 \\
\hline 10 & 1 & 407 & 771 & 635 & 462 & 676 & .40 & 1.70 & 2.10 & 80.95 \\
\hline 10 & 2 & 362 & 744 & 614 & $\$ 22$ & 670 & .70 & 2.40 & 3.10 & 77.42 \\
\hline 11 & 1 & 431 & 689 & 601 & 594 & 601 & .20 & 6.60 & 6.80 & 97.06 \\
\hline 11 & 2 & 388 & 696 & 596 & 424 & 619 & .80 & 3.90 & 4.70 & 82.98 \\
\hline 12 & 1 & 293 & 739 & 562 & 347 & 626 & 2.00 , & 6.80 & 8.80 & -27 \\
\hline 12 & 2 & 280 & 724 & 538 & 352 & 631 & 2.50 & 5.00 & 7.50 & 66.67 \\
\hline 13 & 1 & 362 & 759 & 606 & 408 & 679 & 1.40 & 3.80 & 5.20 & 73.08 \\
\hline 13 & 2 & $35 ?$ & 731 & 611 & 392 & 663 & 1.30 & 5.50 & 6.80 & 80.88 \\
\hline 11 & 1 & 438 & 731 & 623 & 473 & 656 & .60 & 2.70 & 3.30 & 21.82 \\
\hline 14 & 2 & 400 & 751 & 624 & 438 & 658 & .60 & 3.30 & 3.90 & 84.62 \\
\hline 15 & 1 & 354 & 722 & 562 & 443 & $6 \div 2$ & .60 & .90 & 1.50 & 50.00 \\
\hline 15 & 2 & $\$ 11$ & 766 & 610 & 437 & 658 & .60 & 2.20 & 2.80 & 78.57 \\
\hline 16 & 1 & 351 & 699 & 556 & 391 & 509 & .60 & 1.90 & 2.50 & -5.00 \\
\hline 16 & 2 & 359 & 749 & 576 & 387 & 654 & 1.00 & 2.40 & 3.40 & 70.59 \\
\hline 17 & 1 & 323 & 749 & 613 & 441 & 632 & .50 & 4.60 & 5.10 & 0.20 \\
\hline 17 & 2 & 440 & 766 & 380 & 479 & 678 & .40 & 2.30 & 2.70 & 85.19 \\
\hline 18 & 1 & 337 & 722 & 575 & 403 & 628 & 2.20 & 7.00 & 9.20 & 76.09 \\
\hline 18 & 2 & 353 & 800 & 633 & 402 & 693 & .90 & 3.50 & 4.40 & 79.55 \\
\hline 19 & 1 & 322 & 737 & 576 & 353 & 667 & 1.50 & 3.70 & 5.20 & 71.15 \\
\hline 19 & 2 & 341 & 787 & 654 & 379 & 721 & 1.00 & 4.10 & 5.10 & 80.39 \\
\hline 20 & 1 & 334 & 860 & 575 & 400 & 645 & 1.30 & 3.20 & 4.50 & 71.11 \\
\hline 20 & 2 & 324 & 734 & 568 & 386 & 664 & 1.00 & 1.90 & 2.90 & 65.52 \\
\hline
\end{tabular}


Tabela 20-Caracteristicas dos aneis de crescinento de anos tras de nadeira de arvores de Pinus taeda, obtidas atraves de densitonetria de Raios -

Sitio=2 Classe de D!P=5 : $:$ :ore $=2$

\begin{tabular}{|c|c|c|c|c|c|c|c|c|c|c|}
\hline $\begin{array}{l}\text { Idade } \\
\text { (anos } \mid\end{array}$ & Raio & $\begin{array}{c}\text { Dens. } \\
\operatorname{Min} .(9 . \mathrm{dn} 3)\end{array}$ & $\begin{array}{l}\text { Dens. } \\
\operatorname{Max} \cdot\{Q \cdot \operatorname{dn} 3\}\end{array}$ & $\begin{array}{l}\text { Dens. } \\
\text { Med. } \mid \mathrm{a} \text { dn3 } 1\end{array}$ & $\begin{array}{l}\text { Dens.L.P. } \\
|q / d n 3|\end{array}$ & $\begin{array}{l}\text { Dens.L.O. } \\
\left|g_{i} \mathrm{dn} 3\right|\end{array}$ & $\begin{array}{l}\text { Conp.L.P. } \\
\text { (nD) }\end{array}$ & $\begin{array}{l}\text { Conp.L.O. } \\
\text { (DD) }\end{array}$ & $\underset{\text { (DD) }}{\text { Cogp.Total }}$ & $\because$ L.O. \\
\hline 2 & 1 & 272 & 685 & 431 & 372 & 553 & 5.60 & 2.70 & 8.30 & 32.53 \\
\hline 2 & 2 & 307 & 583 & 453 & 392 & 537 & 3.40 & 6.00 & 14.40 & $41.6 ?$ \\
\hline 3 & 1 & 326 & 709 & 487 & 396 & 615 & 6.40 & 4.50 & 10.90 & 41.28 \\
\hline 3 & 2 & 375 & 7ol & 565 & 443 & 601 & 2.60 & 8.70 & 11.30 & -6.99 \\
\hline 4 & 1 & 322 & 756 & 478 & 381 & 637 & $\because 10$ & 4.30 & 11.40 & 37.72 \\
\hline 4 & 2 & 335 & 851 & 582 & 439 & 678 & 4.90 & 7.20 & 12.10 & 59.50 \\
\hline 5 & 1 & 380 & 012 & 565 & 414 & 640 & 3.40 & 6.80 & 10.20 & 56.67 \\
\hline 5 & 2 & 418 & 383 & 643 & 458 & 688 & 2.20 & 9.10 & 11.30 & 30.53 \\
\hline 6 & 1 & 469 & 637 & 685 & 643 & 677 & .10 & 4.80 & 4.90 & a?. 96 \\
\hline 6 & 2 & 506 & 914 & 783 & 739 & 784 & .10 & 5.90 & 5.00 & 28.33 \\
\hline 7 & 1 & 477 & 800 & 655 & 692 & 654 & .10 & 3.10 & 3.20 & 96.88 \\
\hline$?$ & 2 & 514 & 919 & 778 & 656 & 31 & .10 & 4.10 & 1.20 & 9? 62 \\
\hline 8 & 1 & 171 & olt & 682 & 610 & 685 & .10 & 2.70 & 2.80 & 96.43 \\
\hline 8 & 2 & 508 & 398 & $7 i 2$ & 793 & 772 & .10 & 3.90 & 4.00 & 97.50 \\
\hline 9 & 1 & 500 & 795 & 653 & 624 & 655 & .10 & 1.80 & 1.90 & 94.74 \\
\hline 9 & 2 & 504 & 868 & 737 & 728 & 738 & .10 & 3.90 & 4.00 & 97.50 \\
\hline 10 & 1 & 466 & 771 & 651 & 707 & 648 & $.10^{\circ}$ & 1.60 & 1.70 & 94.12 \\
\hline 10 & 2 & 521 & 830 & 739 & 649 & 745 & .10 & 1.50 & 1.60 & 93.75 \\
\hline 11 & 1 & 490 & 812 & 767 & 708 & 769 & .10 & 3.10 & 3.20 & 06.88 \\
\hline 11 & 2 & 504 & 863 & 771 & 634 & 777 & .10 & 2.30 & 2.10 & 95.83 \\
\hline 12 & 1 & 422 & 904 & 714 & 468 & 757 & $.70^{\prime}$ & 4.00 & 4.70 & 35.11 \\
\hline 12 & 2 & 456 & 868 & 728 & 891 & 722 & .10 & 2.70 & 2.80 & 96.43 \\
\hline 13 & 1 & 456 & 837 & 656 & 592 & 659 & .10 & 3.30 & 3.40 & 97.06 \\
\hline 13 & 2 & 517 & 830 & 743 & 766 & $7+2$ & .10 & 2.70 & 2.80 & 96.43 \\
\hline 14 & 1 & 506 & 886 & 821 & 822 & 821 & .10 & 1.70 & 1.80 & 44.44 \\
\hline 14 & 2 & 542 & 830 & 18 & 300 & 14 & .10 & 2.20 & 2.30 & 9.65 \\
\hline 15 & 1 & 451 & 339 & 714 & 566 & $: 22$ & .10 & 1.80 & 1.90 & $\$ 4.74$ \\
\hline 15 & 2 & 464 & $0+2$ & $i 28$ & 747 & 728 & .10 & 3.40 & 3.50 & 97.14 \\
\hline 16 & 1 & 430 & 910 & 03 & 481 & 778 & .60 & 1.80 & 2.40 & -5.00 \\
\hline 16 & 2 & 428 & 837 & 690 & 509 & 753 & .90 & 2.60 & 3.50 & 74.29 \\
\hline 17 & 1 & 515 & 939 & 778 & 619 & 784 & .10 & 2.50 & 2.60 & 96.15 \\
\hline 17 & 2 & 481 & 817 & 733 & 791 & 730 & .10 & 2.60 & 2.70 & 96.30 \\
\hline 18 & 1 & 190 & 904 & 758 & 601 & 762 & .10 & 3.30 & 3.40 & 97.06 \\
\hline 18 & 2 & 430 & 812 & 678 & 498 & 709 & .60 & 3.60 & 4.20 & 0.5 .71 \\
\hline 19 & 1 & 374 & 898 & 751 & 417 & 818 & .80 & 4.00 & 4.80 & 83.33 \\
\hline 19 & 2 & 400 & 837 & 690 & 464 & 726 & .60 & 3.80 & 4.40 & 36.36 \\
\hline 20 & 1 & 383 & 845 & 694 & 452 & 752 & .80 & 3.30 & 4.10 & 80.49 \\
\hline 20 & 2 & 415 & 817 & 667 & 502 & 728 & .60 & 1.60 & 2.20 & 2.73 \\
\hline
\end{tabular}


Tabela 21-Caracteristicas aedias dos aneis de crescinento de anostras de nadeira de arvores de Pinus taeda, obtidas atraves da densitometria de Raios - $\because$.

Sitio=2 Classe de $D ! P=1$ ?.rvore $=1$

\begin{tabular}{|c|c|c|c|c|c|c|c|c|c|}
\hline $\begin{array}{l}\text { Idade } \\
\text { (anos) }\end{array}$ & $\begin{array}{l}\text { Dens. } \\
\text { Min. }(g / d n 3)\end{array}$ & $\begin{array}{l}\text { Dens. } \\
\operatorname{Max.}(g: d m 3)\end{array}$ & $\begin{array}{l}\text { Dens. } \\
\text { Med. }\left(g / d d^{2}\right)\end{array}$ & $\begin{array}{c}\text { Dens.L.P. } \\
(g / \operatorname{do} 3)\end{array}$ & $\begin{array}{c}\text { Dens.L.O. } \\
(g / d \operatorname{di} \mid\end{array}$ & $\begin{array}{l}\text { Conp.L.P. } \\
\mid \operatorname{ma|}\end{array}$ & $\begin{array}{l}\text { Conp.L.O. } \\
\text { (aII) }\end{array}$ & $\begin{array}{l}\text { Conp. Total } \\
\text { (n⿴囗十) }\end{array}$ & L.O. \\
\hline$i$ & 240 & 672 & 359 & 306 & 577 & 10.05 & 2.45 & 12.50 & 19.665 \\
\hline 3 & 240 & 776 & 381 & 293 & 678 & 11.40 & 3.45 & 14.85 & 23.025 \\
\hline 4 & 235 & 791 & 350 & 275 & 649 & 11.30 & 2.85 & 14.15 & 20.130 \\
\hline 5 & 235 & 804 & 367 & 282 & 651 & 9.05 & 2.70 & 11.75 & 22.900 \\
\hline 6 & 282 & 916 & 451 & 337 & 763 & 3.65 & 2.15 & 5.80 & 37.145 \\
\hline 7 & 247 & 958 & 456 & 319 & 750 & 4.35 & 2.05 & 6.40 & 32.005 \\
\hline 8 & 236 & 954 & 497 & 308 & 748 & 4.40 & 3.30 & 7.70 & 43.310 \\
\hline 9 & $24 ?$ & 1007 & 540 & 440 & 875 & 3.80 & 2.50 & 6.30 & 39.620 \\
\hline 10 & 270 & 983 & 583 & 319 & 827 & 2.90 & 2.60 & 5.50 & 49.465 \\
\hline il & 273 & 9.45 & 610 & 321 & 769 & 3.25 & 5.90 & 9.15 & 54.465 \\
\hline 12 & 241 & 928 & 528 & 318 & 755 & 5.15 & 4.75 & 9.90 & 48.005 \\
\hline 13 & 279 & 847 & 553 & 357 & 724 & 4.55 & 5.20 & 9.75 & 53.365 \\
\hline 14 & 325 & 870 & 621 & 393 & 699 & 2.15 & 6.15 & 8.30 & 74.175 \\
\hline 15 & 277 & 335 & 523 & 337 & 688 & 3.35 & 3.80 & 7.15 & 53.080 \\
\hline 16 & 280 & 825 & 503 & 364 & 675 & 4.55 & 2.91 & 7.46 & 39.230 \\
\hline 17 & 322 & 752 & 522 & 375 & 641 & 3.29 & 3.75 & 7.04 & 54.180 \\
\hline 18 & 278 & 781 & 468 & 329 & 650 & 4.80 & 3.85 & $8: 65$ & 43.835 \\
\hline 19 & 270 & 854 & 560 & 326 & 680 & 3.05 & 5.95 & 9.00 & 56.125 \\
\hline \multirow[t]{2}{*}{20} & 281 & 780 & 519 & 358 & 669 & 4.05 & 4.55 & 8.60 & 52.305 \\
\hline & & & & \multicolumn{6}{|c|}{, } \\
\hline $\begin{array}{l}\text { ?nel de } \\
\text { escimento }\end{array}$ & $\begin{array}{l}\text { Dens. } \\
\text { Min.|gidn } 31\end{array}$ & 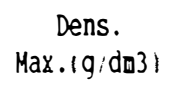 & $\begin{array}{c}\text { Dens. } \\
\text { Med. }(g / d a)\end{array}$ & $\begin{array}{l}\text { Dens.L.P. } \\
|\mathrm{g} / \mathrm{dm} 3|\end{array}$ & $\begin{array}{c}\text { Dens.L.O. } \\
|g / d \operatorname{do} 3|\end{array}$ & $\begin{array}{l}\text { Conp.L.P. } \\
|\ln |\end{array}$ & $\begin{array}{c}\text { Conp.L.O. } \\
\text { Iani }\end{array}$ & $\begin{array}{c}\text { Conp. Total } \\
\text { (QB) }\end{array}$ & L.O. \\
\hline 2 & 218 & 557 & 311 & 280 & 475 & 15.55 & 3.20 & 18.75 & 16.635 \\
\hline 3 & 236 & $6+5$ & 332 & 282 & 567 & 15.25 & 3.25 & 18.50 & 17.540 \\
\hline 4 & 235 & 659 & 332 & 277 & 536 & 14.05 & 3.80 & 17.85 & 21.235 \\
\hline 5 & 260 & 736 & 355 & 298 & 618 & 13.80 & 2.95 & 16.75 & 18.070 \\
\hline ó & 277 & 880 & 487 & 336 & 726 & 5.00 & 3.15 & 8.15 & 38.650 \\
\hline$i$ & 272 & 927 & 466 & 329 & 711 & 5.35 & 3.00 & 8.35 & 35.890 \\
\hline 8 & 267 & 921 & 587 & 343 & 726 & 2.90 & 5.10 & 8.00 & 63.890 \\
\hline 9 & 292 & 954 & 609 & 378 & 783 & 3.25 & 4.15 & 7.40 & 56.765 \\
\hline 10 & 279 & 936 & 624 & 342 & 754 & 2.05 & 3.20 & 5.25 & 61.510 \\
\hline 11 & 320 & 916 & 612 & 374 & 755 & 4.00 & 5.60 & 9.60 & 60.525 \\
\hline 12 & 300 & 938 & 598 & 352 & 747 & 2.65 & 3.90 & 6.55 & 61.570 \\
\hline 13 & 295 & 851 & 550 & 340 & 694 & 2.05 & 3.10 & 5.15 & 63.220 \\
\hline 14 & 331 & 840 & 622 & 376 & 687 & 0.95 & 3.30 & 4.25 & 78.430 \\
\hline 15 & 285 & 885 & 583 & 341 & 754 & 2.05 & 2.85 & 4.90 & 57.885 \\
\hline 16 & 295 & 853 & 534 & 349 & 720 & 2.20 & 1.85 & 4.05 & 48.595 \\
\hline 17 & 296 & 903 & 592 & 375 & 760 & 1.50 & 1.95 & 3.45 & 56.055 \\
\hline 18 & 273. & 9.17 & 535 & 330 & 757 & 2.20 & 2.05 & 4.25 & 48.170 \\
\hline 19 & 272 & 868 & 600 & 343 & 761 & 1.05 & 1.60 & 2.65 & 61.290 \\
\hline 20 & 267 & 799 & 540 & 345 & 721 & 1.40 & 1.65 & 3.05 & 52.555 \\
\hline
\end{tabular}


Tabela 22-Caracteristicas nedias dos aneis de crescinento de anostras de nadeira de arvores de pinus taeda, obtidas atraies da densitometria de Raios - ?..

Sitio $=2$ Classe de DAP $=2$ Arrore $=1$

\begin{tabular}{|c|c|c|c|c|c|c|c|c|c|}
\hline $\begin{array}{l}\text { Idade } \\
\text { Ianos। }\end{array}$ & $\begin{array}{l}\text { Dens. } \\
\text { Min. }(g / \operatorname{dn} 3)\end{array}$ & $\begin{array}{l}\text { Dens. } \\
\text { Max. }(\mathrm{g}: \mathrm{dn} 31\end{array}$ & $\begin{array}{l}\text { Dens. } \\
\text { Med. }(g ; d m 3)\end{array}$ & $\begin{array}{l}\text { Dens.L.P. } \\
(g / d m 3)\end{array}$ & $\begin{array}{l}\text { Dens. L. } 0 . \\
\mid \mathrm{g} / \mathrm{dm} 31\end{array}$ & $\begin{array}{l}\text { Conp.L.P. } \\
\mid \text { (DI) }\end{array}$ & $\begin{array}{l}\text { Conp.L.O. } \\
\text { (ma) }\end{array}$ & $\begin{array}{l}\text { Conp.Total } \\
\text { (n⿴囗十) }\end{array}$ & $\because$ L.O. \\
\hline 2 & 268 & 681 & 387 & 311 & 561 & 7.35 & 3.25 & 10.60 & 30.575 \\
\hline 3 & 226 & 651 & 368 & 282 & 558 & 11.79 & 5.31 & 17.10 & 31.125 \\
\hline 4 & 220 & 711 & 390 & 291 & 623 & 9.29 & 3.90 & 13.19 & 29.705 \\
\hline 5 & 258 & o12 & 453 & 316 & 678 & 7.85 & 4.75 & 12.60 & 37.650 \\
\hline 5 & 303 & 854 & 560 & 357 & 707 & 3.45 & 4.65 & 8.10 & 57.590 \\
\hline 7 & 294 & 800 & 510 & 350 & 667 & 3.75 & 2.45 & 6.20 & 37.230 \\
\hline$\delta$ & 272 & 818 & 535 & 334 & 697 & 3.25 & 4.05 & 7.30 & 55.495 \\
\hline 9 & 305 & 882 & 569 & 362 & 750 & 3.15 & 3.60 & 6.75 & 53.355 \\
\hline 10 & 277 & 885 & 563 & 337 & 757 & 2.45 & 2.85 & 5.30 & 53.775 \\
\hline 11 & 324 & 928 & 647 & 368 & 789 & 2.25 & 4.46 & 5.71 & 56.115 \\
\hline 12 & 299 & 855 & 566 & 344 & 733 & 2.90 & 3.90 & 6.80 & 56.880 \\
\hline 13. & 283. & 344 & 568 & 356 & 720 & 2.80 & 4.19 & 6.99 & 58.715 \\
\hline 14 & 352 & 920 & 691 & 405 & 805 & 1.50 & 3.75 & 5.25 & 1.530 \\
\hline 15 & 294 & 893 & 531 & 341 & 720 & 2.65 & 2.75 & 5.40 & 50.320 \\
\hline 16 & 297 & 868 & 577 & 380 & 757 & 2.35 & 1.59 & 3.94 & 33.225 \\
\hline 17 & 289 & 879 & 588 & 368 & 747 & 1.66 & 2.30 & 3.96 & 58.075 \\
\hline 18 & 277 & 893 & 565 & 333 & 780 & 2.00 & 2.20 & 4.20 & 52.160 \\
\hline 19 & 267 & 901 & 565 & 336 & 760 & 2.00 & 2.29 & 4.29 & 53.845 \\
\hline 20 & 305 & 879 & 596 & 353 & 788 & 1.64 & 2.10 & 3.74 & 55.735 \\
\hline
\end{tabular}

\begin{tabular}{|c|c|c|c|c|c|c|c|c|c|}
\hline $\begin{array}{l}\text { Idade } \\
\text { lanos। }\end{array}$ & $\begin{array}{l}\text { Dens. } \\
\text { Min. }(g / d \operatorname{dm} 3)\end{array}$ & $\begin{array}{l}\text { Dens. } \\
\operatorname{Max.}(g / d \operatorname{dn} 31\end{array}$ & $\begin{array}{l}\text { Dens. } \\
\text { Med. }|\mathrm{g} / \mathrm{dm} 3|\end{array}$ & $\begin{array}{l}\text { Dens.L.P: } \\
|g / \operatorname{don} 3|\end{array}$ & $\begin{array}{l}\text { Dens.L.O. } \\
(g / \operatorname{dm} 3)\end{array}$ & $\begin{array}{l}\text { Conp.L.P. } \\
(\mathbb{m})\end{array}$ & $\begin{array}{l}\text { Conp.L.0. } \\
\text { (am) }\end{array}$ & $\begin{array}{l}\text { Conp.Total } \\
\text { (at) }\end{array}$ & L.O. \\
\hline 2 & 272 & 684 & 378 & 327 & 593 & 9.80 & 2.30 & 12.10 & 19.075 \\
\hline 3 & 289 & .24 & 422 & 352 & 558 & 10.40 & 6.00 & 16.40 & 36.145 \\
\hline 4 & 275 & 845 & 444 & 473 & 653 & 10.15 & 4.46 & 14.61 & 30.500 \\
\hline 5 & 318 & 886 & 529 & 366 & 704 & 5.30 & 4.95 & 10.25 & 48.230 \\
\hline 6 & 341 & 978 & 644 & 401 & 782 & 2.70 & 4.85 & 7.55 & 64.050 \\
\hline 7 & 347 & 1014 & 621 & 395 & .779 & 2.66 & 3.79 & 6.45 & 58.805 \\
\hline 8 & 416 & 984 & 736 & 559 & 786 & 0.86 & 4.45 & 5.31 & 84.745 \\
\hline 9 & 359 & 1036 & 701 & 417 & 861 & 1.85 & 3.20 & 5.05 & 64.890 \\
\hline 10 & 349 & 969 & 573 & 413 & 803 & 1.10 & 3.44 & 4.54 & 75.555 \\
\hline i1 & 392 & 957 & 708 & 454 & 786 & 1.74 & 5.60 & 7.34 & 77.960 \\
\hline 12 & 289 & 962 & 620 & 370 & 773 & 3.30 & 5.50 & 8.80 & 62.170 \\
\hline 13 & 398 & 909 & 594 & 378 & 736 & 3.15 & 4.85 & 8.00 & 60.585 \\
\hline 14 & 343 & 899 & $: 15$ & 408 & 766 & 0.81 & 5.00 & 5.81 & 85.855 \\
\hline 15 & 344 & 945 & 647 & 400 & 740 & 1.25 & 3.36 & 4.61 & 72.650 \\
\hline 16 & 323 & 990 & 646 & 383 & 780 & 1.35 & 2.50 & 3.85 & 65.850 \\
\hline 17 & 388 & 1042 & 759 & 465 & 848 & 0.65 & 2.14 & 2.79 & 76.925 \\
\hline 18 & 312 & 1026 & 650 & 395 & 816 & 1.80 & 2.79 & 4.59 & 60.585 \\
\hline 19 & 290 & 1084 & 707 & 353 & 878 & 1.60 & 3.40 & 5.00 & 67.470 \\
\hline 20 & 328 & 947 & 702 & 434 & 792 & 0.95 & 3.25 & 4.20 & 77.350 \\
\hline
\end{tabular}


Tabela 23-Caracteristicas nedias dos aneis de crescinento de anostras de nadeira de arvores de pinus taeda, obtidas atraves da densitometria de Raios - $x$.

Sitio $=2$ Classe de $D 3 P=3$ :r:rore $=1$

\begin{tabular}{|c|c|c|c|c|c|c|c|c|c|}
\hline $\begin{array}{l}\text { Idade } \\
\text { (anos) }\end{array}$ & $\begin{array}{c}\text { Dens. } \\
\text { Min. }(g / \operatorname{dn} 3)\end{array}$ & $\begin{array}{c}\text { Dens. } \\
\text { Max. }(9 \mathrm{dm} 3)\end{array}$ & $\begin{array}{c}\text { Dens. } \\
\text { Med. }(g / d \operatorname{do} 3)\end{array}$ & $\begin{array}{l}\text { Dens.L.P. } \\
(\mathrm{g} / \mathrm{d} \mathrm{d} 3)\end{array}$ & $\begin{array}{l}\text { Dens.L.O. } \\
(\mathrm{g} / \mathrm{dm} 3)\end{array}$ & $\begin{array}{l}\text { Conp.L.P. } \\
\text { (an) }\end{array}$ & $\begin{array}{l}\text { Conp.L.O. } \\
\text { (an) }\end{array}$ & $\begin{array}{l}\text { Conp.Total } \\
\text { (Do) }\end{array}$ & L.O. \\
\hline 2 & 269 & 807 & 393 & 335 & 639 & 9.04 & 2.00 & 11.04 & 18.895 \\
\hline 3 & 302 & 372 & 454 & 355 & 690 & 8.14 & 3.40 & 11.54 & 29.515 \\
\hline f & 286 & 937 & 477 & 347 & 732 & 7.50 & 5.30 & 12.80 & 40.570 \\
\hline 5 & 335 & 1049 & 600 & 387 & 830 & 4.15 & 5.35 & 9.50 & 55.260 \\
\hline 6 & 354 & 1057 & 727 & 458 & 848 & 1.60 & 4.25 & 5.85 & 72.240 \\
\hline 7 & 382 & 1067 & 732 & 434 & 862 & 1.61 & 3.75 & 5.36 & 69.645 \\
\hline 8 & 311 & 1041 & 762 & 404 & 874 & 1.20 & 3.94 & 5.14 & 76.285 \\
\hline 9 & 393 & 1043 & 798 & 438 & 880 & 0.92 & 4.09 & 5.01 & 31.705 \\
\hline 10 & 391 & 1005 & 792 & 452 & 830 & 0.86 & 3.55 & 4.41 & 80.660 \\
\hline 11 & 413 & 919 & 739 & 513 & 761 & 0.45 & 5.73 & 6.18 & 92.580 \\
\hline 12 & 299 & 978 & 677 & 369 & 769 & 1.90 & 6.41 & 8.31 & 77.080 \\
\hline 13 & 324 & 949 & 698 & 372 & 787 & 1.30 & 4.80 & 6.10 & -8.680 \\
\hline 14 & 335 & 1006 & 725 & 392 & 820 & 1.35 & 4.75 & 6.10 & 77.920 \\
\hline 15 & 326 & 965 & 635 & 372 & 778 & 1.96 & 3.80 & 5.76 & 67.050 \\
\hline 16 & 336 & 9.31 & 656 & 383 & 788 & 1.50 & 3.20 & 4.70 & 67.980 \\
\hline 17 & 353 & 946 & 696 & 421 & 786 & 1.29 & 3.95 & 5.24 & 75.390 \\
\hline 18 & 324 & 1022 & 693 & 411 & 843 & 2.75 & 5.25 & 8.00 & 65.330 \\
\hline 19 & 302 & 968 & 708 & 349 & 828 & 2.15 & 6.84 & 8.99 & 75.115 \\
\hline 20 & 316 & 1008 & 696 & 396 & 786 & 1.75 & 6.00 & 7.75 & 77.035 \\
\hline
\end{tabular}

Sitio $=2$ Classe de DAP $=3$ srrore $=2$

\begin{tabular}{|c|c|c|c|c|c|c|c|c|c|}
\hline $\begin{array}{l}\text { Idade } \\
\text { (anos) }\end{array}$ & $\begin{array}{l}\text { Dens. } \\
\text { Min. } \mid 9 \text { dn } 31\end{array}$ & $\begin{array}{l}\text { Dens. } \\
\text { Max. }\{q \cdot d n\} 1\end{array}$ & $\begin{array}{l}\text { Dens. } \\
\text { Med. }(q ; d \operatorname{m} 3)\end{array}$ & $\begin{array}{l}\text { Dens.L.P. } \\
\text { (g/dm3) }\end{array}$ & $\begin{array}{l}\text { Dens.L.O. } \\
(\mathrm{g} / \mathrm{d} \mathrm{d} 3)\end{array}$ & $\begin{array}{l}\text { Conp.L.P. } \\
\text { (口n) }\end{array}$ & $\begin{array}{l}\text { Conp.L.O. } \\
\text { (ID })\end{array}$ & $\begin{array}{c}\text { Conp.Total } \\
\text { (mm) }\end{array}$ & L.O. \\
\hline 2 & 237 & 663 & 337 & 284 & 566 & 10.85 & 2.50 & 13.35 & 18.745 \\
\hline 3 & 256 & 726 & 400 & 307 & 598 & 9.31 & 4.40 & 13.71 & 32.025 \\
\hline 4 & 260 & 833 & 416 & 309 & 675 & 9.79 & 4.05 & 13.84 & 29.225 \\
\hline 5 & 287 & 943 & 477 & 341 & 783 & 7.05 & 3.30 & 10.35 & 31.460 \\
\hline 6 & 311 & 1052 & 631 & 370 & 810 & 2.95 & 4.30 & 7.25 & 59.310 \\
\hline$?$ & 324 & 1112 & 619 & 380 & 330 & 3.45 & 3.90 & 7.35 & 53.235 \\
\hline 8 & 324 & 1058 & 678 & 392 & 812 & 2.10 & 4.50 & 6.60 & 68.805 \\
\hline 9 & 353 & 1103 & 734 & $\$ 30$ & 866 & 1.60 & 3.70 & 5.30 & 69.725 \\
\hline 10 & 311 & 1107 & 804 & 395 & 916 & 1.05 & 3.80 & 4.85 & 78.375 \\
\hline 11 & 430 & 1014 & 811 & 624 & 851 & 0.95 & 6.95 & 7.90 & 89.365 \\
\hline 12 & 305 & 1061 & 686 & 382 & 858 & 3.30 & 5.55 & 8.85 & 62.750 \\
\hline 13 & 369 & 1066 & 726 & 427 & 823 & 1.75 & 5.45 & 7.20 & 75.595 \\
\hline 14 & 381 & 1091 & 814 & 128 & 895 & 0.65 & 3.05 & 3.70 & 82.870 \\
\hline 15 & 370 & 1093 & 821 & 428 & 915 & 0.70 & 2.90 & 3.60 & 80.000 \\
\hline 16 & 359 & 1058 & 740 & 400 & 859 & 0.80 & 2.30 & 3.10 & 74.040 \\
\hline 17 & 396 & 1084 & 784 & 441 & 853 & 0.55 & 2.70 & 3.25 & 82.530 \\
\hline 18 & 329 & 1038 & 703 & 402 & 847 & 1.45 & 3.10 & 4.55 & 67.400 \\
\hline 19 & 307 & 1030 & 723 & 370 & 899 & 0.85 & 2.60 & 3.45 & 74.955 \\
\hline 20 & 289 & 960 & 663 & 353 & 801 & 0.65 & 1.50 & 2.15 & 67.500 \\
\hline
\end{tabular}


Tabela24-Caracteristicas nedias dos aneis de crescinento de anostras de nadeira de ar:ores de Pinus taeda, obtidas atraves da densitonetria de Raios - $x$.

\begin{tabular}{|c|c|c|c|c|c|c|c|c|c|}
\hline $\begin{array}{l}\text { Idade } \\
\text { \{anos }\end{array}$ & $\begin{array}{l}\text { Dens. } \\
\text { Ain. }(a \cdot d n)\end{array}$ & $\begin{array}{l}\text { Dens. } \\
\text { Max.19.da } 31\end{array}$ & $\begin{array}{c}\text { Dens. } \\
\left.\text { Med. } \mid a_{i} d{ }^{2} 3\right\}\end{array}$ & $\begin{array}{l}\text { Dens.L.P. } \\
|9 / \operatorname{dm} 3|\end{array}$ & $\begin{array}{l}\text { Dens.L.O. } \\
\text { |g/dm } 31\end{array}$ & $\begin{array}{l}\text { Conp.L.P. } \\
|\mathrm{an}|\end{array}$ & $\begin{array}{l}\text { Conp.L.O. } \\
(\mathbb{M Q} \mid\end{array}$ & $\begin{array}{c}\text { Conp. Total } \\
\mid \square] \mid\end{array}$ & L.O. \\
\hline 2 & 308 & 673 & 420 & 359 & 574 & 6.85 & 2.70 & 9.55 & 28.270 \\
\hline 3 & 310 & 748 & 453 & 371 & 638 & 10.70 & 4.75 & 15.45 & 30.710 \\
\hline$t$ & 328 & 779 & 439 & 391 & 642 & 7.95 & 4.65 & 12.60 & 36.980 \\
\hline 5 & 381 & 842 & 558 & 427 & 716 & 5.25 & 4.35 & 9.60 & $\$ 5.625$ \\
\hline 6 & 382 & 883 & 646 & +28 & 736 & 2.05 & 4.00 & 6.05 & 66.935 \\
\hline 7 & 415 & 890 & 630 & 470 & 741 & 2.10 & 3.25 & 5.35 & 59.170 \\
\hline 8 & 383 & 364 & 657 & 430 & 728 & 1.35 & 4.05 & 5.40 & 76.540 \\
\hline 9 & $\$ 12$ & 385 & 643 & 531 & 593 & 0.95 & 3.00 & 3.95 & 30.260 \\
\hline 10 & 362 & 882 & 644 & 441 & 786 & 1.20 & 2.05 & 3.25 & 59.445 \\
\hline 11 & 467 & 888 & 765 & 636 & 768 & 0.10 & 5.65 & 5.75 & 98.200 \\
\hline 12 & 355 & 903 & 643 & 414 & 746 & 1.55 & 3.45 & 5.00 & 69.065 \\
\hline 13 & 388 & 382 & 594 & $\$ 72$ & 763 & 1.10 & 3.70 & 4.80 & -5.495 \\
\hline Is & 488 & 886 & 755 & 761 & 755 & 0.10 & 3.85 & 3.95 & 97.470 \\
\hline 15 & 534 & 866 & 668 & 457 & 744 & 1.15 & 3.35 & 4.50 & 74.000 \\
\hline 16 & 379 & 869 & 613 & 443 & 749 & 1.45 & 2.00 & 3.45 & 57.160 \\
\hline 17 & 450 & 907 & 734 & 649 & 761 & 0.35 & 2.40 & 2.75 & 88.795 \\
\hline 18 & 377 & 914 & 664 & 434 & 742 & 1.00 & 2.95 & 3.95 & 71.935 \\
\hline 19 & 326 & 897 & 710 & 409 & 816 & 1.25 & 3.55 & 4.80 & 73.865 \\
\hline \multirow[t]{2}{*}{20} & 412 & 835 & 702 & 489 & 777 & 0.90 & 3.00 & 3.90 & 74.510 \\
\hline & & & & \multicolumn{6}{|c|}{ ' } \\
\hline $\begin{array}{l}\text { Idade } \\
\text { (anos) }\end{array}$ & $\begin{array}{c}\text { Dens. } \\
\text { Min. }(a, d \ln 3)\end{array}$ & $\begin{array}{l}\text { Dens. } \\
\text { Max. }\{a ; \operatorname{dn} 3 \mid\end{array}$ & $\begin{array}{l}\text { Dens. } \\
\text { Med. }(a / \operatorname{dn} 3)\end{array}$ & $\begin{array}{l}\text { Dens.L.P. } \\
|g / d n 3|\end{array}$ & $\begin{array}{l}\text { Dens.L.0. } \\
\text { (g/dn3) }\end{array}$ & $\begin{array}{l}\text { Comp.L.P. } \\
\mid \text { an } \mid\end{array}$ & $\begin{array}{l}\text { Comp.L.O. } \\
\text { (nn) }\end{array}$ & $\begin{array}{l}\text { Conp. Total } \\
\text { (nd) }\end{array}$ & L.O. \\
\hline 3 & 376 & 755 & 554 & 488 & $5 \% 9$ & 3.20 & 8.95 & 12.15 & -3.825 \\
\hline$f$ & 370 & 774 & 553 & 426 & 650 & 5.90 & 6.00 & 11.90 & 54.225 \\
\hline 5 & 403 & 859 & 624 & 523 & 692 & 2.65 & 5.30 & 7.95 & -4.945 \\
\hline 6 & 589 & 864 & 654 & 430 & 690 & 0.70 & 3.95 & 4.65 & 84.070 \\
\hline 7 & 411 & 870 & 675 & 461 & 733 & 1.15 & 3.70 & 4.85 & 78.300 \\
\hline 8 & 387 & 860 & 666 & 404 & 732 & 0.95 & 4.00 & 4.95 & 78.320 \\
\hline 9 & 386 & 908 & 721 & 471 & 760 & 0.65 & 4.15 & 4.80 & 86.435 \\
\hline 10 & 411 & 884 & 678 & 422 & 724 & 1.05 & 4.65 & 5.70 & 81.180 \\
\hline 11 & 472 & 886 & 741 & 589 & 775 & 0.30 & 4.65 & 4.95 & 89.325 \\
\hline 32 & 376 & 371 & 663 & 489 & 747 & 1.45 & 2.85 & 4.30 & 67.305 \\
\hline 13 & 433 & 853 & 708 & 611 & 720 & 0.25 & 4.15 & 4.40 & 93.030 \\
\hline 14 & 341 & 834 & 701 & 593 & 742 & 0.45 & 2.75 & 3.20 & 84.325 \\
\hline 15 & 389 & 821 & 647 & 459 & 721 & 1.15 & 3.45 & 4.60 & 73.225 \\
\hline 16 & 410 & 831 & 671 & 459 & 725 & 0.95 & 3.80 & 4.75 & 79.965 \\
\hline 17 & 374 & ô13 & 631 & 493 & 685 & 1.30 & 5.45 & 6.75 & -9.560 \\
\hline 18 & 354 & 801 & 597 & 420 & 702 & 1.20 & 2.85 & 4.05 & 65.490 \\
\hline 19 & 370 & 870 & 709 & 431 & 746 & 0.80 & 5.80 & 6.60 & 87.880 \\
\hline 20 & 428 & 805 & 575 & 469 & 683 & 2.90 & 2.90 & 5.80 & 50.000 \\
\hline
\end{tabular}


Tabela 25-Caracteristicas nedias dos aneis de crescinento de anostras de nadeira de arvores de pinus taeda, obtidas atraves da densitometria de Raios - $\$.

\begin{tabular}{|c|c|c|c|c|c|c|c|c|c|}
\hline $\begin{array}{l}\text { Idade } \\
\text { (anos) }\end{array}$ & $\begin{array}{c}\text { Dens. } \\
\text { Min.1g:dm31 }\end{array}$ & $\begin{array}{c}\text { Dens. } \\
\text { Max.|g:dm } 1\end{array}$ & $\begin{array}{c}\text { Dens. } \\
\text { Med. }(g / d \operatorname{dn} 3)\end{array}$ & $\begin{array}{l}\text { Dens.L.P. } \\
\text { (g/dm } 31\end{array}$ & $\begin{array}{l}\text { Dens.L.0. } \\
\text { (g/dm31 }\end{array}$ & $\begin{array}{l}\text { Conp.L.P. } \\
\text { (DII) }\end{array}$ & $\begin{array}{l}\text { Conp.L.O. } \\
\text { (an) }\end{array}$ & $\begin{array}{l}\text { Conp.Total } \\
\text { (ه⿴囗十 })\end{array}$ & L.O. \\
\hline 2 & 263 & 631 & 375 & 331 & 555 & 7.55 & 1.85 & 9.40 & 19.655 \\
\hline 3 & 291 & 681 & 438 & 360 & 590 & 7.30 & 3.70 & 11.00 & 33.585 \\
\hline$t$ & 286 & 711 & 453 & 343 & 616 & 6.15 & 4.05 & 10.20 & 40.360 \\
\hline 5 & 330 & 730 & 507 & 379 & 624 & 5.40 & 6.00 & 11.40 & 52.555 \\
\hline 5 & 368 & 762 & 575 & 425 & 649 & 1.50 & 3.10 & 4.60 & 67.710 \\
\hline 7 & 386 & 788 & 611 & 429 & 687 & 1.10 & 2.85 & 3.95 & 70.835 \\
\hline$\delta$ & 349 & 741 & 582 & 407 & 650 & 1.45 & 4.05 & 5.50 & $i 2.055$ \\
\hline 9 & 380 & 795 & 626 & $\$ 26$ & 693 & 1.10 & 3.25 & 4.35 & 75.000 \\
\hline $1 ?$ & 385 & -58 & 625 & 412 & 673 & 0.55 & 2.05 & 2.60 & 79.185 \\
\hline 11 & 410 & 693 & 599 & 509 & 610 & 0.50 & 5.25 & 5.75 & 90.020 \\
\hline$\therefore ?$ & 286 & 732 & 550 & 349 & 628 & 2.25 & 5.90 & 8.15 & $: 1.970$ \\
\hline 13 & 360 & 745 & 609 & 400 & 671 & 1.35 & 4.65 & 6.00 & 6.980 \\
\hline 14 & 419 & 741 & 623 & 455 & 657 & 0.60 & 3.00 & 3.60 & $\hat{o} 3.220$ \\
\hline 15 & 383 & 744 & 586 & 440 & 650 & 0.60 & 1.55 & 2.15 & 59.285 \\
\hline 16 & 355 & 724 & 566 & 389 & 631 & 0.80 & 2.15 & 2.95 & 73.295 \\
\hline 17 & 382 & 758 & 497 & 460 & 655 & 0.45 & 3.45 & 3.90 & 87.695 \\
\hline 18 & 345 & 761 & 604 & 402 & 660 & 1.55 & 5.25 & 6.80 & 77.820 \\
\hline 19 & 332 & 762 & 615 & 366 & 694 & 1.25 & 3.90 & 5.15 & 75.770 \\
\hline 20 & 329 & 797 & 571 & 393 & 655 & 1.15 & 2.55 & 3.70 & 68.315 \\
\hline \multicolumn{10}{|c|}{$\ldots$} \\
\hline $\begin{array}{l}\text { Idade } \\
\text { (anos) }\end{array}$ & $\begin{array}{c}\text { Dens. } \\
\text { Min. }|g ; \operatorname{dm} 3|\end{array}$ & $\begin{array}{l}\text { Dens. } \\
\operatorname{Max} .(g d \operatorname{dn} 3)\end{array}$ & $\begin{array}{l}\text { Dens. } \\
\text { Med. }(g / d m 3)\end{array}$ & $\begin{array}{l}\text { Dens.L.P. } \\
|9 / \operatorname{dm} 3|\end{array}$ & $\begin{array}{l}\text { Dens. L.0. } \\
\text { (g/dm3) }\end{array}$ & $\begin{array}{l}\text { Conp.L.P. } \\
\text { (an) }\end{array}$ & $\begin{array}{l}\text { Conp.L.O. } \\
\text { (DDi }\end{array}$ & $\underset{\text { Comp. Total }}{\text { Conp }}$ & ¿ L.O. \\
\hline 2 & 290 & 684 & $4+2$ & 382 & 545 & 7.00 & 4.35 & 11.35 & 37.100 \\
\hline 3 & 350 & 745 & 526 & 420 & 608 & 4.50 & 6.60 & 11.10 & 59.135 \\
\hline 4 & 328 & 809 & 530 & 410 & 658 & 6.00 & 5.75 & 11.75 & 48.610 \\
\hline 5 & 399 & 847 & 604 & 436 & 664 & 2.80 & 7.95 & 10.75 & 73.600 \\
\hline 6 & 487 & 875 & 734 & 691 & 731 & 0.10 & 5.35 & 5.45 & 98.145 \\
\hline 7 & 495 & 860 & 716 & 674 & 718 & 0.10 & 3.60 & 3.70 & 97.250 \\
\hline 8 & 490 & 856 & 727 & 702 & 728 & 0.10 & 3.30 & 3.40 & 96.965 \\
\hline 9 & 502 & 831 & 695 & 676 & 697 & 0.10 & 2.85 & 2.95 & 96.120 \\
\hline 10 & 494 & 801 & 695. & 678 & 696 & 0.10 & 1.55 & 1.65 & 93.935 \\
\hline 11 & 497 & 852 & 769 & 671 & 773 & 0.10 & 2.70 & 2.80 & 96.355 \\
\hline 12 & 439 & 886 & 721 & 680 & 740 & 0.40 & 3.35 & 3.75 & 90.770 \\
\hline 13 & 487 & 834 & 699 & 679 & 700 & 0.10 & 3.00 & 3.10 & 96.745 \\
\hline 14 & 524 & 858 & 769 & 811 & 767 & 0.10 & 1.95 & 2.05 & 95.045 \\
\hline 15 & 463 & 865 & 721 & 656 & 725 & 0.10 & 2.60 & 2.70 & 95.940 \\
\hline 16 & 429 & 873 & 697 & 495 & 765 & 0.75 & 2.20 & 2.95 & 74.645 \\
\hline 17 & 498 & 893 & 755 & 705 & 757 & 0.10 & 2.55 & 2.65 & 96.225 \\
\hline 18 & 460 & 858 & 718 & 549 & 736 & 0.35 & 3.45 & 3.80 & 91.385 \\
\hline 19 & 387 & 867 & 720 & 441 & 772 & 0.70 & 3.90 & 4.60 & 84.845 \\
\hline 20 & 399 & 831 & 680 & 477 & 740 & 0.70 & 2.45 & 3.15 & 76.610 \\
\hline
\end{tabular}


Tabela 26. Valores de densidade volu-gravimétrica (obtidos pelo método de deslocamento de $\mathrm{Hg}$ ) e radiótica (obtidos pela leitura das radiografias) de madeira, para o cálculo do fator de correção.

\begin{tabular}{lccccc}
\hline Amostra & $\begin{array}{c}\text { Densidade } \\
\text { volu-grav. } \\
\left(\mathrm{g} / \mathrm{dm}^{3}\right)\end{array}$ & $\begin{array}{c}\text { Densidade } \\
\text { radiótica } \\
\left(\mathrm{g} / \mathrm{dm}^{3}\right)\end{array}$ & Amostra & $\begin{array}{c}\text { Densidade } \\
\text { volu-grav. } \\
\left(\mathrm{g}^{3} \mathrm{dm}^{3}\right)\end{array}$ & $\begin{array}{c}\text { Densidade } \\
\text { radiótica } \\
\left(\mathrm{g} / \mathrm{dm}^{3}\right)\end{array}$ \\
\hline 1 & 448 & 546 & 10 & 365 & 447 \\
2 & 416 & 476 & 11 & 375 & 451 \\
3 & 453 & 506 & 12 & 447 & 502 \\
4 & 432 & 484 & 13 & 436 & 503 \\
6 & 500 & 572 & 14 & 436 & 441 \\
7 & 516 & 596 & 15 & 470 & 504 \\
8 & 393 & 385 & 16 & 496 & 516 \\
9 & 474 & 488 & 17 & 469 & 529 \\
\hline
\end{tabular}

